\title{
VALIDATION AND ASSESSMENT OF THE RESPONS MODEL
}

\author{
Murrey D. Goldberg and Ellen A. Cherniavsky
}

December 1976

ENERGY DATA AND MODELS GROUP

NATIONAL CENTER FOR ANALYSIS OF ENERGY SYSTEMS

DEPARTMENT OF APPLIED SCIENCE

BROOKHAVEN NATIONAL LABORATORY ASSOCIATED UNIVERSITIES, INC.

UNITED STATES ENERGY RESEARCH AND DEVELOPMENT ADMINISTRATION 


\section{DISCLAIMER}

This report was prepared as an account of work sponsored by an agency of the United States Government. Neither the United States Government nor any agency Thereof, nor any of their employees, makes any warranty, express or implied, or assumes any legal liability or responsibility for the accuracy, completeness, or usefulness of any information, apparatus, product, or process disclosed, or represents that its use would not infringe privately owned rights. Reference herein to any specific commercial product, process, or service by trade name, trademark, manufacturer, or otherwise does not necessarily constitute or imply its endorsement, recommendation, or favoring by the United States Government or any agency thereof. The views and opinions of authors expressed herein do not necessarily state or reflect those of the United States Government or any agency thereof. 


\section{DISCLAIMER}

Portions of this document may be illegible in electronic image products. Images are produced from the best available original document. 
BNL 50642

(Coal Conversion and Utilization-

Systems Studies, Policy and Legislation - TID-4500)

\title{
VALIDATION AND ASSESSMENT OF THE RESPONS MODEL
}

\author{
Murrey D. Goldberg and Ellen A. Cherniavsky
}

December 1976

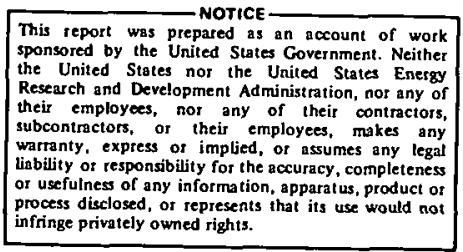

Prepared for the

OFFICE OF THE ASSISTANT ADMINISTRATOR FOR FOSSIL ENERGY

UNITED STATES ENERGY RESEARCH AND DEVELOPMENT ADMINISTRATION

NATIONAL CENTER FOR ANALYSIS OF ENERGY SYSTEMS

BROOKHAVEN NATIONAL LABORATORY

UPTON, NEW YORK 11973 
NOTICE

This report was prepared as an account of work sponsored by the United States Government. Neithcr the United States nor the United States Energy Research and Development Administration, nor any of their employees, nor any of their contractors, subcontractors, or their empluyees, makes any warranty, experes !.! in' illisi, or agoumes any legal liability or responsibility for the accuracy, completeness or usefulness of any information, apparatus, product or process discloscd, or represents that its use would not infringe privately owned rights.

Printed in the United States of America

Available from

National Technical Information Service

U.S. Department of Commerce

5285 Port Royal Road

Springfield, VA 22161

Price: Printed Copy $\$$; Microfiche $\$ 3.00$

June 197\% 2.25 370 copies 


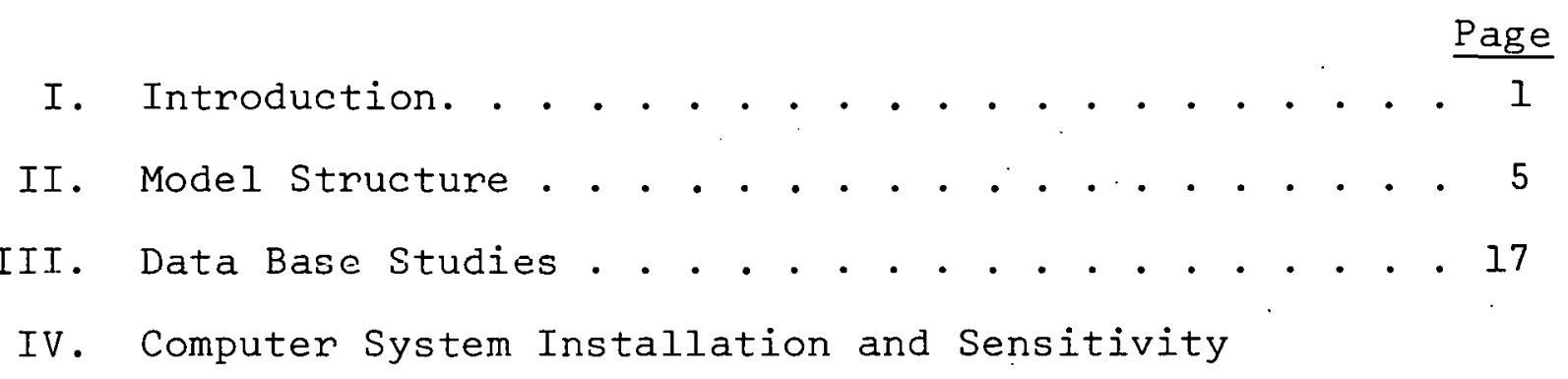
Analysis. . . . . . . . . . . . . . 41

V. Conclusions and Recommendations . . . ..... . 73 Appendix

Scenario Input Data Tables. . . . . . . . . 81

\section{Map Figures}

1. RESPONS Modified PAD Regions. .......... 19

2. Base Case Coal Flows. . . . . . . . . . . . . . 54

3. Revised Sulfur Standards Case Coal Flows. . . . . . 54

4. Coal Price Changes Case Coal Flows. . . . . . . . . 62

5. Slurry Pipeline Capacity Change Case Coal Flows . . . . 62

6. Slurry Pipeline Cost Changes Case Coal Flows. . . . . 66

7. Reduced Unit. Train Coste Case Coal Fluws. . . . . . . 72 


\section{Tables}

Page

1. Guide to Model Descripticn. . . . . . . . . . . 9

2. Recalculated Slurry Pipeline Cost Figures . . . . . . . 3I

3. Facility Capital Cost Data for Power Plants . . . . . 39

4. Water Availability. . . . . . . . . . . . . . 44

5. Coal Types and Characteristics. . . . . . . . . . 45

6. Coal Sulfur/Btu Content Ratios. . . . . . . . . . . 46

7. Unit Coal Costs for Power Plants. . . . . . . . . . . 48

8. Changes in Chaxacteristics of Coal Used for RCI and Power Plants Under Relaxed Sulfur Standards . . . 51

9. Comparison of Regional Coal Production Patterns in the Base and Relaxed Sulfur Standards Cases. . . . . 52

10. Comparison of Coal Type Consumption in the Base and

Relaxed Sulfur Standards Cases . . . . . . . . 53

11. Recalculated Coal Prices.... . . . . . . . 56

12. Changes in Characteristics of Coal Used for RCI and

Power Plant Applications under Coal Price Changes. . 58

13. Comparison of Regional Coal Production Patterns in

the Rase and Coal Price Changes Cases. . . . . . . 60

11. Comparison of Coal Type Consumption in the Base and

Coal Price Changes Cases. . . . . . . . . . . . . bl

15. "Improved" Slurry Pipeline Costs . . . . . . . . . 64

16. Comparison of Regional Production Patterns in the

Base and Reduced Unit Train Costs Cases. . . . . . . 66

17. Comparison of Coal Type Consumption in the Base and

Reduced Unit Train Costs Cases . . . . . . . . 87

18. Allowed Transportation Modes. Between MPAD Districts. 68

19. Base Case Shipments. . . . . . . . . . . . 70

20. Reduced Unit Train Cost Case Shipments... . . . 71

21. Percentage Distribution 1975/1985 Coal Production . . 84

22. 1985 Coal Mining Capacities, by MPAD . . . . . . 86

23. Proposed Water Availability Values for 1985 Coal

Energy Use . . . . . . . . . . . . . . 99 


\section{ABSTRACT}

A critical validation and assessment has been performed on the "Regional Energy System for the Planning and Optimization of National Scenarios" (RESPONS) model for ERDA/AFE. The objectives of the study were to determine the utility and quality of the model and data base, as published by the model developers, and evaluate the applicability of the model and data to relevant policy concerns. The model structure was examined, and constraints and assumptions were identified. Runs were performed to test the sensitivity of the model results to data input and implicit and explicit assumptions. The tables contained in the data base were examined as to methods for generation, sources of information, assumptions used, algorithms developed, quality limitations, and ease of modification. A few data areas were explored in detail. Conclusions pertinent to the objectives of the study were summarized, and recommendations as to possible modifications to the model and data base which would enhance model applicability and performance were provided. 


\section{ACKNOWLEDGMENTS}

The authors are grateful to all those who aided them in the course of this study. Their Brookhaven colleagues, Naresh K. Bhagat and Douglas S. Gunwaldsen, contributed greatly in the exploration of the many data-related problems discussed in the report. Harold Abilock did an excellent job of installing the model in an independent computer environment and performing sensitivity runs. Steven Rattein and Frederick Orthlieb, and their associates in the firm of Donovan, Hamester, and Rattein, provided invaluable support in the detailed evaluation of data sources and data manipulation and in suggesting areas of policy application of the RESPONS system.

Under separate support contract with the Bechtel Corporation, Leon Olver provided advice on the mechanics of getting the model up and running and in achieving replication of the model demonstration results, and Phiroze Nagarvala provided help in dealing with a number of data questions.

Donna Visone did yeomen duty in typing the many drafts, and Jean Goldberg provided copy editing and proofreading services. 


\section{Chapter I}

\section{INTRODUCTION}

At the request of the Office of Program Planning and Analysis of ERDA/AFE, an independent critical validation and assessment has been performed of the "Regional Energy System for the Planning and Optimization of National Scenarios" mathematical model (to be referred to as the RESPONS model). This model was developed by the Bechtel Corporation of San Francisco under contract to ERDA. The validation and assessment effort was carried out under the supervision of the Energy Data and Models Group (ED/MG) of the National Center for Analysis of Energy Systems (NCAES), Department of Applied Science, Brookhaven National Laboratory, as part of the Systems Support Program of the ED/MG for ERDA/AFE. Personnel of the NCAES performed the tasks requested, with subcontracted assistance from the firm of Donovan, Hamester, and Rattein of Washington, D.C. The ERDA/AFE Technical Project officer for the systems support Program is James E. Quinn.

The two basic objectives of the validation and assessment effort were:

- To identify assumptions and source documentation used in leveloping the data base and in constructing the model in order to understand how the model behaves and to determine which variables and assumptions significantly affect model results, and

- To assess the performance of the model and to identify options for ERDA/AFE to utilize the model for various policy applications. 
In order to achieve these objectives, the work was divided into two sets of tasks. The first set was directed at an examination of the quality of the information developed and the assumptions made in generating the data base which provides the basic parameters describing the system being modeled. The second set was directed at an examination of the quality of the methodological approach and the effect on model results of assumptions made in the development of the modeling methods. Since a model and its data base are intimately interrelated, no attempt was made to draw a fine line separating thesc two task. sets, and this report provides an integrated presentation of the results of the entire effort. As an example of Bechtel's use of the model and data base, their computations performed and conclusions reached for the 1985 ERDA Scenario $V$ were chosen for detailed examination. However, in order to consider the performance of the model over a range of potential policy applications, this assessment explored model and data base validation questions which go beyond those required for this particular ERDA scenario example. All of the data development, model description, and scenario computations are presented in lie final Bcchtel noport on the RESPONS modeI.*

A brief outline of the validation and assessment methodology employed reflects the division of work into the two task sets. For the data base, the task sequence was as follows: (1) An overview of the full range of data compiled and developed for model use was obtained by examining the pertinent content of the Bechtel report. (2) The data tables used as input to the ERDA scenario $V$ com= putations were examined as to methods for generation, sources of information, assumplions used, algorithms diveloped, quality limitations, and ease of modification. A description of these factors for each of the scenario $V$ data tables is included in

* Nagarvala, Phiroze J., Ferrell, George C. and Olver, Leon A., Regional Energy System for the Planning and Optimization of National Scenarios. ERDA-76-109 (also numbered FE 1552-18), June, 1976. 
this report. (3) Spot checks were made of both the underlying source data and the algorithms or statistical methods used to obtain the input data from the source data. (4) 3ecause of problems detected by spot checks or because of the importance of particular data to the Scenario $V$ results (or to other policy applications), several data areas were selected for in-depth analysis, including substitution of other possible source data. For the model, the task sequence was as follows: (1) The model structure was examined,' and assumptions made in the development of the model were identified, as well as all constraints contained in the model, either explicitly or implicitly. (2) After the model was brought up in an independent computer environment, runs were made to investigate model behavior, to test the sensitivity of model results to various data inputs, and to assess the impacts of model assumptions. (3) Possible modifications to enhance model applicability and performance were identified and evaluated.

It should be noted that the objectives of this validation and assessment study were directed at providing ERDA/AFE with an evaluation of the utility and quality of the model and data base as described in ERDA-76-109. The objectives of the Bechtel Corporation staff, as defined for them by the funding agency, had a different emphasis and are clearly stated at the very beginning of their report (page 3 ). Their work was directed toward:

- "Fomulating an energy model that would allow questions on energy policy, particularly with respect to coal energy, to be systematically analyzed.

- Developing a data base that was sufficiently accurate to permit a realistic demonstration of the model's capabilities.

- Developing a methodology that would link the energy model and the associated data base in a manner that would provide a flexible, rapid, and economic means of evaluating a large variety of energy supply options." 
The first of the above objectives is directly relevant to the question of the determination of the policy applicability of RESPONS, identified as one of the two main objectives of this assessment study. Beyond this, the remaining objective of the assessment called for a determination of the quality of the data collected in the Bechtel development effort and a judgment as to what effects use of the model input data provided in the RESPONS report would have on model results. It was recognized that the constraints of time and effort and the interest, as expressed in the second objective above, in simply acquiring sufficiently accurate data for demonstration purposes, and the fact that the data were collected approximately two years ago, would limit data quality. Indeed, many of the data limitations delineated in the remainder of this report were also noted in the RESPONS report. The report clearly states that assumptions used in the development of the data base and the accuracy of various important parameters should be considered before each model run. As for the third of the Bechtel Corporation objectives, this report has little to say. In sum, the validation and assessment effort is directly focused on the needs set by ERDA/AFE for an evaluation of the utility of the model and its data base "as is" and does not address the question of how well the model dovelopers asonmplished their stated objectives.

In the report which follows, the structure of the model is first examined, and a number of considerations peculiar to the model are described. This is followed by a detailed consideration of several of the more important data-related areas which were explored in some depth. The main body of the report is then completed with a briet discussion of the computer syatrm inetallation and a set of sensitivity analyses which were designed to examine the detailed behavior of the model. Gelleral conclusions from the assessment work are summarized and a set of recommendations to ERDA/AFE are presented. In an appendix, each of the data base tables for ERDA Scenario $V$ is discussed as to content, development methodology, and quality. 


\section{Chapter II}

\section{MODEL STRUCTURE}

The assessment of the quality and utility of the RESPONS model focused on two areas: (1) examination of the structure of the model and of the underlying assumptions embedded in that structure, and (2) computer implementation of the model and investigation of its sensitivity to various parameter changes. The results of the work under area (I) will be discussed in this chapter. Computer implementation and sensitivity analyses will be described in Chapter IV.

General LP Model Considerations

In escapably, all models have flaws and imperfectly represent the real world. In section II of the RESPONS report, for example, the developers of the model enumerate a number of areas of potential weakness in what they have created. As a linear programming (LP) model RESPONS has, apart from model-specific assumptions, certain characteristics and limitations which must be understood before any assessment of its usefulness for any particular application can be made. All LP models have an objective function.which is to be minimized or maximized and constraints which define the boundaries within which that objective may be arhieved. In the RESPONS model, the objective is minimization of total system cost. Both the objective function and the constraints are linear functions of the variables. Any feasible solution of an LP model will obey all the constraints while finding the minimum value of the objective function. LP models are normative: they do not predict or simulate (unless a decision maker rhooses to be goverued by the optimal solution). 
Constraints limit levels of activity within the model. For example, in the absence of transportation capacity constraints, all inter-regional coal shipments will go by the cheapest mode, whatever that is. If there are capacity constraints, as much coal as possible will be sent by the cheapest transportation mode, then the next cheapest, and so on. In the real world, this simple behavior does not happen for a variety of reasons. Better adherence to real world conditions can be attained, if desired, through the imposition of additional. constraints. It should be emphasized that in using the outputs of any model lu answer policy questions, due regard should be given to the considerations which are omitted as well as to the assumptions that are made.

It is also characteristic of LP models that very small changes in input parameters, particularly objective function coefficients, can lead to quite substantial changes in the results. For example, if one region mines only Type $A$ coal and another nearby only Type B, it is quite possible that a change of f.o.b. costs, within the error limits on those numbers, would cause the model output to indicate a complete "flip-flop", with the first region now mining only Type $B$ coal and the other only Type A. Sensitivity analysis can easily pinpoint such unnealistic cases.

Closely related to thic phanomenon is the possibility of nonurique solutions. This happens when competing options cannot be ristinguished on the basis of cost (assuming that is the objective function): In this case, there exists an infinite number of solutions which are equally good in that they all achieve the same minimum value of the objective function. However, the implications and real-world feasibility of alternative solutions may be quite different. For example, in the RESPON3 model, coal to be burned in nonscrubber conventional power plants in Region 6 or 7 may be shipped directly from Region 13 by unit train, or, alternatively, it may be shipped firet by unit train to a dock in Region 13 and then by rail to the power plant. Similarly, at the same cost, coal may be delivered directly by water from Region 6 
to Region 7 or may arrive at a dock in Region 7 , then to be shipped by rail to the power plant. That many solutions to the problem may be obtained which achieve the same (or even very nearly the same) objective function value in no way invalidates the results of the model. However, the fact of non-uniqueness or near nonuniqueness (which can be readily determined from the output of the model) serves as a warning that a particular solution should not be a rigid guideline to a policy decision. In fact, as a general principle, it is wise to engage in sensitivity analysis with any LP model.

Structure of the RESPONS Model

There are four types of equations in the model: balance equations, bound equations, accounting rows, and ratio equations.

The balance equations conserve energy flow. The amount of fuel or electricity produced in a region plus imports must equal or exceed that consumed plus exports. Coal entering a dock must be shipped to a dock in another region or to a consuming plant in the same or another region. Plants producing electricity, liquids, or gas from coal require coal inputs in proportion to the level of output.

Through the bound equations, variables or sums of variables are restricted to chosen levels. These equations limit pipeline capacities, electric power plant generation, extraction of coal (of a particular type in a particular region), and require demands for crude oil, natural gas, coal, and electricity to be met.

Accounting rows are non-binding equations that are used to suin up coal extraction; scrubbing capacity; system cost components, such as transportation and distribution costs; sulfur dioxide emissions; and water consumption, by plant type and region. These equations could be made binding for purposes of sensitivity analysis.

The ratio equations assure that the ratio of the sulfur dioxide emitted to the energy contained in the coal burned for residential/ commercial/ industrial demands, or in conventional coal steam 
electric plants, will not exceed Environmental Protection Agency or state standards.

The equations are discussed in detail below. A guide to the model description is provided in Table 1.

a. Balance Equàtions

BAL. ( $r) \cdot(f) \quad$ Fuel of type $f$ produced in region $r$
plus imports equals amount used plus
exports.

$\operatorname{COBL}(r) 2(L)$

Dock fucl balance equatinn. Coal entering the dock in region $r$ goes to a consuming plant in this or another region, or to a dock in another region.

$\operatorname{COECN}(r)(p)$

Coal inputs required for producing the outputs of coal-consuming plant $\mathrm{p}$.

EECNV. ( $r)$

Electricity generated in a region plus imports equals or exceeds the amount used plus exports.

b. Bounds and Bound Sets
(APG) CAPAC
(CRD)
(GAS)
Total new advanced coal power generation (APG), liquefaction (CRD), gasification $\left(G A S^{\prime}\right)$.
(CRD)
(REF)
(BTU) DEM( $r$ )
Sets consumption of total fossil Btus (B'IU), Oil (CRD), gas (BAS), or refined
products (REF).
coavl $(r)$.
Upper bound on total coal extraction in region $r$.
COAVL $(r)(t)$
Upper bound on coal reserves of type $t$ in region $r$.
$(C P):(r) \cdot(s)$
$(G P)$
(SP)
Pipeline shipment of crude (CP), gas
(GP), slurry (SP) from region $r$ to reginn $\varepsilon$ (s may equal $s$ ). Some bounds are infinite, i.e., constraint is nonbinding.
$\operatorname{TGENC} \underset{(\mathrm{O})}{(\mathrm{O})}(\mathrm{r})$
New $(N)$ or old $(O)$ conventional coal power gencration in region $r$,

The bound sets are used to set upper or lower bounds on chosen variables or to fix their activity levels. Included are variables 
Table 1

Guide to Model Description

$r$ - denotes the region. There are 16 regions (MPAD districts). States included in each are listed below.

QA 1. Maine, New Hampshire, Vermont, Massachusetts, Connecticut, Rhode Island, New York

QB 2. Pennsylvania, New Jersey, Maryland, Delaware, Virginia, East Virginia

QC 3. North Carolina, South Carolina, Georgia, Florida

QD 4. Michigan, Indiana, Ohio

QE 5. Kentucky, Tennessee

QF 6. Illinois

QG 7. Wisconsin, Minnesota

QH 8. Iowa, Missouri, Nebraska, Kansas, Oklahoma

QI 9. North Dakota, South Dakota

QJ 10. Alabama, Mississippi, Arkansas, Louisiana

QK 11. Texas

QL 12. New Mexico

QM 13. Wyoming, Montana, Idaho

QN 14. Colorado, Utah

QO 15. Oregon, Washington

QP 16. California, Nevada, Arizona

f - denotes fuel type.

$\mathrm{J}=$ coal gasified in a high Btu Lurgi plant

$\mathrm{L}=$ high Btu BCR Bigas

$P=$ crude liquefaction SRC

$Q=$ crude liquefaction COED

$X=$ natural gas

$\mathrm{Y}=$ natural crude oíl

$t$ - denotes coal type. There are 15 types, differentiated by Btu and sulfur content, and origin (Western or Eastern).

p - Denotes plant type. Coal consuming plants include liquefaction and gasification facilities, electric power generation plants, and residential/commercial/industrial users. 
representing high Btu low sulfur coal (type A) exported abroad from docks in Regions 2 and 6 , new gasification and liquefaction facilities in each region, natural gas and natural crude oil availability, residential/commercial/industrial demands, advanced coal power generation capacity, and new and old noncoal generation capacity.

\section{c. Accounting Rows}

COAL

COS'IC (CRD)

(GAS)

$\operatorname{COSTEP}(A)$

(R)

(S)

(T)

COSTDCOA

COSTENTR

$\operatorname{COSTN}(C R D)$

(GAS)

(REF)

$\operatorname{cosTN}(P) \cdot(C)$

$(R) \cdot(G)$

$(W) \cdot(R)$
Total coal extraction.

Cost of synthetics production of oil (CRD) or gas (GAS).

Costs of outputs from coal consuming electric plants of different types: advanced power (A); nonscrubber (R); scrubber (S); total ( $\mathrm{T}$ ).

Coal distribution costs (within destination region).

Electricity transmission costs.

Cost of resource production for oil

(CRD), gas (GAS), refined products $(\mathrm{REF})$.

Cost of oil (C), gas (G), or refined produets ( $R$ ); tranemiesion by pipeline $(P)$, rail (R), watcr (W) (gas is shipper by pipeline only).

Costs of new and old power plant generation $G=$ gas, $H=$ hydroelectric, $\mathrm{N}=$ nuclear, $\mathrm{O}=$ oil, $\mathrm{T}=$ total.

Cost of pipeline (P), rail (R), siurry $(S)$, unit train (U) or waler (W) transporlalion of agal (COA), nil (CRD), gas (GAS), or refined products (REF). There is one equation for each combination of transportation mode and fuel type.

Total cost. Objective function.

01d and new scrubbing capacity.

Total. $\mathrm{SO}_{2}$ emissions. 
WATER (APG)

$(C P G)$

(CRD)

(GAS)

(REF)

( )

WATER. ( $r)$

d. Ratios

SO2... $(r)(p)$
Water consumption in advanced coal power generation (APG), conventional coal power generation ( $C P G$ ), liquefaction (CRD), gasification (GAS), refined products (REF), or total ( ).

Water consumption in coal conversion facilities.

Ratio of $\mathrm{SO}_{2}$ output to Btu coal input must meet air quality standards in residential/commerical/industrial (RCI) applications and conventional power plants.

By showing which equations typical variables appear in, the structure of the model is further illuminated. Variables in the model fall into four classes: coal flows, outputs of conversion facilities, interregional transmission of electric power or shipments of gas and oil (natural or coal-derived), and natural crude oil or gas production.

\section{e. Coal Flow Variables}

A typical coal flow variable is of the form $X$ (region $r$, source, region s, plant type, coal type, mode). $r$ is the origin and $s$ the destination region. The source is either a mine or transshipment dock. The plant is any of the coal consuming facilities listed in Table $l, t$ is the coal type, and $m$ the transportation mode.

A coal flow variable appears in constraints showing that it leaves a mine or dock: COAVL $(r)$ and COAVL $(r)(t)$, or COBL $(r) 2(t)$; that it arrives at a dock or consuming plant: COBL(s).2(t:) or $\operatorname{coECN}(s)(p)$; that if the coal is burned for residential/ commercial/industrial purposes or in conventional coal power plants, environmental standardc arc met: $S 02 \ldots(s)(p)$.

f. Conversion Facility Output

A typical conversion facility output variable is of the form $E$ (region $r, p$, age, class) where age = old or new and output 
class = electricity, gas, or oil. Plants $\mathrm{p}$ include all electricity generating capacity and coal conversion plants.

A variable of this type shows up in the following binding constraints: (1) EECNV. ( $r$ ) and, for coal facilities, in (2) $\operatorname{COECN}(r)$ and (3) TGENC(age) $(r$ ), or (APG) (CRD) (GAS) CAPAC. An entry in the bound set may also be present.

g. Shipment Variables

These are of the form $S$ (region $r$, region $s$, fuel form, mode) or ' $l$ ' (region $r$, region $s$, electricity tranomiccion). Fuel forms are gasified or liquefied coal, natural gas, and crude oil. The variables appear in balance equations: BAL.( $r) .(f)$ and BAL.(s).(f) or EECNV.( $r$ ) and EECNV.(s). The $S$ variables may also show up in mode capacity constraints such as CP.( $r) .(s)$, and, when $r=s$, in the (BTU) (CRD) (GAS) DEM( $r$ ) equations. Bound set entries may also occur.

h. Natural Fuels Production

These variables are of the form NCBTU.( $r$ ) (natural crude oil) and NGBTU.(i) (natural gas). The bound set entry limits the amount available and the variable also appears in BAL.( $r)$.(f).

Particular RESPONS Considerations

The particular characteristics of the RESPONS mudeI stem from its formulation, described above, and must be recognized when undertaking applications. The policy analyst must be sure that the objective function is suitable for his needs and interests. At present, total national energy cost is minimized, certainly a valid objective. However, if one wishes to minimize $\mathrm{SO}_{2}$ emissions or if it seems more important to achieve the low energy costs in one region than another, then the appropriate objective function should be substituted. The objective function is the single most important equation in the model: it defines the criterion according to which a single solution is chosen from the wide range of feasible solutions to the problem. 
One reason why there is such a variety of feasible solutions is that the model is structured so that relatively few equations. have a real impact on the results. The balance equations and accounting rows perform essential bookkeeping functions but do not shape the solution. The bound equations, bound sets, and sulfur dioxide emission constraints determine the feasible solution space. Of these, the most interesting are the ratio equations and those limiting transportation and coal production capacities.

Coal production in the model is constrained in two ways. First, the total amount of coal of all types that can be mined in a given region is limited; this is the regional mining capacity. Second, extraction of a particular type of coal is not permitted to exceed the reserves of that type present in the region. This constraint exerts no influence when the reserves of the particular coal type exceed the regional mining capacity, as happens in the scenario runs contained in the RESPONS report, in all mining regions for at least one, and usually all, coal types. It is possible, even likely, for only one type of coal to be mined within a region: this happens with seven of the thirteen mining regions in ERDA Scenario V (See Table 16). This seems unrealistic, since various types of coal are mined within any given region now, and such drastic shifts would require existing mines to close and new ones to open, with possible effects on coal prices.

Other capacity constraints concern transportation. Of these, some limit the capacities of many but not all crude oil and gas pipelines. In the ERDA Scenario $V$ a number of these constraints became active, this is, the capacity was utilized to the fullest possible extent. This was especially noticeable with respect to cruaje oil shipments to region 4 and gas transmission to regions 2 and 8. Furthermore, as is noted in the model dald tables, the constraint on pipeline capacity from New Mexico to Texas produced an infeasible solution when imposed on ERDA Scenario $V$, and had to be relaxed. If pipeline capacities are anticipated to be a problem in the real world, the model. should include quantified constraints on them. 
Apart from pipelines, the only other transportation capacities currently restricted in the model are the tons per year that may be carnied by each of the five slurry pipeline links. Since no data were available, limits were not set on the other options for coal transport: unit train, rail and water-borne carrier. These three do not. compete among themselves: between any two regions, only the cheapest one is permitted (unfortunately for the purposes of sensitivity analysis, costs for the other modes do not appear in the data tables). This is a reasonable approach within the LP framework, since in the absence of limits on these modes, the LP wil]. choose to ship all coal by the cheapest means; including economically noncompetitive modes adds to the size of the problem unnecessarily. However, since travel distances are not assumed to be the same for the three modes, intermodal competition ic not accurately represented. In the model, costs are based on centroid to centroid distances for rail and unit train, while costs for slurry pipeline and water-borne carrier are based on actual distances. Because of these simplifying assumptions, the model should not be relied on for more than rough indications in the design of coal transportation systems.

The sulfur dioxide emission constraints exert the most interesting influence on the outcome of the model. Because of these environmental considerations, the model must choose stack gas scrubbing or mixing of coal types to achieve a fuel with an acceptable sulfur to Btu content ratio. The nudel allow one to assess the impact of sulfur emission regulations on the coal sector but not, however, on the entire energy system. Crude oil. is not characterized by its sulfur content so that electricity generation with oil wulld be unaffected if enyinnnmental standards were tightened; the price or availability of oil which could meet these standards would not be taken into account. In order to investigate the effects of sulfur dioxide emission regulations on the entire energy system, the treatment of oil (and coalderived liquids used in power plants, if the model were revised 
to include this possibility) with respect to sulfur content should be consistent with that accorded coal. This might well be a large undertaking, and the effort may not be justified; effects of $\mathrm{SO}_{2}$ emission regulations on the coal sector alone may be adequate for many planning needs.

A final observation about the structure of the model (duly noted in the RESPONS report) is that the coal sector is loosely coupled to the rest of the energy system. There is no interfuel substitution. Demands are specified exogenously for coal for residential, commercial, industrial uses, and for liquids, gases, and electricity, though competition is permitted within the electric sector. Since the availabilities of oil and natural gas are stated apart from those amounts burned for electric generation, the model cannot choose whether to use the natural fuels in power plants or whether to substitute coal-derived fuels or even whether to forego electric generation with liquids and gases and use them to meet demands directly. To evaluate alternate energy supply and demand scenarios with this model, such flexibility seems desirable, and might be achieved through coupling with an interfuel substitution model.

In order to examine the behavior of the model under varying assumptions, the model was put up on a computer, and a number of sensitivity analysis runs were made. These are described in Chapter IV. 
THIS PAGE

\section{WAS INTENTIONALLY LEFT BLANK}


Chapter III

\section{DATA BASE STUDIES}

As mentioned in the Introduction, each of the data tables which were used in the model demonstration runs for ERDA Scenario $V$ has been examined in some detail. The results are presented in the Appendix at the end of this report. Several data areas of particular interest or importance were selected for in-depth analysis of the methodology employed and the basic data used to develop the values input to the model. In this Chapter investigations of the geographic regionalization scheme, the use of inflation indices, and the techniques for costing slurry pipelines and large-scale energy facilities are described. Geography and Coal Transportation

The RESPONS model was designed to treat the national coal system as a geographically dispersed set of fuel supply sources serving a similarly dispersed set of demand centers. Mineable coal is found over a large area of the country but is by no means uniformly distributed regionally. Additionally, coals have a range of characteristics which make them usable in a range of applications, and coals with particular sets of chararterietics ane not uniformly distributed throughout a given coal mining region. Similarly, the present demand for coals for the various applications is not uniformly distributed throughout the country either, being more or less correlated with population density and with historical developments of local energy-supply systems.

The formulation of RESPONS reflects an atteinpt to model future coal flows between supply sources and demand centers, given a variety of assumptions concerning supplies, demands, costs, 
environmental constraints, etc. The linear programming methodology finds the minimum cost pattern of distribution and conversion. The variable costs of coal energy to a coal user are the FOB price of a usable coal at the mine, the costs of transportation and distribution of the coal, the costs of conversion of the coal to intermediate energy forms, and the costs of any required environmental controls.

To simulate coal transportation, it is necessary to regionalize the country in some faslition, and the rhoice of regionalization scheme is crucial to the quality of the results. It becomes very important to explore with care any departures from realworld conditions built into the model results by virtue of this choice. The RESPONS model itself is structured independent of any particular regionalization scheme, so a user may avail himself of the model's capabilities with any such scheme he chooses. The only restrictions involved are those assuciated with the effort required to develop the necessary input data, the cost of computer use, and the ability to handle and interpret the mass of results. Each of these restrictions can be a substantial one, and each must be considered carefully before choosing a regionalization scheme.

For demonslration purposes, a cunsistent neginnal disjagregation, based on the five Petroleum Allocation Defense (PAD) districts, was chosen. [Another scheme, based on Air Quality Control Regions, was considered but not used in demonstration. 0ther possibilities are also noted.1 Each PAD district was subdivided into two or more smaller regions to create 16 modified-PAD (MPAD) regions (see Figure 1), and these served as the regions of analysis for all of the work descirihed in the RESPONS report. As noted on page 51 of the report;

"To facilitate the computerized calculation of transportation distances and cost...., a sentroid was chosen for each region. The centroid was defined by the latitude and longitude of the city or town that would be most representative of the supply and demand center of the region, with some consideration of the access of various 


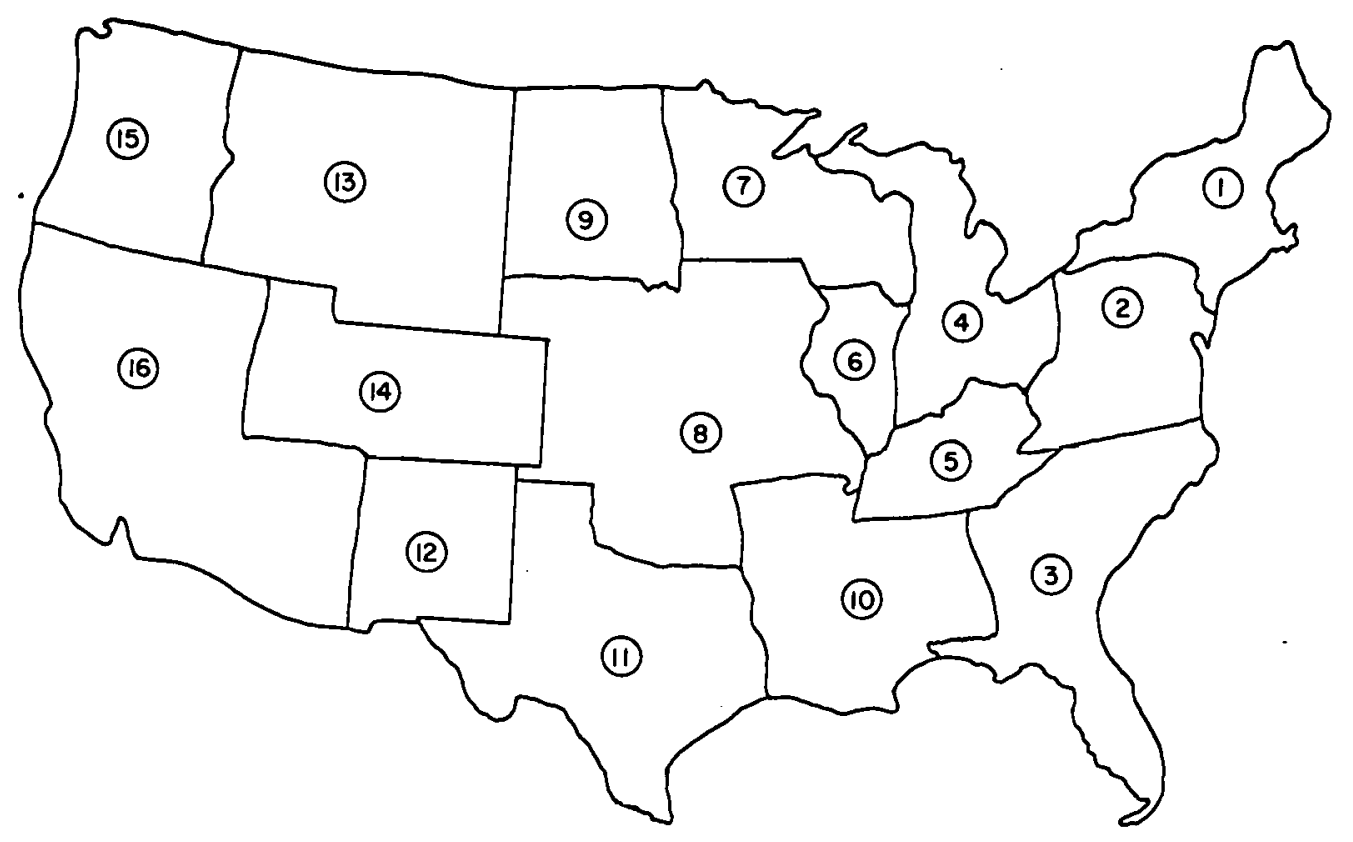

Figure 1. RESPONS modified PAD regions. 
modes of transportation to the city. One point within each geographic region was chosen for both the supply and demand centroid. Thus, although in some respects arbitrary, the city chosen as the centroid was generally close to major coal deposits or major energy demands."

From page 47, "cost and schedule considerations" dictated the use of the MPAD level as the regionalization scheme, and, from the above quote, the need "to facilitate the computerized calculation of transportation costs" dictated the use of a centroid to represent the region and the use of a single centroid for hoth supply and demand in each region. It should be. strongly emphasized at this point that this was a completely legitimate choice on the part of the model developers. All modeling activity is at the mercy of cost and schedule considerations, the need to facilitate computerized calculations, and other factors which limit the accuracy and introduce departures from reality into use of the best of models. This should be kept in mind through the following discussion.

To assure proper use of the RESPONS model by ERDA/Fossil Energy to address policy-related issues, it is essential to expose and quantify (as far as possible) distortions introduced by selection of a particular regionalization scheme. This is by no means an easy task and. might require a number of runs of lle model to ascertain whether apparent distortions introduce real impacts and to quantify the extent of any real impacts found. Though a number of apparent distortions were clearly identified (e.g., cost distortions resulting from choice of common supply and demand centroids in each region), detailed model explorations required to quantify them were not performed. Nevertheless, based on the brief discussion below but primarily on the many problems detailed throughout the discussions of the data tables, the participants in the present study believe that a change in the regionalization scheme must be made if the model is to be applied to practical issues of energy transpurl. The supply and demand regions should be decoupled. The input data pertinent to coal supply regions should be generated on the basis of the 23 Bureau of Mines coal districts (or perhaps some careful aggregation 
thereof). The input data pertinent to energy demand regions should be generated on the basis of the five PAD districts, the nine Census regions, the 16 MPADs, or the 48 states, depending upon the level of precision required. Centroids should be chosen for each region which reflect actual present and potential transportation mode realities (similar to that done in the demonstration runs for slurry pipelines and for barge transport).

Adoption of this regionalization.scheme will provide major improvements in many of the factors developed for the data tables, including such elements as transportation costs, constraints on transportation link capacities, water availability constraints, and others. Many examples can be cited of apparent distortions arising from the present regionalization scheme which should be essentially eliminated by changing to the proposed one. Typical of these are the following:

(1) In locating the supply centroid for MPAD 2 at Baltimore, Maryland, instead of at the more appropriate Charleston, West Virginia, a rail, shipment of coal to the MPAD 4 centroid at Lima, Ohio, would be charged an additional 300 miles of transport. This adds roughly $\$ 3.00$ per ton to the calculated cost of this coal in Lima and could easily result in choice of coal from a different region that would be less economic in real-world terms. This cost is not only representative of the costs of coal shipment between these regions. This is only one of many cases where the relation of distribution costs to transportation costs causes unnecessary delivered-price distortions. Along with the proposed new regionalization scheme, it is also suggested that transportation link capacities between supply and demand centers be quantified and intermodal competition be allowed.

(2) The regionalization scheme proposed above would allow more detailed and careful consideration of all possible real-world transport links between supply and demand centroids, including mixed-mode ones (which are already allowed in the model). For 
example, American Electric Power Company has recently announced plants to build a $\$ 100$ million transshipment facility on the lower Ohio River at Metropolis, Illinois to transfer rail-shipped Wyoming coal to barges for shipment to its power generating plants in the Ohio River Basin. Also, in an unpublished and ongoing study at Brookhaven, it has been estimated that, given FEA 1985 projected coal prices and conservative Bechtel Corporation transportation cost estimates, Colorado bituminous coal could be shipped to Houston, Texas by unit train and transferred to ocean-going freighters for transport to New England utilities at a lower delivered cost than the hauling of North Appalachian coal to New England by unit trains. Location of transshipment points at several potential ports--say Duluth, Minnesota, St. Louis, Missouri, and Houston, Texas--would allow the model to explore whether mixed-mode transport would enter the solution when appropriate waterway constraints are applied.

These examples should serve to illustrate the types od distortions introduced by the regionalization. scheme chosen for use in the KE'SPUNS model demonstration runs. Clearly, there is menat to be no implication that introduction of the suggested new regionalization scheme will eliminate all biases from the model. But our review has led to the conclusion that the changes outlined here would provide a more realistic and useful representation of the geographical factors which will influence future coal transportation patterns. The data exist to create the modified data base, and the required effort does not seem prohibitive. The present structure of the model will readily accomodate the modified scheme, and any cost considerations can be easily factored into the choice of the final regional disaggregation level. Inflation Indices

Incorporated in the costs used in the model's data base for the ERDA seenario runs are inflation indices, which attempt to take into account changes in the relative prices of goods and services during 
the ten year period 1975-1985. A different index is used for each of four main categories: fuels, capital costs, operation and maintenance costs, and transportation. No attempt is made to differentiate among price trends within each category, nor are any arguments presented for the choices of the values used.

The inflation rate indices, through their effects on costs, may have substantial impacts on the results of this model, so it is advisable to choose these factors carefully and to consider the consequences of incorrectly estimating the rates of future inflation. In order to explore the problem, a number of sources were used to gather pertinent information, including the National Economic Outlook (NEO), the FEA's Project Independence Evaluation System (PIES), the 1975 Data Research Inc. (DRI) energy model, the 1976 Wharton Economic Forecast (WEF), Economic Indicators, the Oil and Gas Journal, Electric World, and publications of the Bureau of Mines (BOM) and the Office of Coal Research of the Department of Interior. Suggestions for new cost inflation indices will be made for use in the model, with full recognition of the uncertainties involved.

What costs or inflation indices are appropriate for model use will, of course, be dependent upon the application. Therefore, the following discussion serves only to raise a number of the issues which should be taken into consideration and does not attempt to provide a set of "Best" indices.

FUELS

Prediction of future fuel prices is particularly risky in the face of unresolved environmental, regulatory, and international questions. Evaluation and choice of fuel-specific inflation indices requires careful consideration of recent price trends and of possible future shifts in the energy marketplace. The model input coel and nuclear fuel cost data were computed assuming a net annual escalation rate of $5 \%$. [The net rate is the difference between the inflation rate of costs between 1975 and 1985 and a deflator used to express 1985 costs in 1975 dollars. A value of $5 \%$ per year has 
been used for deflation (the GNP deflator) throughout the data base.] The values used for 1985 oil and gas prices imply inflation rates of $1.5 \%$ and $7 \%$, respectively. As noted above, no justification is provided in the documentation for the choice of the particular values used.

While the values appear reasonable enough, the model user might wish to pick different numbers, based on the following considerations.

The consensus of all. sources consulted was that the coal production prices will remain stable over the next ten years. The NEO, for example, reasons that since reserves are vast, the supply curve relatively flat, and the market for steam coal relatively competitive, the price of coal will not be bid up despite an increase in demand. The swift rise in coal prices over the last three years was in response to the sudden increase in the price of oil. It seems likely that the relative prices between coal and oil will remain close to constant.

With regard to oil, most analysts, NEO and Wharton included, expect the price of oil to stay at a constant thirteen dollars per barrel in 1976 dollars. This is a reasonable assumption, if this nation strongly emphasizes a Project Independence and the OPEC nations continue to show concern over future world-wide economic growth patterns. and prospects (OPEC has stated its intention to tie oil prices to the United States Consumer Price Index, or thereabouts.?. Aggressive development of new oil and other energy resources and a strong conservation effort are expected to provide downward pressure on oil prices. A net inflation index of $0 \%$ is suggested. If coal and oil prices are anticipated to remain relatively constant, a coal price intlation rate of $1 \%$ would also be implied. [It should be noted that the price of oil will not affect the solution unless it is higher (on a Btu basis) than the cost of coal 
liquids or unless oil steam electric generation is more expensive (on a MWh basis) than environmentally acceptable coal electric generation.]

Sulphur emission regulations might potentially cause disruption of prices among different qualities of coal. However, the precise effects of stringent sulphur control regulations are difficult to determine since high sulphur content coals are easier to scrub than low sulphur coals. Upward price pressures for low sulphur coals might occur if standards are set which cannot be met with available scrubbing systems. For Eastern low sulphur coals, when strict sulphur controls are involved, an inflation index of $4 \%$ per year is suggested.

The PIES model projects regional inflation indices for the real price of coal as follows:

$\begin{array}{lc}\text { New England } & -.2 \% \\ \text { Mid Atlantic } & 3.8 \\ \text { East North Central } & 3.8 \\ \text { West North Central } & .2 \\ \text { South Atlantic } & -.7 \\ \text { East South Central } & -1.9 \\ \text { West South Central } & 1.0 \\ \text { Pacific } & -1.3 \\ \text { United States } & 2.2\end{array}$

Although these are estimates for delivered coal prices, available information indicates that transportation costs were not inflated for the purposes of the projections.

Natural gas and nuclear fuels are less stable in price because of supply and regulatory conditions. Natural gas prices have been rising at relatively the same rate as coal, while nuclear fuels have had a slightly higher price increase. The increased pres-. sure to lessen price controls on both these fuels, if effective, will cause large escalations in their prices. The NEO projects that the market clearing price for natural gas in 1985 will be 
\$2.03 per million scf in 1975 dollars. Regional PIES projections for real price inflation indices are:

$\begin{array}{ll}\text { New England } & 0.4 \% \\ \text { Mid Atlantic } & 4.6 \\ \text { East North Central } & 4.5 \\ \text { West North Central } & 5.8 \\ \text { South Atlantic } & 4.0 \\ \text { East South Central } & 7.2 \\ \text { West South Central } & 6.6 \\ \text { Rocky Mountains } & 2.1 \\ \text { Pacific Coast } & 3.9\end{array}$

A weighted average of the above values is $5.7 \%$ so a value of $6 \%$ is suggested for use as a net inflation index for natural gas for use in the model. Nuclear fuel prices are more difficult to predict since utilities purchase nuclear fuels on long-term contracts that are much lower than quoted spot market prices, though escalation clauses may be included in the contracts. Any effects due to deregulation will eventually be felt within the nuclear energy sector. A net inflation index of $5 \%$ per year, lower than that seen in open market prices, is suggested as an approximate value for nuclear fuel use in the model. Thus, the 5\% index value used seems reasonable for both natural gas and nuclear fuel.

CAPITAL COSTS

In estimating prices in 1975 dollans for capital goods used in power generation and synthetic fuels development, the industrial commodity price index should be used. From Economic Indicators, May 1976, this is

\begin{tabular}{|c|c|}
\hline YEAR & INDEX \\
\hline 1972 & 100 (index year) \\
\hline 1973 & 106.7 \\
\hline 1974 & 130.1 \\
\hline 1975 & 145.5 \\
\hline
\end{tabular}


The rate for 1975 and for the first two quarters of 1976 has been about $4.6 \%$. The costs in the model were based on a value of $5 \%$. Assuming a steady conservation growth pattern over the next ten years, the $5 \%$ value seems to be a good choice for use as the net inflation index for capital costs.

OPERATION AND MATNTENANCE COSTS

These costs are primarily a function of labor costs, which have tended to follow the GNP deflator index. According to the WEF, unit labor costs are expected to rise at only. a total $4 \%$ per year rate during the period to 1985. The costs in the data base were derived using a $2 \%$ per year net inflation index. A value of $0 \%$ would be more in line with that used by the WEF.

\section{TRANSPORTATION}

The RESPONS data base for the model runs incorporates a net escalation rate of $2.5 \%$ for three of the four modes of coal transport -- conventional rail, unit trains, and barges -- and for oil and gas pipelines. Implicit escalation is provided for slurry pipelines through the GDI implicit price deflator (page 98 of the RESPONS report) which is built into the equations used to develop costs for this mode. The implication of this is that slurry pipeline charges are basically the return on capital, which is already included in the cost. But this would presumably be true also of oil and gas pipelines, whcih were costed using a general utility financing method. Conventional rail, unit train, and.barge rates are more sensitive to inflationary pressures since they are subject to greater needs for capital replacement and for incremental labor requirements. Therefore, a value of $0 \%$ is suggested here for the net escalation index for all pipelines. For want of any better information, the RESPONS value of $2.5 \%$ is suggested for conventional rail, unit trains, and barges.

SUMMARY

The following set of net inflation indices have been suggested by the development above: 
Coal

$0 \%$

4 (Eastern, with strict sulphur controls)

Oil $\quad 0$

Natural Gas 6

Nuclear 5

Capital 5

OEM

0

Conventional

$\begin{array}{ll}\quad \text { Rail } & 2.5 \\ \text { Unit Trains } & 2.5 \\ \text { Barges } & 2.5 \\ \begin{array}{c}\text { Pipelines } \\ \text { (all) }\end{array} & 0\end{array}$

The above list should not be considered as definitive but only as a set of documented values which are just as reasonable as the undocumented values used to compute the costs for the RESPONS model scenario runs. For the purpose of developing good indices, there would seem to be much value in trying to determine just how fuel companies, utilities, and transportation concerns in the real world are currently applying inflation forecasting in their own costing and decision making. It would require a considerable number of sensitivity runs of the model to determine just how important the exact values used as net inflation indices are and how they affect the actual optimization results. It might be most sensible to consider these indices parametricaliy in the context of particular policy questions. Still another approach might be to tie costs for the model to standard forecast assumptions, such as those made by ERDA for planning purposes. In general, the choice of cost values will be highly scenario dependent.

The purpose of the development of the new set of indices above was to indicate the nature of a problem which requires further exploration. And since inflation is a time-varying factor, continued use of the model will require periodic reconsideration of its current state. 


\section{Slurry Pipeline Costs and Capacities}

For purposes of the ERDA scenario demonstration runs, five coal slurry pipeline links have been defined as available for use in 1985. All five are actually in various stages of planning. The only currently operational pipeline, the Black Mesa line, is excluded since it is wholly intra-MPAD. It should be noted that the origin and destination points of the five lines are not located at the same points as the selected geographic supply/demand centroids of the MPAD in which they originate or terminate.

Two points should be noted about the inclusion and/or exclusion of pipelines. The Black Mesa line is excluded, as noted, because it is wholly intra-MPAD. However, the Nevada Power Company line (Link 4 ) is included, even though it is scheduled to have $80 \%$ of its capacity installed between Alton, Utah and St. George, Utah, making it effectively intra-MPAD also. In addition, the ETSI line (Link 1 ) is in considerable jeopardy since the defeat in the Spring of 1976 by the Kansas legislature of a bill which would have granted eminent domain for pipeline construction through to Arkansas from Wyoming. There is certainly room to doubt that this line will be in a place by 1985, at least by the proposed surveyed route, and its exclusion from the 1985 model runs might significantly alter the regional least-cost solution to the scenarios. This is explored in some detail in Chapter IV.

The cost and capacity data in the table were developed from proprietary information provided by Bechtel's Pipeline and Production Services Division and thus are not verifiable. The capacity figures, which are used to constrain the maximum flow through any link, are presumably not in question. The development of the cost figures by Bechtel was based on fitting curves to data for four 
hypothetical pipelines (all data proprietary) of varying capacity. This results in the following formulae for calculating the "fixed" $\left(\mathrm{C}_{f}\right)$ and "variable" $\left(\mathrm{C}_{v}\right)$ unit transportation cost (capital charge plus operating cost) in cents per ton ("fixed") or in cents per ton-mile ("variable"):

$$
\begin{aligned}
& C_{f}=0.73(G D I)-10.48 / T+1.69(G D I / T)-16.84, \\
& C_{v}=0.0015(G D I)-0.627 / T+0.0259(G D I / T)-0.0415,
\end{aligned}
$$

where $T$ is the line capacity value in millions of tons per year supplied, and GDI is the Gross National Product Implicit Price Deflator Index. The GDI base value for 1974 was projected to be 181.4. The cost values for the table are meant to be. the total cost in 1985, given in 1975 dollars. A cost escalation of 5 per cent per year in the GDI grom 1974 was assumed. [In the body of the RESPONS neport, on page 96 , bottom, a typographical error occurs in the equation for the variable. cost $C_{v}$ (equation 6-7). The equal sign. between the final two terms should be a minus sign.]

If one uses the above equations, the 1974 projected GDI value, and the assumed 5 per cent/year escalation factor, one does not reproduce the numbers given in the table for the five pipelines. The escalated GDI vale should be $(181.4)(1.05)^{1.1}=$ 310.26. To reduce to 1975 dollars, the final total cost $\left(C_{f}+C_{v}\right)$ should be divided (i.e., de-escalated) by $(1.05)^{10}=1.63$. Using these values the cost figures generated are given in Table 2. and compared to the values tabulated by Bechtel. All generated values are approximately 15 per cent above the tabled values. Use of the GDI value for 1973 (15.3.9) instead of the 1974 values yields cost values very close to those in lable 2. Presumably this was done, though the RESPONS report (page 9.8) indicates that the 19.74 value was used, Note that the 19.73-74 escalation rate was not 5 per cent but 18 per cent.

If the higher values given in Table 2 were used to perform the demonstration scenario runs, it is unlikely that the model results would have been affected since the slurry pipeline costs are so much lower than those for other transportation modes, 
Table 2

Recalculated Slurry Pipeline Cost Figures

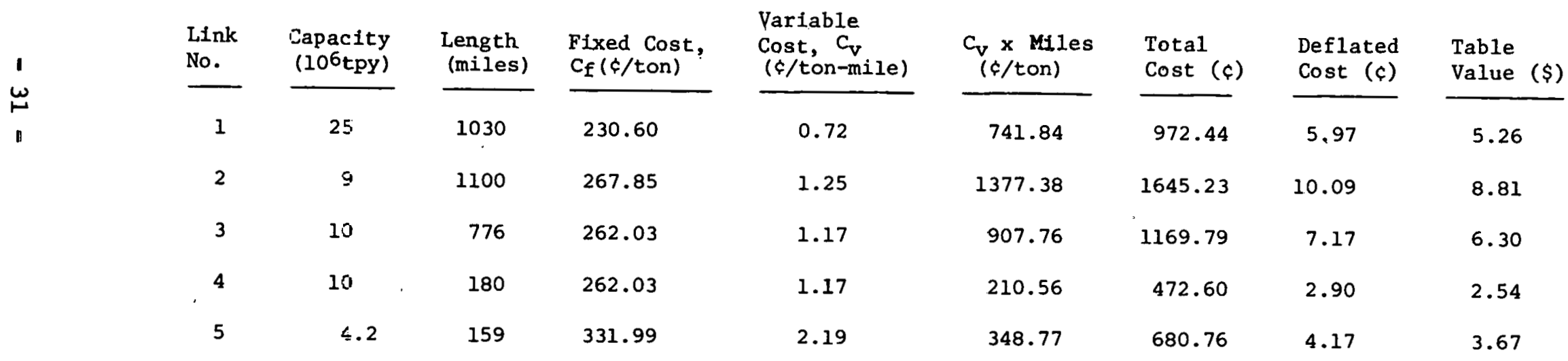


excepting barges. The use of noncentroidal distances and exclusion of distribution costs make these costs relatively too low as compared to other modes. In addition, pipeline lengths should be compared to the interregional distances used for unit trains.

Another area of concern involves load factor assumptions. The RESPONS report notes (page 98 ) that the load factor can have "substantial effects on the unit cost of operating slurry pipelines" and provides a plot of load factor cost multipliers versus load factor (Fig. 6-2) that can be used to modify the $C_{f}$ and $C_{V}$ calculations. No such adjustments were made for the scenario runs. The question arises as to whether a siurry pipeline would be built if its capacity were substantially underused, or, conversely, whether a built underutilized pipeline would net soon become fully utilized, since the alternative of having no pipeline would be even more expensive. For thie purposes of the model, of course, the pipelines could be resized

Assuming that the capacity values in the table are the rated capacities, using values for the actual projected 1985 usage of links 2 and 3 derivable from the ERDA scenarios, and taking values from Figure 6-2 (page 99), new cost factors can be calculated. For Link 2, utilization is 72.2 per cent, giving correction multipliers of $F_{f}=0.125$ and $F_{v}=0.145$ and a new cost of $\$ 11.47$ in 1975 dollars. Similarly, the 67 per cent utilization of Link 3 yields a new cost of $\$ 8.18$. Using these values and those calculated in Table 2, an improved set of table input costs would be

$\begin{array}{cc}\text { Link } & \text { Cost }(\$) \\ 1 & 5.97 \\ 2 & 11.47 \\ 3 & 8.18 \\ 4 & 2.90 \\ 5 & 4.17\end{array}$


Note that these are only an "improved" set of cost figures for the ERDA seenario runs. The discussion of slurry pipeline costs is hedged by many disclaimers and caveats (page 97-98 of the RESPONS report) associated with water availability, terrain, etc., none of which are accounted for in the scenario calculations. Only one of these (underutilization) has been dealt with above. The impact of others must be considered in the future and their importance will depend on the policy issue under study.

The Costing of Energy Facilities

In order to provide future energy needs, new power plants and new synthetics plants will be required. In the RESPONS model, the regional costs of constructing and operating new coal, oil, gas, nuclear, and hydroelectric plants and various combinedcycle, coal gasification, and coal liquefaction plants are developed and used for cost optimization. Capital and operating costs are separately determined and summed, and fuel costs are added where appropriate. The method employed in the cost computations is indicated as "a typical utility financing method."

The basic equation used to calculate new unscheduled power plant eapital costs (equation 7-8, page 125 of the RESPONS reportl was:

$$
A F C=\frac{C C O S T(I+C L C H G)(F C H G)}{8760(P F)},
$$

where

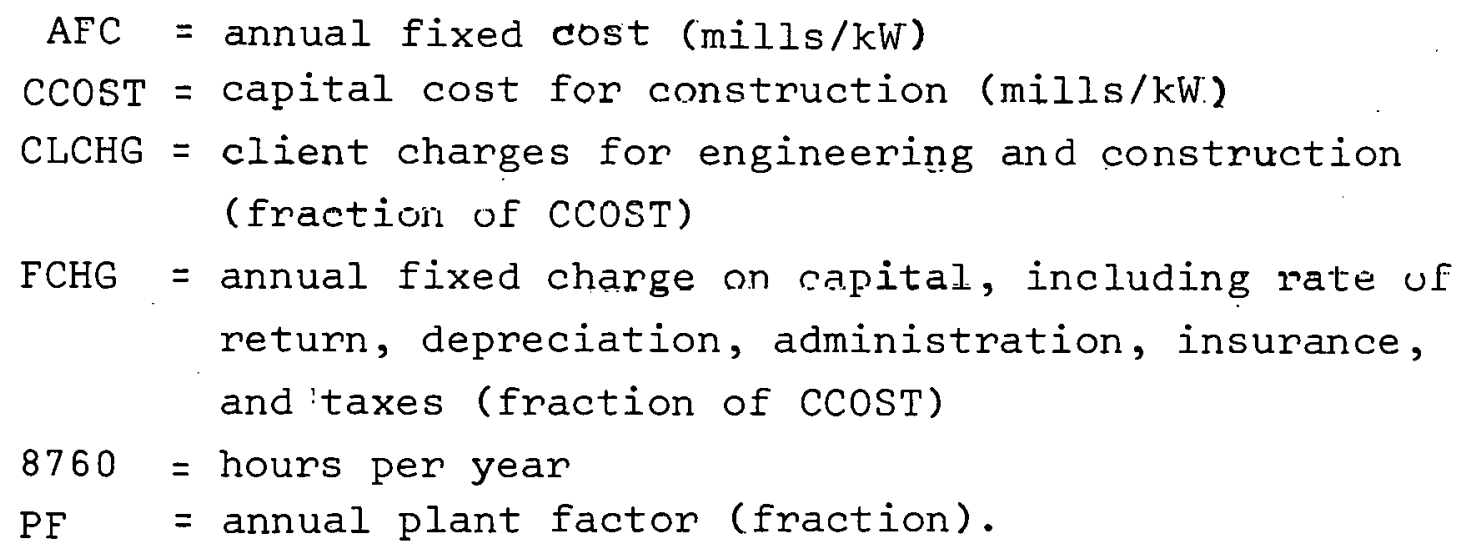


[The meaning of the components of this equation, listed on page 125 of the RESPONS report, contains some minor dimensional errors. The units of ccost should be mills $/ \mathrm{kW}$, not $\$ / \mathrm{kW}$, and the value of FCHG should be expressed as a fraction, not as a percentage.] The computed annual fixed cost is escalated at 10 per cent per year to get 1985 cost estimates and then deflated by 5 per cent per year to put the cost in the required 1975 mills. The factor cCost is a typical "builder's" cost figure. The values (in mid-1974 dollars) used are listed in Table $/-6$, page 126, and are referenced to "Bechtel." From data in general use in energy studies of the National Center for Analysis of Energy Systems (NCAES), the values listed seem generally low, and particularly so in the case of gas-fired power plants. The one exception to this is the value for hydroelectric facilities, which seems to be too high. [Note error in Table 7-6, under notes. Low-BTU coal should have a heat content of 10,000 BTU/Lb.]

The factor CLCHG represents the "owner's" costs for engineering and construction and for such things as any necessary licenses or environmental impact statements. By far the largest factor in these costs is interest accrued during construction on borrowed capital. Though the documentation does not define the value used for this factor for the various facilities, the computation for nonscrubbing coal-fired plants on page 170-171 indicates that a value of 10 per cent was used, at least for this one facility.

The factor FCHG covers the cost of irisurance, deprcciation, etc., as listed in the equation tactor definitiuns, above. In the data table documentation, the flat statement is made that a "20 per cent capital carrying charge" was utilized. The coalfired power plant computation on page 171, howcver, uses a value of 15 per cent for this factor. 
The factor PF is not further defined and seems to be used interchangeably in the documentation with something called the "operating factor" (page 118) or "lifetime average operating factor" (page 130). There is considerable uncertainty as to how this factor is interpreted and used for the tabled cost values. The report text notes that a value of 55 per cent was used for baseload fossil-fired plants (page 118) and for nuclear plants (page 130), and says nothing about hydroelectric facilities. Yet Table 7-6 (page 126) lists an "operating factor" along with the capital cost components. Coal-fired and nuclear plants have values of 80 per cent according to this table, oil-fired plants are listed as 85 per cent, gas-fired plants as 90 per cent, and hydroelectric as 100 per cent. The value of 80 per cent was used as $P F$ in the computation for coal-fired plants (page 1.71) cited above. An operating factor of 20 per cent is noted for peaking facilities, but this number seems never to be used in any way in new facility costing.

The uncertainty in the values used for the various factors in the annual fixed cost equation is highlighted by the value computed on page 171 of the RESPONS report. Using 276,000 mills/kW as construction cost, 10 per cent client charges, 15 per cent annual fixed charges, and 80 per cent plant factor, 10 per cent annual escalation, and 5 per cent annual deflation, the final annual fixed cost for nonscrubbing coal-fired power plants comes out to be $11.39 \mathrm{mllls} / \mathrm{kWh}$. The value given in the data table (Line 1746) is $13,54 \mathrm{mills} / \mathrm{kWh}$. No easy logical manipulation of factor values is apparent which will resolve the discrepancy. For instance, changing the annual fixed charge value to 20 per cent leads to a cost of $15.17 \mathrm{mill} / \mathrm{kWh}$. It is clear that future use of facility costs in the model will require more careful documentation of factor values. Certainly, interest charges during construction are highly dependent on construction times and would presumably be greater for nuclear facilities than for, say, a gas-fired plant. This may have been 
reflected in the deriving of the tabled values for the scenario runs, but there is no documentation one way or the other. This plant factor confusion noted above points up one problem with the model as used for demonstration purposes and as presently structured. The capital cost for any given facility is calculated with only one plant factor (whatever its value) for model use. Thus, the relative economic costs and tradeoffs of different facility types, depending on whether they are designed for peak or base loading, are not reflected and cannot be explored. The model apparently creates new baseload capacity in order to fulfill total regional demands for electricity. To the extent that peaking problems are felt to be important in defining energy policy, the model sheds no light and might even be misleading with regard to load management tradeoffs.

To obtain operation and maintenance (OEM) costs (for both new and existing facilities), Federal Power Commission 1969 values for estimated annual $0 \& M$ costs for typical fossil-fired plants were fitted by Bechtel as a function of plant capacity, yielding exponential equations for computing the needed values. An example, for coal-fired plants, is

$$
\mathrm{OMC}=0.914 \exp [-0.196(\mathrm{MW} / \perp \cup 0)]+0.336,
$$

where OMC is the annual OEM cost (in mills/kWh) for coal-fired plants in 1969. Similar equations were obtained for oil and gas plants. An annual escalation of 7 per cent and an annual deflation of 5 per. cent were assumed. For the scenario runs plant capacities of 800 MWe were used. By a similar procedure, FPC 1972 annual OEM costs (based on historic data, and excluding fuel) for nuclear plants were fltted by an exponential equation of the form

$$
\text { OMN }=4.01(\mathrm{MW} / 100)^{-0.696}(\text { in } \mathrm{mills} / \mathrm{kWh}) .
$$

A similar proccdurc wae ueed for hydroelectric plants using 1971 FPC data. The fittings for both nuclear and hydroelectric are well documented on page 130 of the RESPONS report. The escalation and deflation factors were assumed to be the same as for fossil-fired plants. 
For the noncoal using. facilities, the unit cost of fuel (in mills/kWh, like the rest) must be added to the capital and OEM costs. As indicated in the RESPONS report (page 121), fuel costs for coal, gas, and oil were published as FPC national average values for 1972 in the report "Steam-Electric Plant Construction Cost and Annual Production Expenses," April, 1974. Use of these, costs (in cents/106 BTU) and the national average heat rate for generating plants leads to 1972 fuel costs for coal, oil, and gas of $3.95,3.15$, and $6.10 \mathrm{mills} / \mathrm{kWh}$, respectively. Though these values could be escalated to future years, the actual cost figures (for oil and gas) used in the scenario runs were prices directly assumed for 1985. These cost figures are discussed later under the Energy Supply table (Line Span $1250-1304$ ).

In. the scenario runs, additional facilities are considered, and must be costed, for conversion of coal to electricity, to gas, and to crude. Two of each were allowed to enter the model runs. For all six of these, another utility financing method was used, with the following formulation (page 137):

$$
\text { \$/unit }=\frac{(\text { CAPC })(F C)+F A O M}{(\text { OUT })(L F)}+(\text { FUEL })(H R)+\text { VAOM }=\text { CREDIT }
$$

where

$$
\begin{aligned}
& \text { CAPC = capital cost (including interest during construction) } \\
& \text { FC } \quad=\text { fixed charge or capital carrying charge } \\
& \text { FAOM }=\text { fixed annual OEM costs } \\
& \text { OUT }=\text { output capacity (nameplate) } \\
& \text { LF }=\text { annual operating load factor } \\
& \text { FUEL = input fuel cost } \\
& \text { HR }=\text { heat rate or equivalent } \\
& \text { VAOM = unit variable annual OEM costs } \\
& \text { CREDIT = unit by-product credits }
\end{aligned}
$$

A set of $v a$ ? ues for the factors above are presented in the RESPONS report (pages 136-139) for a Lurgi gasification process plant, one of the six facility types allowed, and a 
sample determiniation of the $\$ /$ unit made. Most of the information regarding this facility was apparently taken from a Bureau of Mines publication, "Lurgi Process" (Restricted), February 1975. Data sheets are presented with useful numbers for each of the two gasification and each of the two liquefaction included in the model, all referenced to various Bureau of Mines sources. No similar information is included for the two combined-cycle facilities.

The metliod used to coct these synthetir coal process plants is an accepted one, and the data are not unreasonable for values with a high degree of uncertainty. By way of comparison, the capital, fuel, and OEM cost developed by Bechtel for the Lurgi process is $\$ 4.26 / \mathrm{milli}$ ion scf. The value used in NCAES work is $\$ 4.77 / \mathrm{milli}$ on scf. Similarly, the same comparison for coal liquefaction is $\$ 14.24 / \mathrm{bbl}$ (Bechtel) and $\$ 15.49 / \mathrm{bbl}$ (NCAES). This roughly 10 per cent difference in the two values must be considered quite reasonable.

It should be noted that the model provides for regionspecific costs, but all values used in the scenario demonstration runs are constant for all regions for each facility. No doubt this was a proper choice for the intent of the runs. To explore the possible variations in costs when other dulu are used, an alternate calculation of capital costs for some of the facilities inoluded has been made using the RESPONS utility financing equation. The basic capital cost ( $C O O S T)$ values are taken from Table IV-B, page E-23 of the FEA's 1976 National Energy Outlook, reflecting the "medium" scenario, equivalent to a "business as usual" construction trend. The values are given for 1982 facilities in 1975 dollars, so the RESPONS 10 per cent escalation and 5 per cent deflation factors are applied. The client charge values (CLCHG) are taken from Table D-2, page D-6 of "the Energy Supply Planning Model, Vol. 2," Bechtel Corp., August 1975, which lists owner's costs as a percentage of capital costs. For fossil-fueled plants the value is 25 per 
cent, for hydroelectric 30 per cent, and for nuclear 40 per cent. The annual fixed charge on capital ( $F C H G$ ) was set to the RESPONS data table value of 20 per cent. The plant factor (PF) used was 70 per cent, a typical figure for base loaded plants in the literature (e.g., in the Project Independence Blueprint reports). The values of $A F C$ resulting are shown in Table 3 , and the corresponding Bechtel generated capital costs from the model runs are listed for comparison.

Table 3

Facility Capital Costs Data for Power Plants

\begin{tabular}{|c|c|c|c|}
\hline Facility & $\begin{array}{l}\operatorname{cosT} \\
(\$ / k W) \\
\end{array}$ & $\begin{array}{c}\mathrm{AFC} \\
(\mathrm{mills} / \mathrm{kWh}) \\
\end{array}$ & $\begin{array}{l}\text { Table AFC } \\
\text { (mills } / \mathrm{kWh})\end{array}$ \\
\hline Coal (no scrubher) & 437 & 17.81 & 13.54 \\
\hline Coal (with scrubber) & 552 & 22.49 & 20.83 \\
\hline oil & 356 & 14.51 & 8.44 \\
\hline Gas & 310 & 12.63 & 5.09 \\
\hline Nuclear & 632 & 28.82 & 17.33 \\
\hline Hydroelectric & 356 & 15.09 & 13.30 \\
\hline
\end{tabular}

It is by no means clear that one set is any better than the other, beyond the question of documentation. Under the conditions adopted for the demonstration runs, the solution would be independent of the choice of either. For other policy studies, a cost optimization model obviously requires careful consideration of all cost factors. 


\section{THIS PAGE \\ WAS INTENTIONALLY \\ LEFT BLANK}




\section{Chapter IV \\ COMPUTER SYSTEM INSTALLATION AND SENSITIVITY ANALYSES}

In this chapter, a brief discussion of computer system installation of RESPONS will be followed by a detailed description of the results of selected sensitivity runs performed to explore the response of the model to various parameter changes.

Computer System Installation

There are two ways of putting the model up on a computer system. The first is to acquire a tape of the problem in standard format; the second is to use the DATAFORM tables and associated programs to generate the problem.

The advantage of the first method is that any computer system will do as long as one has an LP algorithm capable of handling the problem. However, only minor sensitivity analyses (e.g., setting slurry pipeline link 1 capacity to 0 ) can be made with ease.

The second method allows easy changes to all data inputs but requires the use of a computer on which DATAFORM is available, since the model's data tables and programs were set up for input to this code. DATAFORM is a module of a proprietary software package, MPSIII, developed by Management Science Systems. MPSIII runs solely on IBM computers, and may be obtained through a lease or purchase agreement with Managcment science Systems, or may be used at one of a number of IBM service bureaus. DATAFORM, after generating the problem, can write a tape in standard format for solution by any LP algorithm. It should be observed that the use of DATAFORM permits easy changes to any of the data in the input tables (see, e.g,, Appendix $B$ of the RESPONS report). 
Bechtel supplied to Brookhaven a tape of the ERDA Scenario V data tables and programs as well as a tape, presumably of the resulting problem, in standard format. However, when the problem on the tape was solved (in an independent computer environment), one change (relaxation of the coal gasification capacity constraint, GASCAPAC) was necessary to achieve feasibility. When an optimal solution was obtained, it differed significantly from Bechtel's ERDA Scenario. V results. Different objective function values were achieved. The cause of the discrepancy has not been determined but difference in computer environments has been eliminated as a factor.

Tlie ERDA Seenario $V$ wac then generatel from the tape of DATAFORM tables and programs. The resulting problem solution differed from the tape Bechtel sent and from the problem solved and reported in ERDA-76-109. It was learned that Bechtel had not created their ERDA Scenario $V$ problem by substituting the changed tables, shown in ERDA-76-109 Appendix $C$, as inputs to the DATAFORM programs. Instead, another MPSIII program was employed, and not all the data were changed correctly. Exponts of coul etayed at ERDA Srenario 0 levels and natural gas availabilities were set to positive levels in regions 7 and 15 instead of 0 as they should have been. Changes in the tables were made to conform to the problem Bechtel actually solved, and the ERDA Scenario V results were replicated. Subsequently, a number of computer runs were made to explore the sensitivity of the model to changes in various parameters and to verify that it hehaved as its structure would suggest.

Sensitivity Analyses

Allalyses were pcrformed through hand calculations and romputer runs to investigate the sensitivity of the model to changes in data which had been identified as questionable and to explore the model's behavior. Areas considered were: water availability, coal power plant scrubber efficiency, sulfur dioxide emissions standards, minemouth coal prices, and slurry pipeline availability and cost. 


\section{A. Water Availability}

Water availability will determine the feasibility of building a coal liquefaction or gasification plant in a given location. The RESPONS model includes equations that sum up water usage by coal synthetics production and coal electric power generation (but not RCI uses and slurry pipelines). However, water availability limitations were not quantified. Possible availability figures are compared with water usage in ERDA Scenario $V$ in Table 4. Although a significant error appears to have been detected in the coefficient for conventional coal steam electric plants (the table value is 0.00041 compared to the 0.94 figure obtained from other sources), the solution would not have been affected. If water availability constraints are employed, they must be carefully quantified, and consideration should be given to altering the present regionalization scheme, which may obscure acute water problems in subareas of certain regions.

B. Scrubber Efficiency

Changing the scrubber efficiency to $95 \%$ had no effect on the result of the computer model run. Further analysis revealed that this is the outcome that would be expected, based on the data.

At the assumed scrubber efficiency of $85 \%$, coal plants thus equipped are already able to burn any type of coal represented in the model. Table 5 shows the coal types and their characteristics. Improving the scrubber efficiency, therefore, confers no advantage. The constraint that must be met is

$$
(1-\text { scrubber efficiency }) * 2 * S_{c} * 10^{-2} /\left(b_{c} * 10^{-6}\right) \leq 1.2
$$

where $s_{C}$ is the percentage sulfur content and $b_{C}$ the Btu content of the coal. The 1.2 figure represents the state implementation plan for $\mathrm{SO}_{2}$ emissions in terms of pounds of $\mathrm{SO}_{2}$ per million Btu's input (see p. B-27 of ERDA-76-109). Table 6 shows $\mathrm{SO}_{2}$ emissions to Btu content ratios, and required scrubber efficiencies for each coal type. 
Table 4

Water Availability

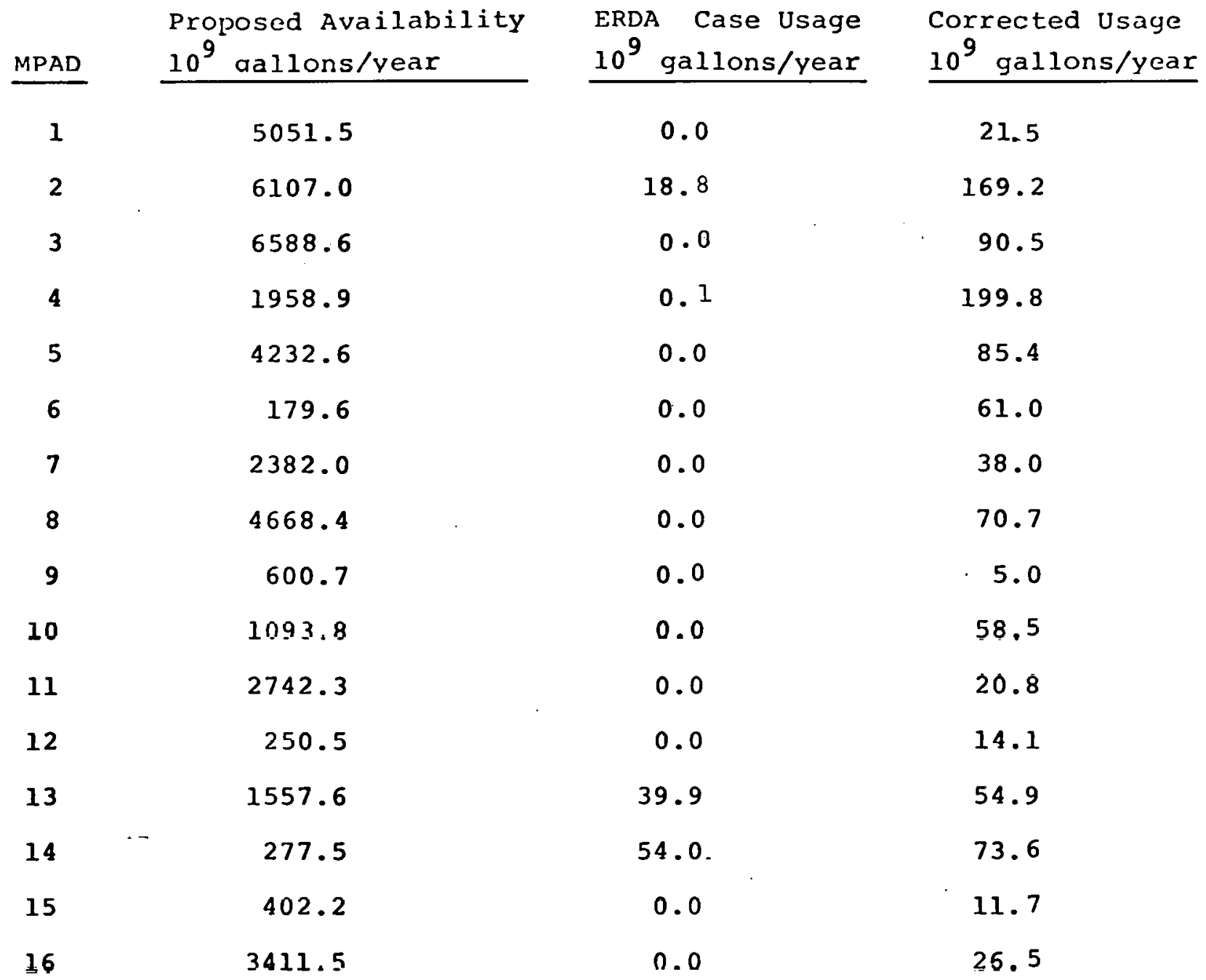


Table 5

Coal Types and Characteristics

\begin{tabular}{ccc}
$\begin{array}{c}\text { Coal } \\
\text { Type }\end{array}$ & $\begin{array}{c}\text { Sulfur } \\
\text { Content }\end{array}$ & $\begin{array}{c}\text { Btu/1b } \\
\text { Content }\end{array}$ \\
\cline { 2 - 3 } $\mathrm{A}$ & 0.70 & 13800 \\
$\mathrm{n}$ & 1.50 & 13500 \\
$\mathrm{C}$ & 3.36 & 11800 \\
$\mathrm{D}$ & 0.64 & 11900 \\
$\mathrm{E}$ & 1.40 & 11900 \\
$\mathrm{~F}$ & 0.90 & 10300 \\
$\mathrm{G}$ & 0.63 & 8300 \\
$\mathrm{H}$ & 0.70 & 13800 \\
$\mathrm{I}$ & 1.50 & 13500 \\
$\mathrm{~J}$ & 0.64 & 11900 \\
$\mathrm{~K}$ & 1.40 & 11900 \\
$\mathrm{~L}$ & 0.30 & 8600 \\
$\mathrm{M}$ & 0.90 & 10300 \\
$\mathrm{~N}$ & 3.85 & 10500 \\
$\mathrm{O}$ & 0.75 & 7000
\end{tabular}


Table 6

Coal Sulfur/BTU Content Ratios

\begin{tabular}{|c|c|c|c|}
\hline $\begin{array}{l}\text { Coal } \\
\text { Type }\end{array}$ & Ratio & $(1-0.85) *$ Ratio & $\begin{array}{l}\text { Required Scrubber } \\
\text { Efficiency, Percent }\end{array}$ \\
\hline A & 1.01 & 0.15 & 0 \\
\hline B & 2.22 & 0.33 & 46 \\
\hline c & 5.69 & 0.85 & 79 \\
\hline D & 1.08 & 0.16 & 0 \\
\hline$E$ & 2.35 & 0.35 & 49 \\
\hline$F$ & 1.75 & 0.26 & 31 \\
\hline G & 1.52 & 0.23 & 21 \\
\hline H & 1.01 & 0.15 & 0 \\
\hline$I$ & 2.22 & 0.33 & 46 \\
\hline $\mathbf{J}$ & 1.08 & 0.16 & 0 \\
\hline $\mathrm{K}$ & 2.35 & 0.35 & 49 \\
\hline L & $0.70^{\circ}$ & 0.10 & 0 \\
\hline M & 1.75 & 0.26 & 31 \\
\hline $\mathbf{N}$ & 7.33 & 1.10 & 84 \\
\hline $\mathrm{O}$ & 2.14 & 0.32 & 44 \\
\hline
\end{tabular}


Except for types $C$ and $N$ coal, no coal type alone requires better than 50\% scrubber efficiency. Since operation and maintenance costs depend on scrubber efficiency, reduction of its level would place scrubbers on a more competitive tooting with the alternative of burning low sulfur coal in nonscrubber plants. Alternatively, scrubbers might not be used at all, but another technology, such as washing, might be employed. Another factor not modeled is that mixing of coal types or use of different coal types to achieve lower sulfur content may require an existing plant to burn coal for which its boilen was not originally designed, ash melting temperature and mineral content being the crucial coal properties; however, there is no penalty for blending coal types. To make a fair comparison of scrubbers versus low sulfur coal in nonscrubber plants, these considerations will have to be taken into account. The extent to which scrubbers fail to be economically attractive under present model cost values can be seen from Table 7. The first column shows the lowest cost coal obtainable in the region in mills per kWh output from the scrubber plant (regardless of sulfur content since at $85 \%$ efficiency, all coal types can be burned in scrubber plants), the second shows the cost, computed from the ERDA Scenario $V$ model run results in mills per $k$ Wh output from the nonscrubber plant. To be more attractive, the unit coal cost for the scrubber must be at least $3.64 \mathrm{mills} / \mathrm{kWh}$ less than that for the nonscrubber since that is the difference in operation and maintenance costs for the two plant types, and the capital cost of the scrubber plant will be higher. The difference in capital costs should, however, probably be smaller than the data now used. [Note that the scrubber plant incurs a $10 \%$ combustion efficiency reduction, which may increase its unit coal cost above that for the nonscrubber plant; see Appendix B-47 of the RESPONS Report.]

From a review of the cost data used for new facilities ( $p$. B-39 ff. of the RESPONS Report) it appears that an accidental exchange occurred between capital charges for nuclear and scrubber- 


\section{Table 7 \\ Unit Coal Costs for Power Plants \\ (Mills per kWh Output)}

Region

$$
1 .
$$

2

3

4

5

6

7

8

9

10

11

12

13

14

15

16
Min Coal Cost

For Scrubbers

12.42

8.68

11.64

7.82

6.81

7.16

10.01

8.45

6.36

4.87

8.80

5.14

5.15

7.49

5.41

4.82
Actual Coal Cost For Nonscrubbers
12.52
11.05
11.52
8.71
7.80
9.62
10.26
10.42
7.24
5.80
8.97
4.63
5.95
6.90
6.16
6.02 
equipped coal-fired power plants. Ebasco* prepared a report on new facility cost data for the Electric Power Research Institute. Normalizing Ebasco's capital costs to those in the RESPONS model by equating costs for oil-fired plants, the following results were obtained:

Capital charges, mills/kWh

$\begin{array}{lrc} & \begin{array}{c}\text { Ebasco } \\ \text { Report }\end{array} & \begin{array}{l}\text { RESPONS } \\ \text { Report }\end{array} \\ \text { Oil-fired } & 8.44 & 8.44 \\ \text { Coal-fired (ncnscrubber) } & 13.48 & 13.54 \\ \text { Coal-fired (scrubber) } & 17.84 & 20.83 \\ \text { Nuclear } & 21.10 & 17.33\end{array}$

The Ebasco numbers are consistent with other estimates, and may represent more current information.

C. Sulfur Dioxide Emissions Standards

Sulfur dioxide emissions standards had a decisive effect on the types and quantities of coal used in the ERDA Scenario $V$ model run. This is seen from the number of regions in which the ratio of $\mathrm{SO}_{2}$ emitted to $\mathrm{Btu}$ content exactly equals the permitted level. For nonscrubber plants, this happened in all regions but MPAD District 12; for RCI uses this happened in MPAD Districts $1-8,10$, and 13. One would expect that relaxing the standards would result in reduced system cost and use of higher sulfur coal.

A sensitivity run was made with $\mathrm{SO}_{2}$ emission standards lowered by $10 \%$. Cost decreased from $\$ 212.977 \times 109$ to $\$ 212.840$ $\mathrm{x} 109$ or $-0.064 \%$. Coal use increased $0.38 \%$ from $719.3 \times 106$ tons to $722.1 \times 106$ tons. The same regions as before had difficulties in meeting the standards. The general trend was toward use of

*Fossil and Nuclear 1000MW Central Station Power Plants Investment Estimates. Prepared by Ebasco Services Inc, N.Y. EPRI TPS 75-601 Sepl. 1975. 
higher sulfur, higher Btu content of coal for.RCI uses as shown in Table 8. For nonscrubber plants, lower Btu content coal was favored. Changes in production and consumption are shown in Tables 9 and 10. Base case flows are represented in Figure 2, and coal flows for this case are depicted in Figure 3 . The model behayed as expected.

D. Coal Prices

Coal prices were changed as detailed below to probe the model's behavior in response to variation of such a vital parameter. The methodology that had been used to develop prices was to establish a relationship between price and sulfur content on a national basis and then adjust this price by MPAD to reflect regional price levels. A single coal price equation was derived from BOM price data:

$$
\text { Price in } 1973 \$=9.77(Q)-0.336 \text {, }
$$

where $Q$ is sulfur content in pounds per $10^{6}$ Btu (See page 65 of the RESPONS report).

A specific MPAD price level adjustment was made by using the data contained in Tables $5-5$ and $5-6$ of the RESPONS report which show production level by state and average specific sulfur and price per ton by state. Two consequences of this methodology are that the multiplier based on average price level and average sulfur content is constant for ali coal types in a given MPAD, and that the higher the specific sulfur content of a given coal, the lower its price relative to the other coal types in an MPAD. The following table shows the hierarchy of coal types from most to least expensive resulting from this pricing scheme:

\begin{tabular}{ccc} 
Eastern Coals & lbs. Sulfur per $10^{6}$ Btu & \multicolumn{1}{c}{$(Q)(-.336)$} \\
\cline { 2 - 3 } A & 0.5 & 1.26 \\
D & 0.54 & 1.23 \\
G & 0.75 & 1.10 \\
F & 0.87 & 1.05 \\
B & 1.11 & 0.966 \\
E & 1.17 & 0.949 \\
C & 2.84 & 0.704
\end{tabular}


Table 8

Changes in Characteristics of Coal Used for RCI and Power Plants Under Relaxed Sulfur Standards

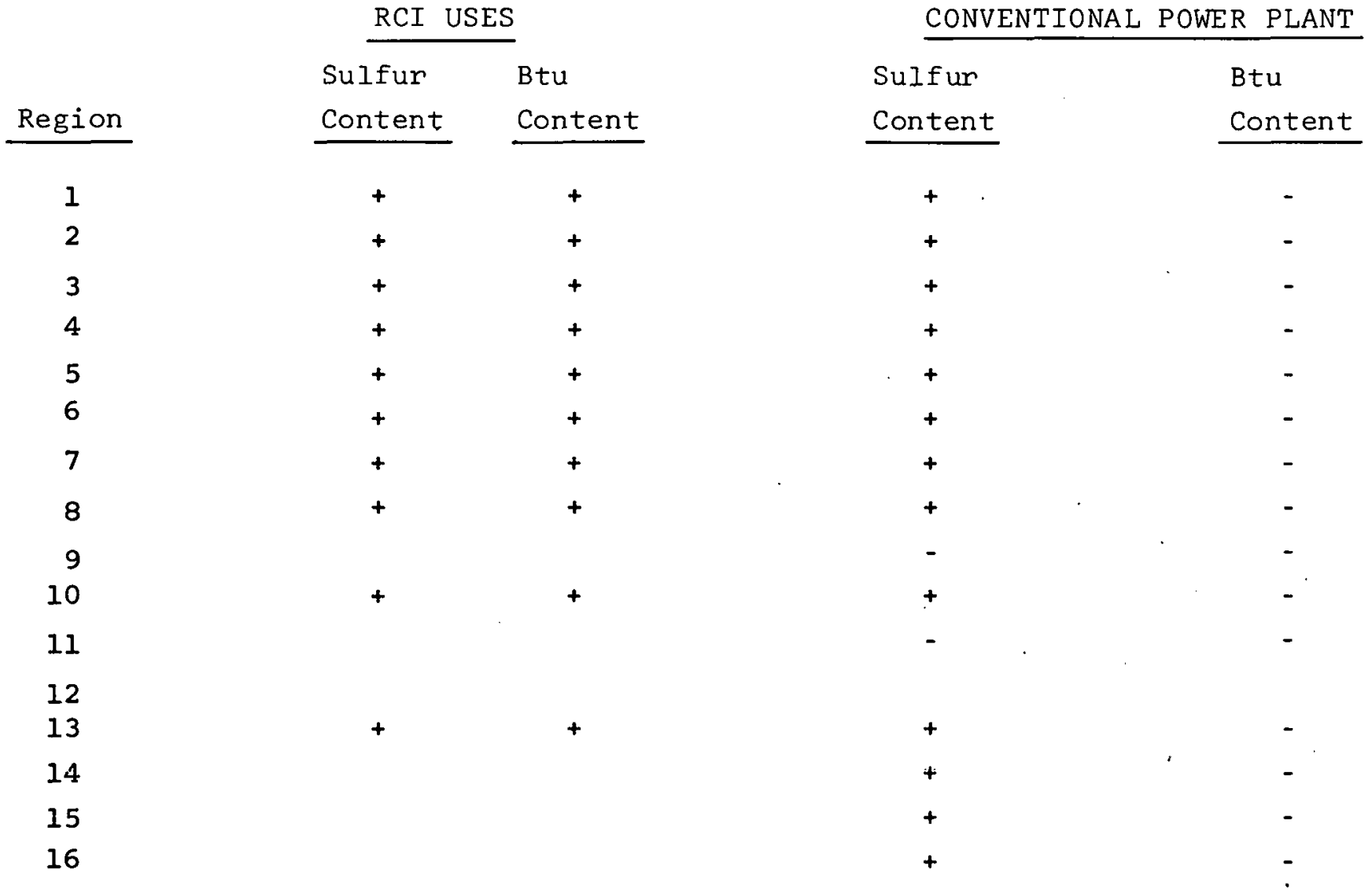


Table 9

Comparison of Regional Coal Production

in the Base and Relaxed Sulfur Standards Cases

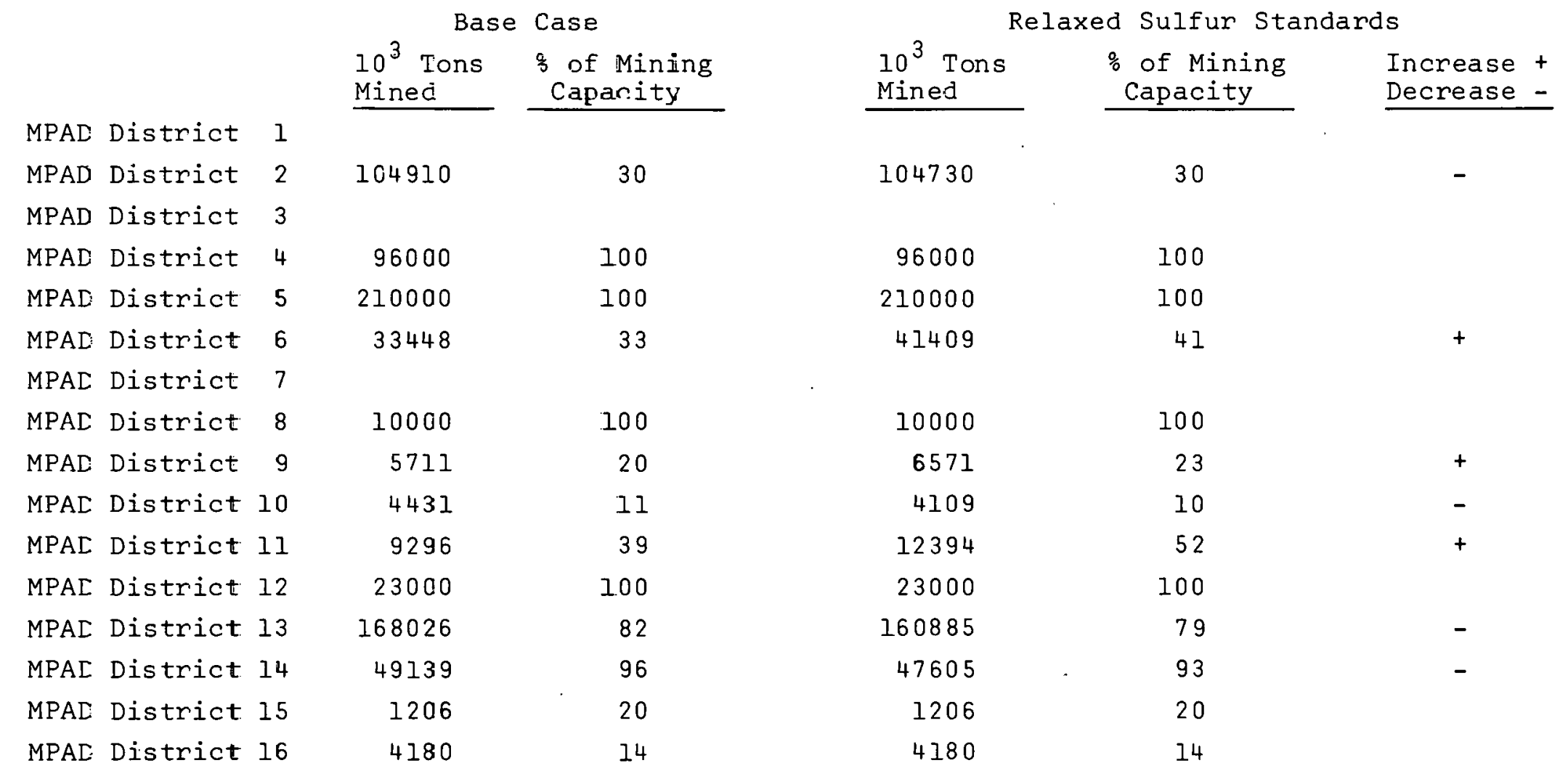


Table 10

Comparison of Coal Type Consumption in the Base and Relaxed sulfur Standards Cases

\begin{tabular}{|c|c|c|c|c|c|}
\hline $\begin{array}{l}\text { Coal } \\
\text { Type }\end{array}$ & . & $\begin{array}{l}\text { Base Case } \\
10^{3} \text { tons }\end{array}$ & $:$ & $\begin{array}{l}\text { Relaxed } \\
\text { Sulfur } \$ \text { tand- } \\
\text { ards } 10^{3} \text { tons }\end{array}$ & $\begin{array}{l}\text { Increase + } \\
\text { Decrease - }\end{array}$ \\
\hline A & & 150735 & & 136779 & - \\
\hline B & & 163356 & & 173028 & + \\
\hline c & & 30900 & & 46698 & + \\
\hline D & & 73333 & & 63722 & - \\
\hline E & & 21846 & & 22724 & + \\
\hline $\mathrm{F}$ & & 18620 & & 23296 & + \\
\hline$G$ & & 15007 & & 18965 & + \\
\hline $\mathrm{H}$ & & 4940 & & 3076 & - \\
\hline I & & 37868 & & 39454 & + \\
\hline $\mathrm{J}$ & & 154138 & & 145978 & - \\
\hline K & & 0 & & 0 & \\
\hline $\mathrm{L}$ & & 6331 & & 5075 & - \\
\hline$M$ & & 4180 & & 4180 & \\
\hline $\mathrm{N}$ & " & 38094 & & 39112 & + \\
\hline 0 & & 0 & & 0 & \\
\hline
\end{tabular}




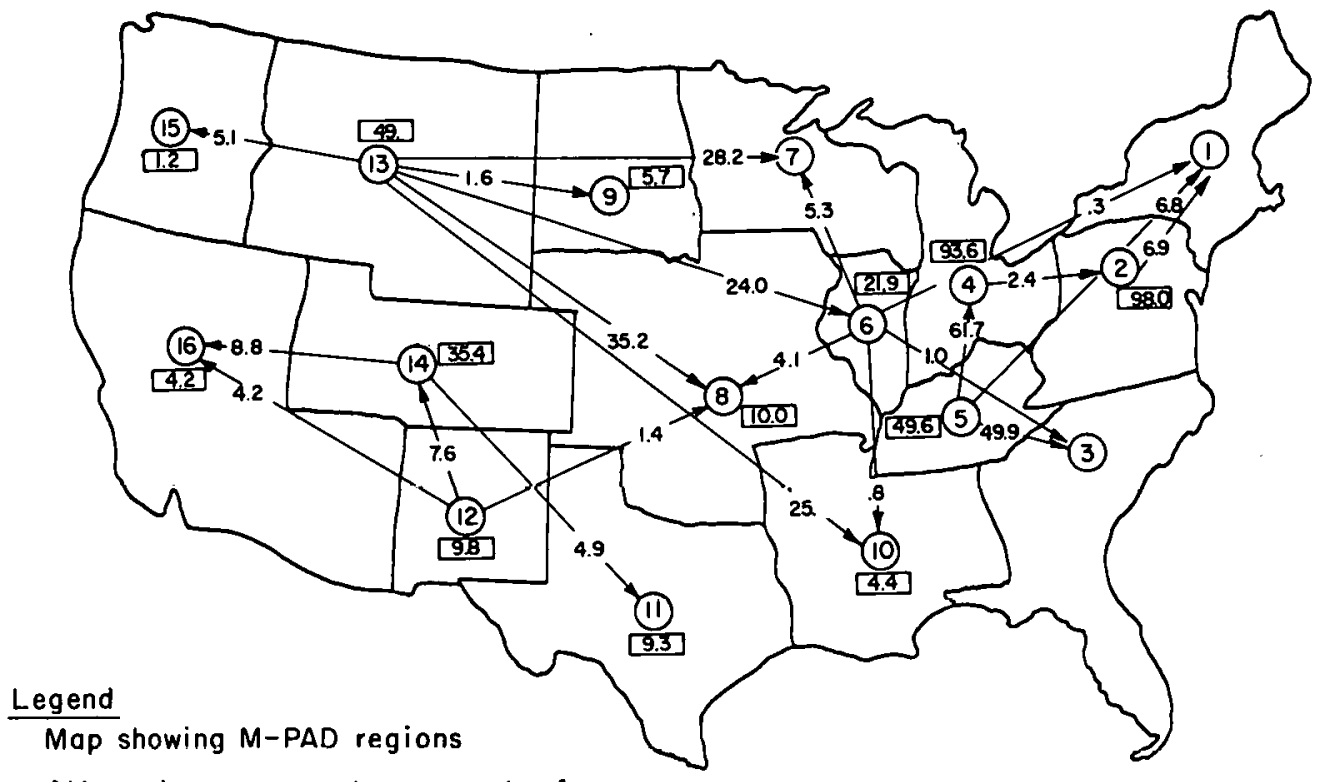

All numbers represent movements of coal in 106 tons

A circle oround a M-PAD region represents the intraregional shipments

Figure 2. Base case coal flows.

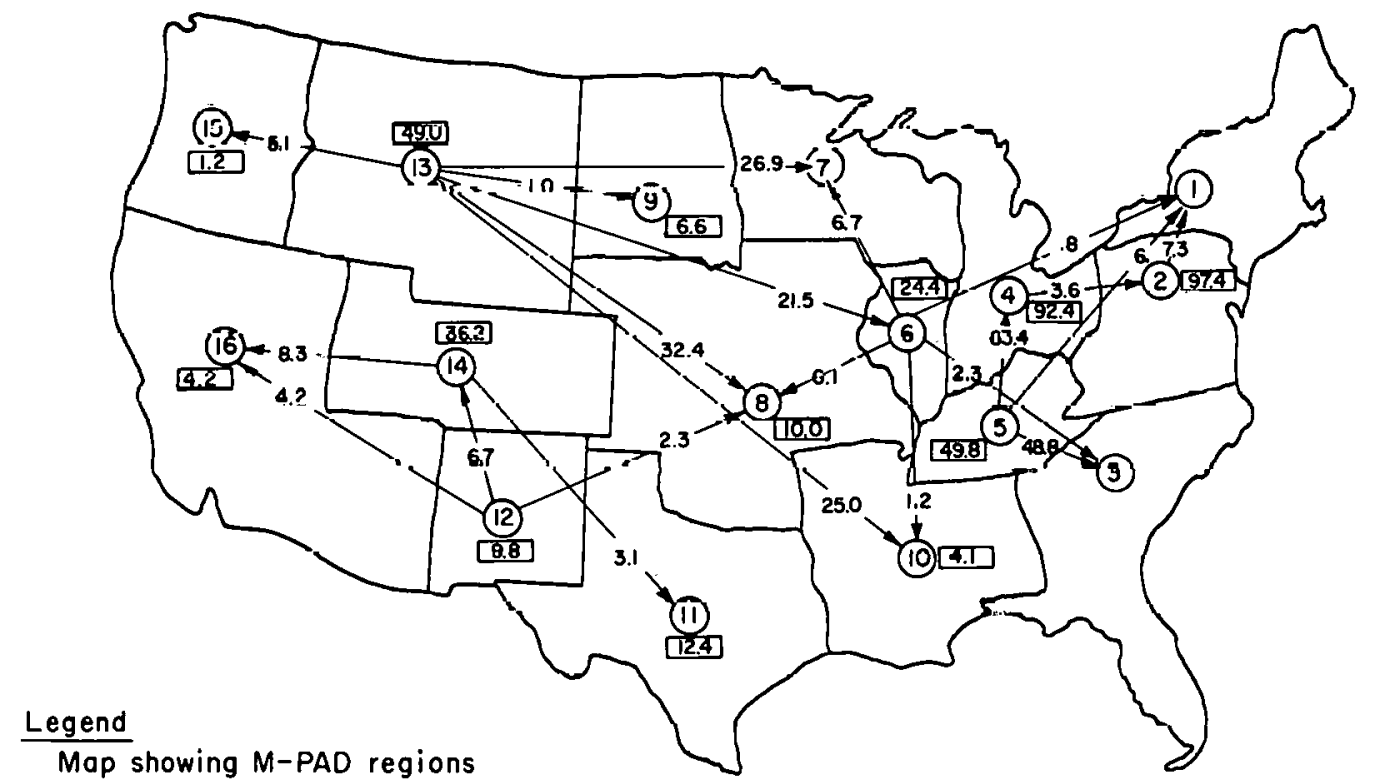

All numbers represent movements of coal in 106 tons

A circle around a $M-P A D$ region represents the intraregional shipments

Figure 3. Revised sulfur standards case coal flows. 
Western Coals $\quad$ lbs. Sulfur per $10^{6} \mathrm{Btu}$

$\begin{array}{lll}\mathrm{L} & 0.35 & 1.42 \\ \mathrm{H} & 0.507 & 1.26 \\ \mathrm{~J} & 0.537 & 1.23 \\ \mathrm{G} & 0.75 & 1.10 \\ \mathrm{M} & 0.87 & 1.05 \\ \mathrm{I} & 1.11 & 0.966 \\ \mathrm{~K} & 1.17 & 0.949 \\ \mathrm{~N} & 3.6 & 0.650\end{array}$

Within a group of coals in any region, the order of most to least expensive should be as above. Wherever type $L$ is mined, it will be more expensive than type $J$, which will be more expensive than type $K$. Intuitively, however, (and in reality) since the Btu content of type $L$ coal is 8,3000 , while that of type $H$ is 13,800 - and since either meets $\mathrm{SO}_{2}$ regulations when burned, type $\mathrm{H}$ is a more valuable coal. [Another off-setting consideration is that it may be easier to remove sulfur from high-sulfur coal by washing.] Nonetheless, according to this pricing scheme, type L coal will be more expensive. In any case, very few of the coal prices in the present input data agree with the prices derived using the reported source data and equations. Table 11 gives the recalculated prices. [Apparently the disagreement arises because Bechtel used average price and coal quality by county, weighted to resources in that county. However, these data are not presented in the RESPONS report, and the results derived from them do not agree with those derived using the state data. It is not clear why the state data were given if they were not used.]

A computer run was made with the recalculated prices. Total system cost increased $0.31 \%$ to $\$ 213.634 \times 10^{9}$. Coal production went from $719.346 \times 10^{6}$ tons to $720.843 \times 106$ tons, an increase of $0.21 \%$.

The general trend was toward burning of coals with both higher sulfur and Btu contenl, which is anticipated as higher sulfur content coals become less expensive. Increase in Btu content is then necessary in order to meet sulfur dioxide emissions standards. Table 12 shows the changes in coal type usage for RCI and power plant applications. 
Table 11

Recalculated Coal Prices

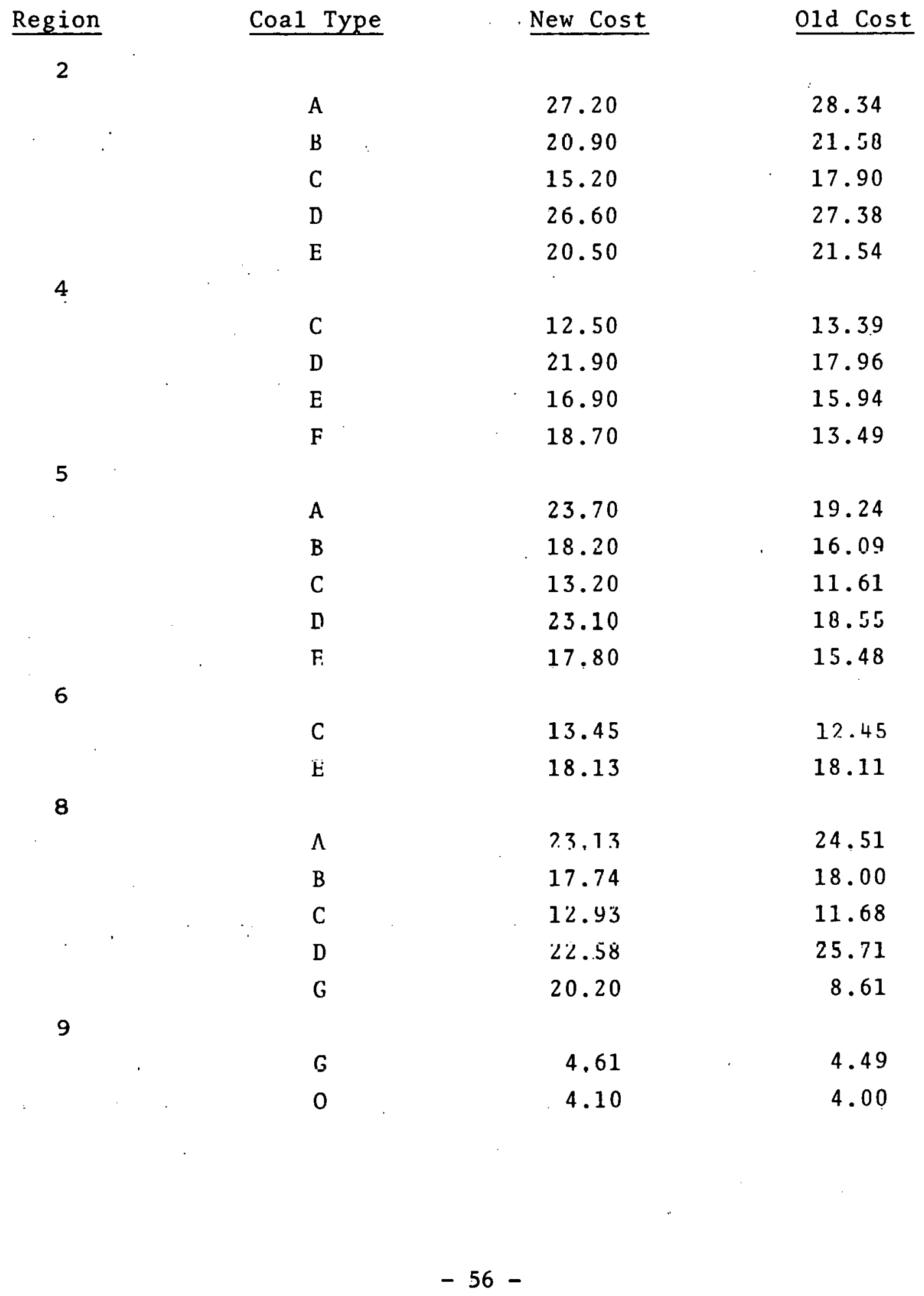


Table 11 (continued)

\begin{tabular}{|c|c|c|c|}
\hline Region & Coal Type & New Cost & OId Cost \\
\hline \multicolumn{4}{|l|}{10} \\
\hline & A & 26.05 & 24.22 \\
\hline & $\mathrm{B}$ & 19.96 & 20.65 \\
\hline & $\mathrm{C}$ & 14.54 & 18.11 \\
\hline & $D$ & 25.41 & 26.81 \\
\hline & $\mathrm{E}$ & 19.61 & 20.20 \\
\hline \multicolumn{4}{|l|}{12} \\
\hline & $\mathrm{I}$ & 5.52 & 13.63 \\
\hline & $\mathrm{J}$ & 7.02 & 6.92 \\
\hline & M & 6.00 & 10.82 \\
\hline \multicolumn{4}{|l|}{13} \\
\hline & G & 7.81 & 6.50 \\
\hline & $J$ & 8.73 & 8.76 \\
\hline & $\mathrm{L}$ & 10.10 & 8.84 \\
\hline & $\mathrm{M}$ & 7.46 & 7.41 \\
\hline & $\mathrm{N}$ & 4.62 & 4.19 \\
\hline & 0 & 7.60 & 4.52 \\
\hline \multicolumn{4}{|l|}{14} \\
\hline & $\mathrm{H}$ & 20.90 & 18.25 \\
\hline & I & 16.00 & 13.63 \\
\hline & $\mathrm{J}$ & 20.40 & 19.95 \\
\hline & $\mathrm{K}$ & 15.80 & 11.86 \\
\hline & $\mathrm{L}$ & 23.60 & 10.98 \\
\hline & $\mathrm{M}$ & 17.40 & 14.24 \\
\hline & 0 & 10.43 & 10.43 \\
\hline \multicolumn{4}{|l|}{15} \\
\hline & $\mathrm{G}$ & 14.48 & 12.92 \\
\hline & $\mathrm{J}$ & 16.20 & 11.88 \\
\hline & $\mathrm{L}$ & 18.71 & 9.91 \\
\hline & M & 13.77 & 10.82 \\
\hline
\end{tabular}


Table 12

Changes in Characteristics of Coal Uses for RCI and Power Plant Applications Under Coal Price Changes

$\underline{\text { Region }}$

RCI USES

CONVENTIONAL POWER PLANT

Sulfur

Btu

Content

Content

Sulfur

Btu

1

2

3

4

5

6

7

8

9

10

11

12

13

14

15

16 
Regional production and consumption patterns changed as shown in Tables 13 and 14. The main effects were to render coal of types $B, D$, and I less attractive while encouraging production of types $C$ and $\mathrm{E}$. The former three have lower sulfur to Btu content ratios than the latter two. Since the effect of the cost changes was to raise relative prices of coals with lower sulfur/Btu ratios, this behavior was to be expected. Figure 4 shows coal flows. The model behaved reasonably and as would be anticipated.

E. Slurry Pipeline Availability

Because slurry pipeline Link 1 connecting Arkansas and Wyoming (regions 10 and 13) may not be built, a run was made with the capacity of this link set to 0 . One would not expect this change to have a major impact on the results since a number of options are available, including substitution of unit train between the two regions. This would raise total cost by $\$ 0.358 \times 10^{9}$ or $0.168 \%$.

In the model run, cost rose $\$ 0.310 \times 10^{9}$ or $0.146 \%$. Changes occurred in the mining patterns of MPAD District 10, the Link 1 destination region, where production of coal types $A, B$, and $C$ increased by a total of 22 million tons; in MPAD District 6 coal production of type $C$ decreased 0.5 million tons; in MPAD District 13, the Link 1 source region, coal production of type $J$, similar in Btu and sulfur content to type $C$ coal and formerly shipped by slurny to MPAD District 10, decreased by 24.8 million tons. Shipments are shown in Figure 5. Since the Btu content of type $\mathrm{J}$ coal is slightly lower than that of type $C$ coal, net coal production decreased. The major effect was that region 10 now mined coal for its own uses instead of relying on coal from region 13. One reason that coal from outside the region can appear more attractive than coal from within the region is that slurry pipeline charges may need adjustment with respect to other transportation mode costs. Again, model behavior was reasonable. 
Table 13

Compariscn of Regional Coal Production Patterns

in the Base and Coal Price Changes Cases

Base Case

$10^{3}$ Tons
Mined $\quad \begin{aligned} & \% \text { of Mining } \\ & \text { Capacity }\end{aligned}$

MPAD District 1

MPAD District 2

MPAD District 3

MPAD District 4

MPAD District 5

MPAD District 6

MPAD District 7

MPAD District 8

MPAD District 9

MPAD District 10

MPAD Distri=t 11

MPAD Distriat 12

MPAD Distriat 13

MPAD District 14

MPAD District 15

MPAD District 16
104910

96000

210000

33448

10000

5711

4431

9296

23000

168026

49139

1206

4180

$3 C$
Coal Price Changes Case

\begin{tabular}{ll}
$\begin{array}{c}10^{3} \text { Tons } \\
\text { Mined }\end{array}$ & $\%$ of Mining \\
Capacity \\
\hline
\end{tabular}

128141

96000

167886

31353

10000

29000

5205

9296

23000

204000

11576

1206

4180
Change

37

$+23230$

100

80

$-42144$

$-2095$

100

100

$+23289$

$+\quad 775$

39

100

100

$+35974$

$-37563$ 
Table 14

Comparison of Coal Type Consumption in the Base and Coal Price Changes Cases

\section{Coal Type}

\section{A}

B

C

D

E

F

G

$\mathrm{H}$

I

$\mathrm{J}$

K

L

$\mathrm{M}$

$\mathrm{N}$

0

$$
10^{3} \text { Tons }
$$

Base Case

150735

163356

30900

73333

21846

18620

15006

4940

37868

154138

0

6331

4180

38094

0

\author{
$10^{3}$ Tons \\ Coal Price Changes
}

168932

110953

64098

29000

94603

0

9296

9920

9156

182612

0

0

4180

38094

0
Increase +

Decrease -

$+18197$

- 52403

$+33198$

- 44333

$+72757$

- 18620

- 5710

-4980
$-\quad 28712$

- 28712

+. 28474

- 6331 


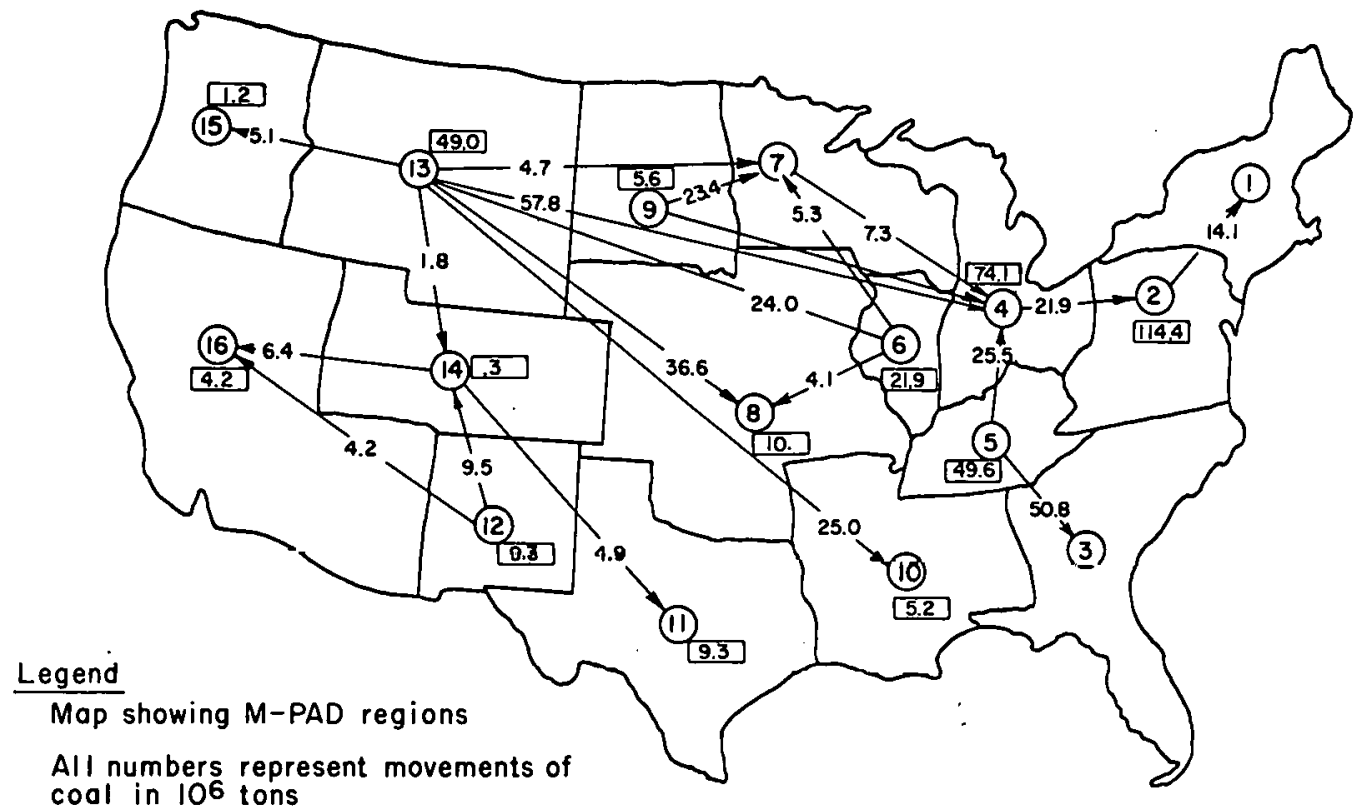
coal in 106 tons

A circle oround a $M-P A D$ region

represents the intraregional shipments

Figure 4. Coal price changes case coal flows.

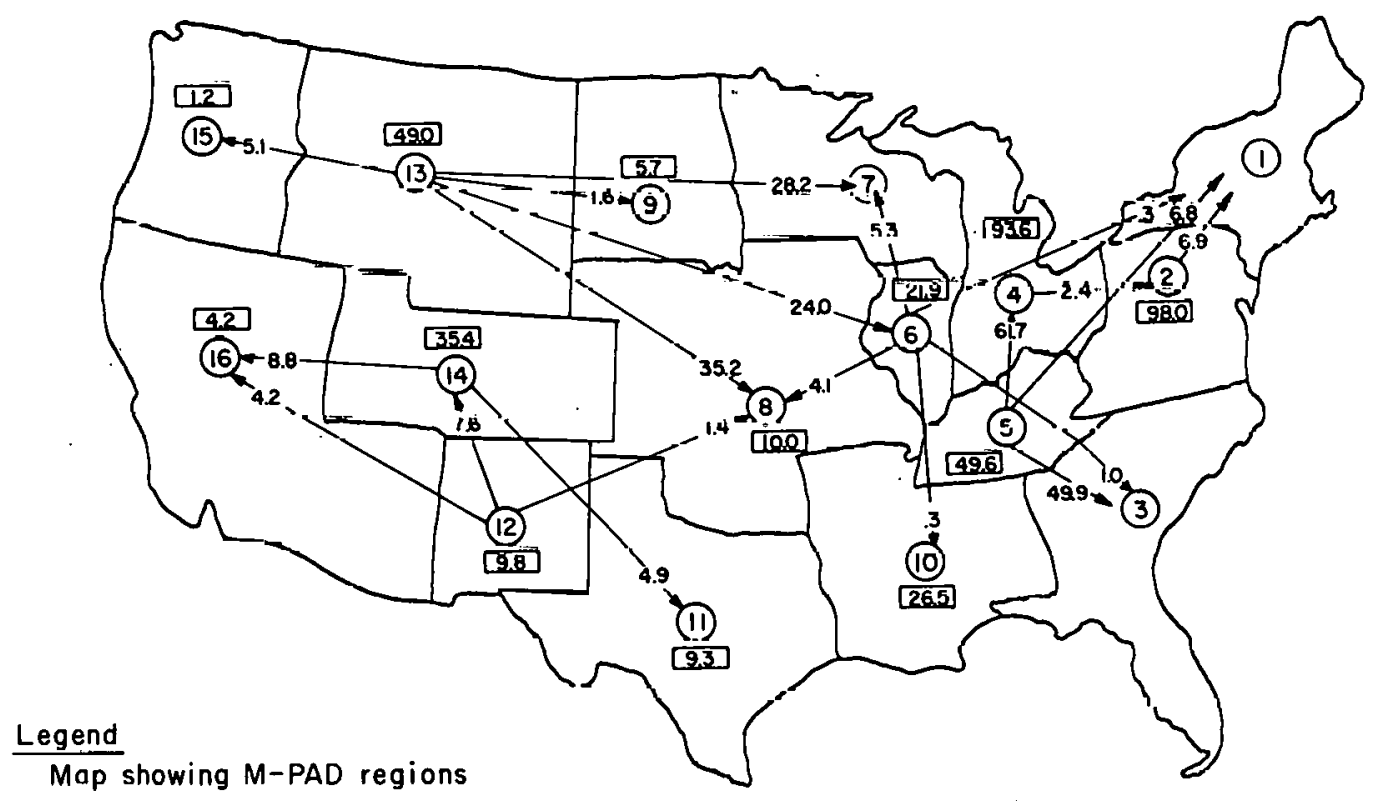

All numbers represent movements of coal in 106 tons

A circle around a $M-P A D$ region

represents the introregional shipments

Figure 5. Slurry pipeline capacity change case coal flows. 


\section{F. Slurry Pipeline Costs}

A run was made to probe the sensitivity of the model's transportation sector to changes in slurry pipeline costs. Three assumptions in the model may result in unfair cost comparisons between slurry pipelines and unit trains. First, charges for the pipelines are computed on the basis that the capacity is fully utilized, but in the ERDA Scenario $V$ run this is only true for Links 1 and 5 . Link 4 serves the same destination as Line 5; if both are built region 16 will in 1985 have slurry pipeline capacity in excess of total demand for coal.

The second assumption causing difficulty is that unit train costs are based on distances computed from centroid to centroid, while slurry pipeline distance is actual length. [Barge costs are also based on actual distances rather than on centroid-tocentroid distances.] Third, distribution costs within the destination region are charged to unit trains but not to slurry pipelines, though unit trains would also be built from point to point.

A set of "improved" costs for pipelines was calculated in Chapter III. For the run, these were added to distribution cost within the destination region. Of course this obscures the advantage that both unit train and slurry pipeline may enjoy with respect to waterborne carrier and rail. The costs used are shown in Table 15.

These cust changes had very little effect on the solution. Although some regional coal production patterns shifted, the difference from the base case did not exceed 7 million tons in any region.

Slurry pipeline usage was affected. Line 2 ceased to be used; region 11 mined more coal and received the remaindcr required from region 12 by unit train. Usage of Link 3 was reduced from $51 \%$ to $3 \%$ of capacity; region 15 increased mining up to its production limit. Links 1 and 5 were still fully utilized, but usage of link 4 dropped from $88 \%$ to $31 \%$ of capacity. In general, 
Table 15

"Improved" Slurry Pipeline Costs

\begin{tabular}{|c|c|c|c|c|}
\hline Link & Regions & $\begin{array}{l}\text { Bechtel } \\
\text { Cost } \\
\end{array}$ & $\begin{array}{l}\text { "Improved" } \\
\text { Cost } \\
\end{array}$ & $\begin{array}{l}\text { "Improved" Cost } \\
\text { \& Distribution }\end{array}$ \\
\hline 1 & $13-10$ & 5.26 & 5.97 & 11.50 \\
\hline 2 & $14-11$ & 8.81 & 11.47 & 16.82 \\
\hline 3 & $13-15$ & 6.30 & 8.18 & 13.97 \\
\hline 4 & $14-16$ & 2.54 & 2.90 & 9.64 \\
\hline 5 & $12-16$ & 3.67 & 4.17 & $1 \cap .9 .1$ \\
\hline
\end{tabular}


the increases in slurny costs tended to make mining coal within a slurry destination region, or imponting coal from a nearby region other than the slurry source region, more economically attractive than the pipeline. Shipments are shown in Figure 6.

A subsequent computer run was made in which distribution costs within the destination region were not included in the costs of interregional unit trans transportation. The objective was to permit fairer comparison of unit trains with slurry pipelines (for which the original costs were used) while reflecting their advantage over waterborne carrier and conventional rail. Since only the cost of the cheapest mode appears in the data tables, it was not possible to determine whether unit trains would, through this cost reduction, have become the mode of choice between any two regions where it was previously not allowed. [Although costs were calculated for the three competing modes -- rail, barge, and unit train -- only the cheapest was allowed between any two regions since no transportation capacities were set. When such constraints are absent, an LP will always choose the cheapest mode.]

These cost changes had a substantial effect on the solution. Region 2's production was cut in half; while region g's quadrupled and region 12's quintupled. Production pattern changes are shown in Table 16. Type of coal mined differed from the base case, with considerably lower consumption of types A, B, C, F and significant growth in usage of types D, E, G, J. Changes in coal type consumption are listed in Table 17. In general, the trend was toward consumption of lower sulfur coal, which happened in regions $2,3,6$, 7, 8, 10, 11, 13. Regions 4 and 9, however, used higher sulfur coal.

A number of shifts occurred in transportation patterns. One would expect increased shipments by unit train, due to its reduced cost, with corresponding decreases in shipments by alternate modes. Regions most likely to experience changes, namely those which can receive shipments by unit train, can be identified by looking at Table 18. 


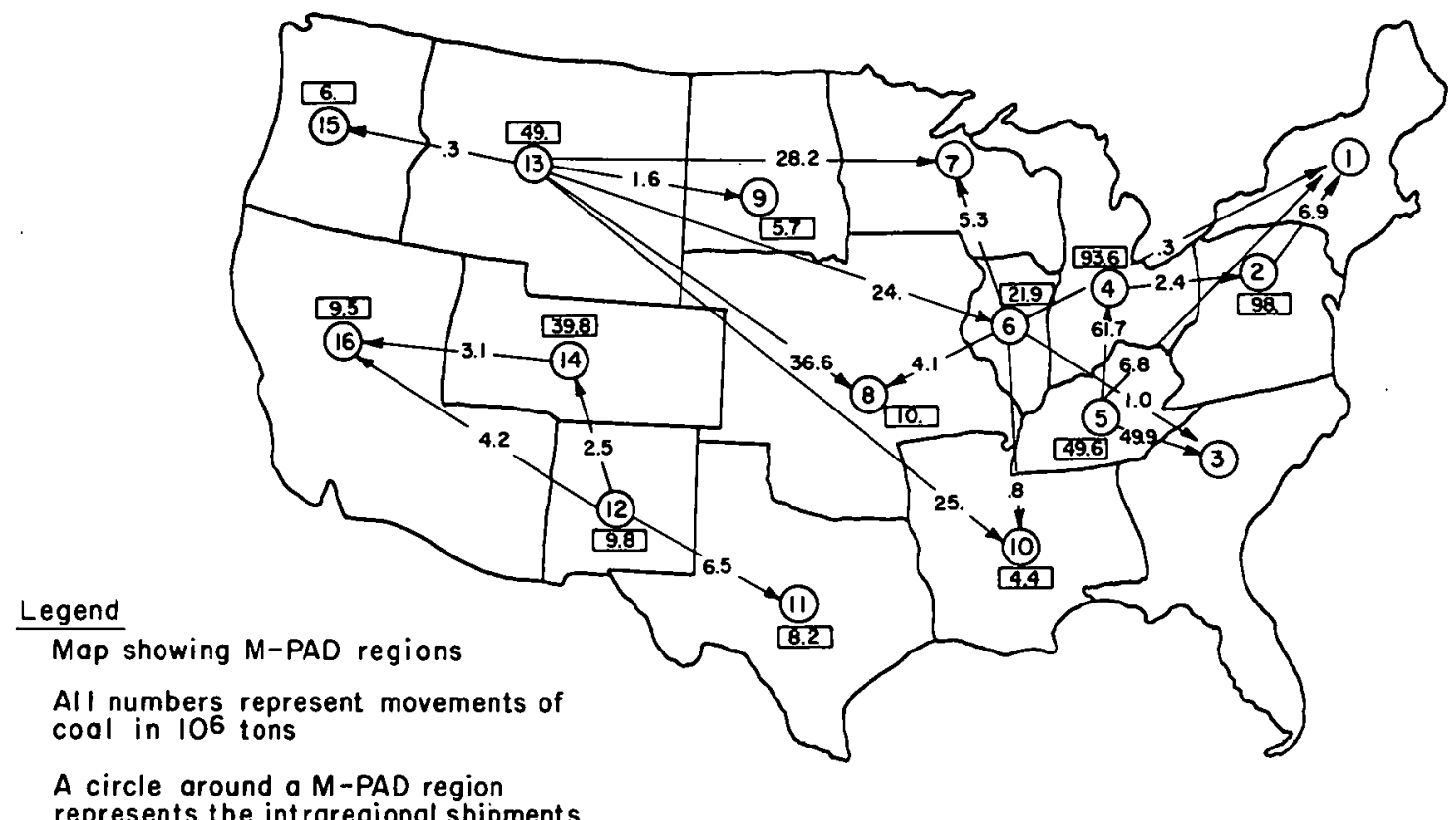

Figure 6. Slurry pipeline cost changes case coal flows.

Table 16

Comparison of Regional Production Patterns in the Base and Reduced Unit Train Costs Case

Base Case

MPAD

District

1

2

3

4

5.

6

7

8

9

10

11

12

13

14

15

16
Tons

Mined

1049.10

96000

210000

33448

10000

5711

4431

9296

23000

168026

49139

1206

4180

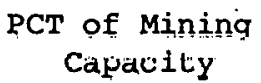

Capacity

30

100

100

33

100

20

11

39

100

82

9.6.

20

14

Redured Inft Train Costs

\begin{tabular}{lcc}
$\begin{array}{l}\text { Tons } \\
\text { Mlned }\end{array}$ & $\begin{array}{c}\text { PCT of Mining } \\
\text { Capactey }\end{array} \quad \begin{array}{c}\text { Jncrease + } \\
\text { Decrease - }\end{array}$ \\
\hline
\end{tabular}

51423

15

100

$210000 \quad 100$

41675

41

100

100

29000

17419

73

23000

100

204000

100

48058

6000

94

100

4179

14 


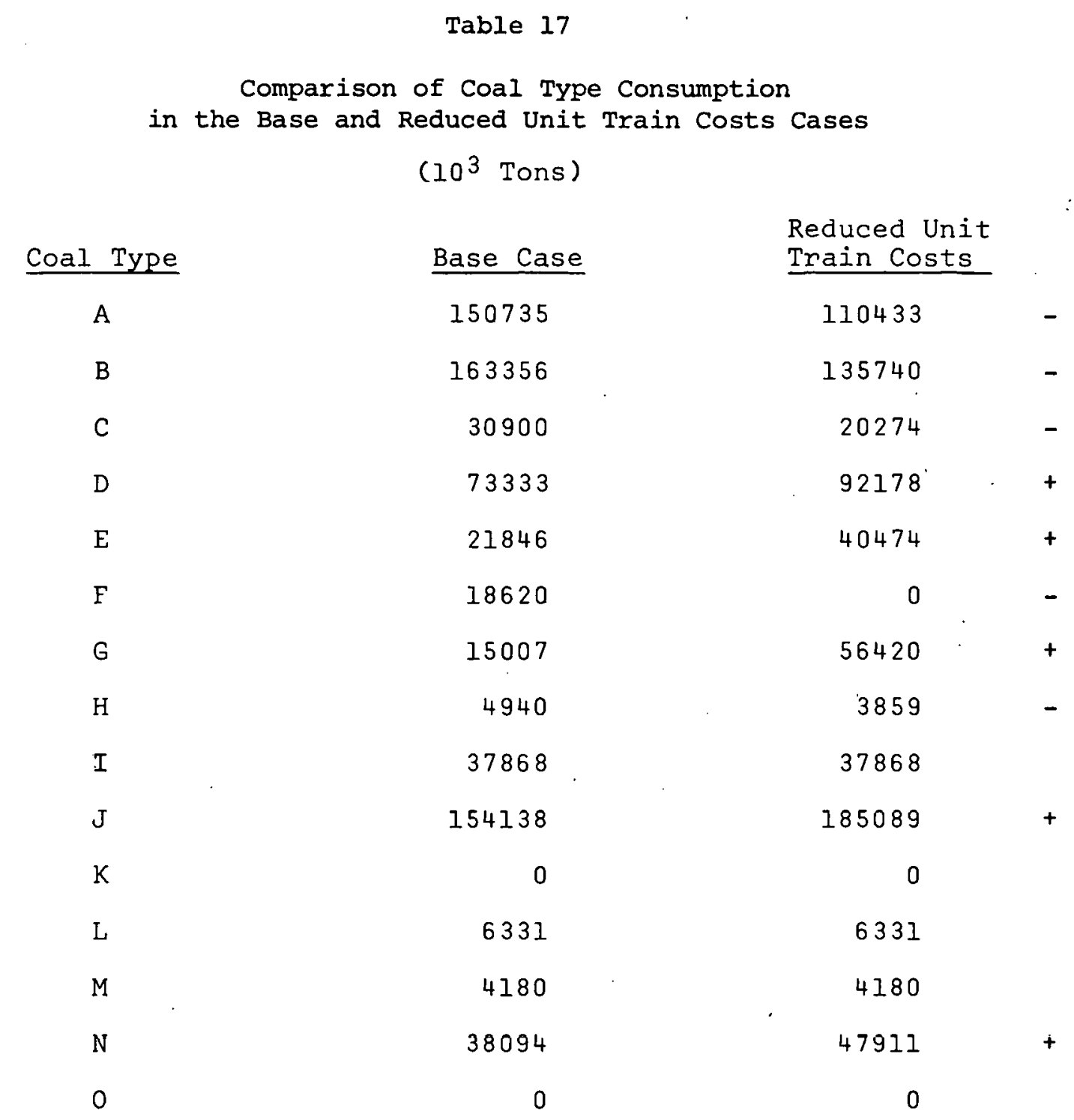


Table 18

Allowed Transportation Modes

Between MPAD Districts

From/To

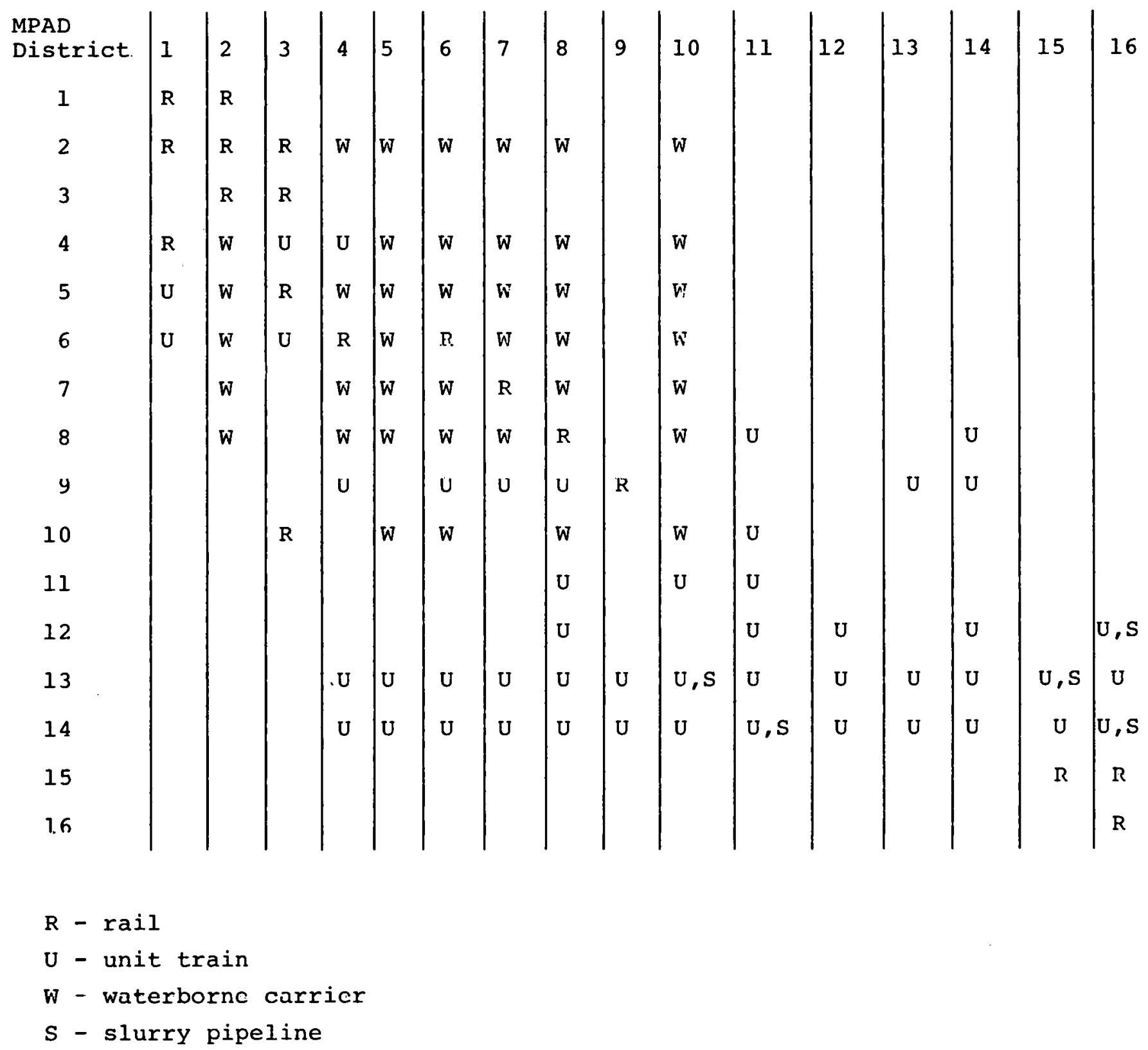

A blank indicates that transportation is not permitted. 
A few observations should be made about this table, which was compiled from the data tables on coal transportation costs* (pp, B-48, 59, 50 of the RESPONS report). The table is not symmetric, e.g., coal may be transported from region 9 to region 8 , but not from region 8 to region 9. Probably certain coal flows considered suboptimal by the authors were eliminated in order to reduce the number of variables. As the model is currently formulated, allowing transportation between two regions implies the definition of roughly 9 (plant types $3,4,5, \mathrm{D}, \mathrm{E}, \mathrm{J}, \mathrm{L}, \mathrm{P}, \mathrm{Q}) \times 6$ (coal types mined in source region) $=54$ variables. [This situation could be ameliorated by defining pcols of each coal type in each region and/or reducing the number of coal types. At most 240 additional equations would be needed, but the number of variables could be lowered appreciably. There are now 111 paths permitted, which causes the definition of about 5994 variables. The alternate formulation requires about $111 \times 6+16 \times 15$ (total coal types) $=906$ variables. Trade-offs here are not clear, however, since it is usually cheap (in terms of the LP solution algorithm) to add variables and expensive to add equations.]

Under the new set of cost assumptions, coal flows were affected in accordance with expectations. Table 19 shows the base case shipments (the mode may be identified by referring to the transportation modes, Table 18), while Table 20 gives the changes under the new unit train cost assumptions. Figure 7 depicts coal flows.

Regione 2, 5, 9, 12, 14, 15, and 16 took delivenies from the same sources as before. Regions $1,3,4,6,7,8,10$, and 11 shifted dependence to source regions which could ship by unit train.

A deviation from the general pattern occurred in region 6 , which decreased dependence on its own mining and on unit train shipments from region 13 in favor of shipments by water from region 8. Region 8 now received all its coal by unit train from region 13 *An error was discovered in Table T:TCCOALQJ, entry QJ. Transportation cost within a region should equal distribution cost; here it does not. Therefore, costs associated with all variables of the form QJ-QJ_ _ - were too high by 1.25 . 
Table 19

Base Case Shipments

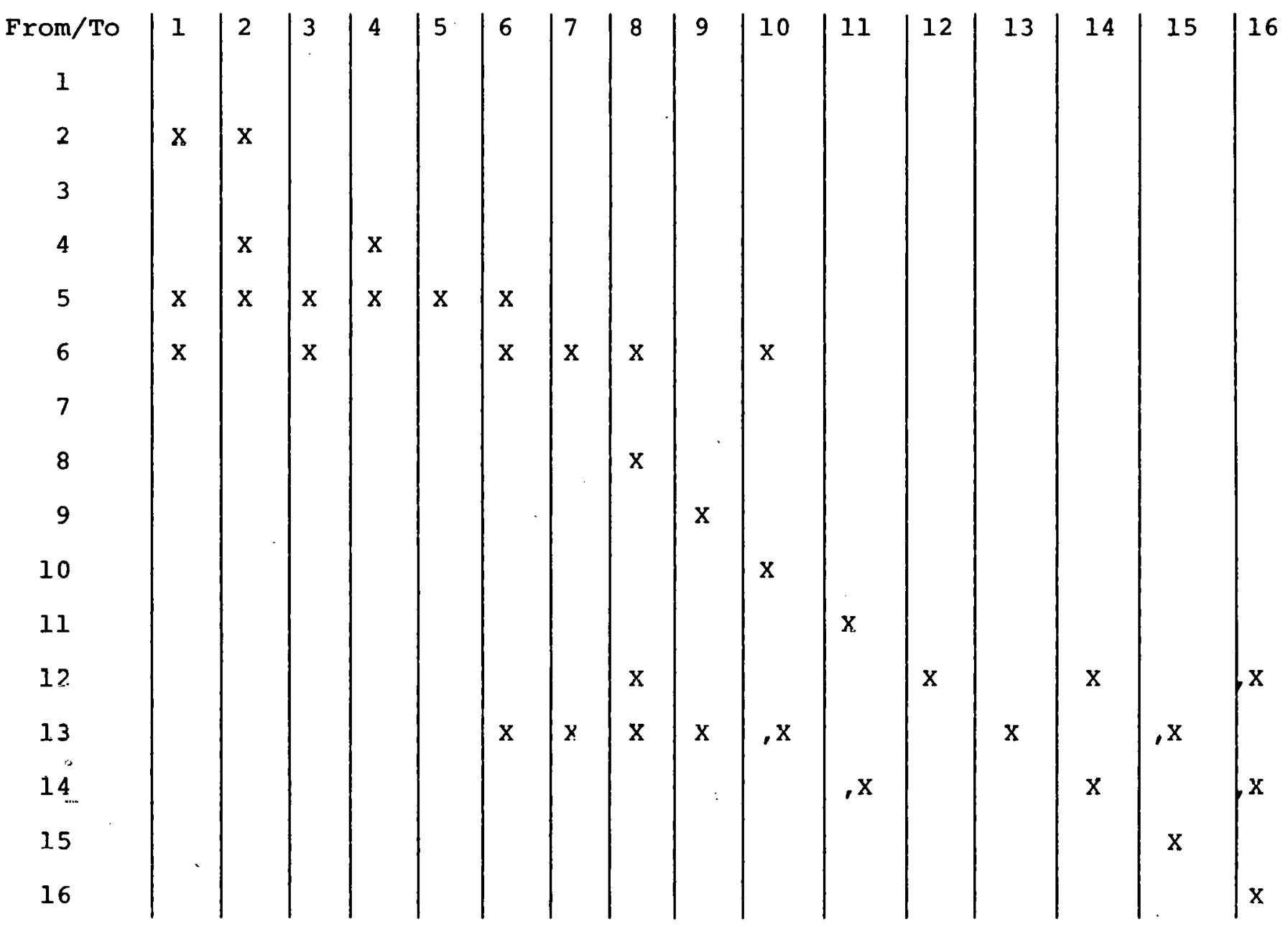

"X" indicates that slurry pipeline wae the mode of choice between the two regions; uilit truill, nail on barge was not used. 
Table 20

Reduced Unit Train Cost Shipments

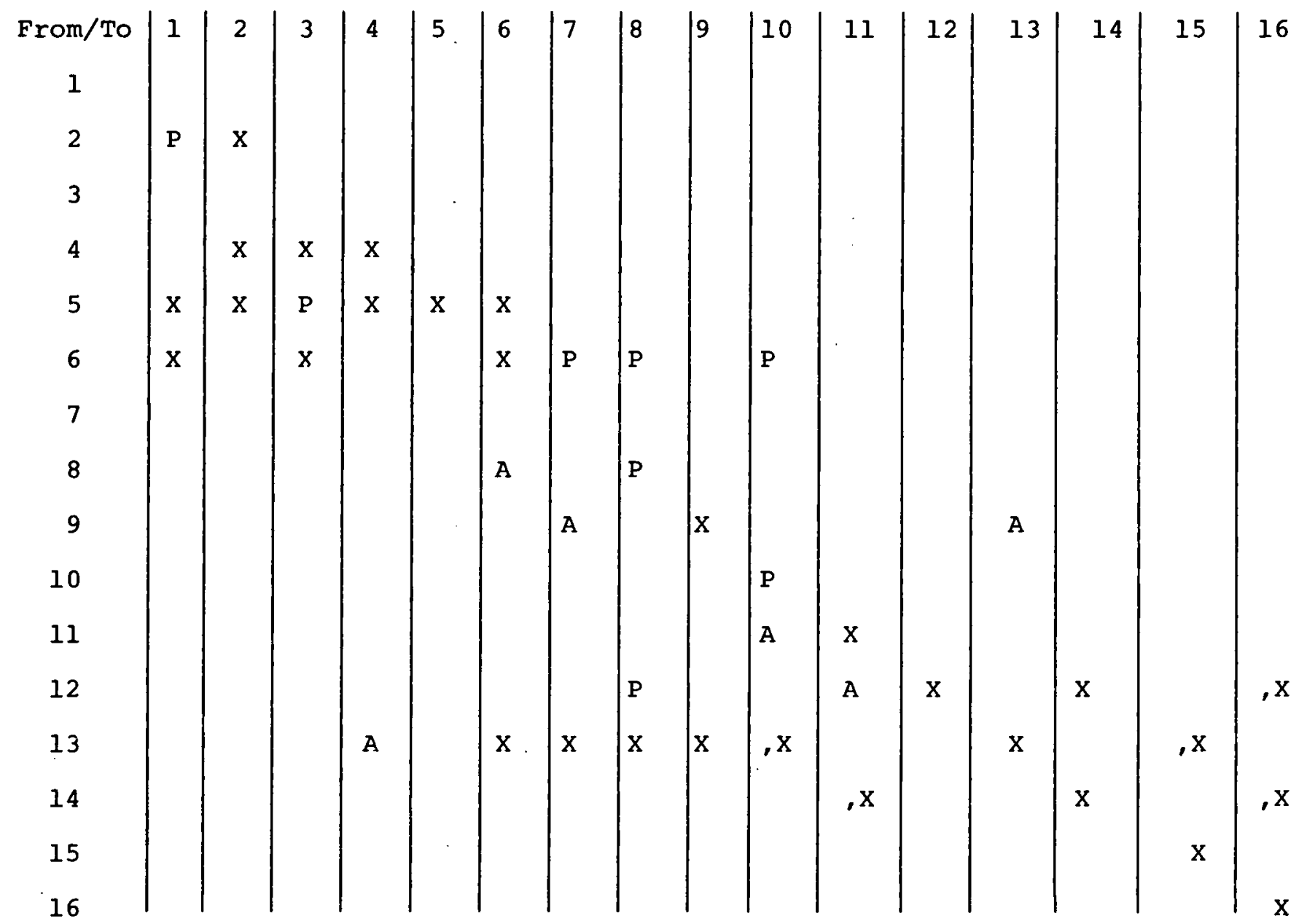

$P$ indicates present in base case but absent here.

A indicates absent in base case but present here.

$\mathrm{X}$ indicates present in both cases.

, $x$ indicates that slurry pipeline was the mode of choice between the two regions; unit train, rail or barge was not used. 


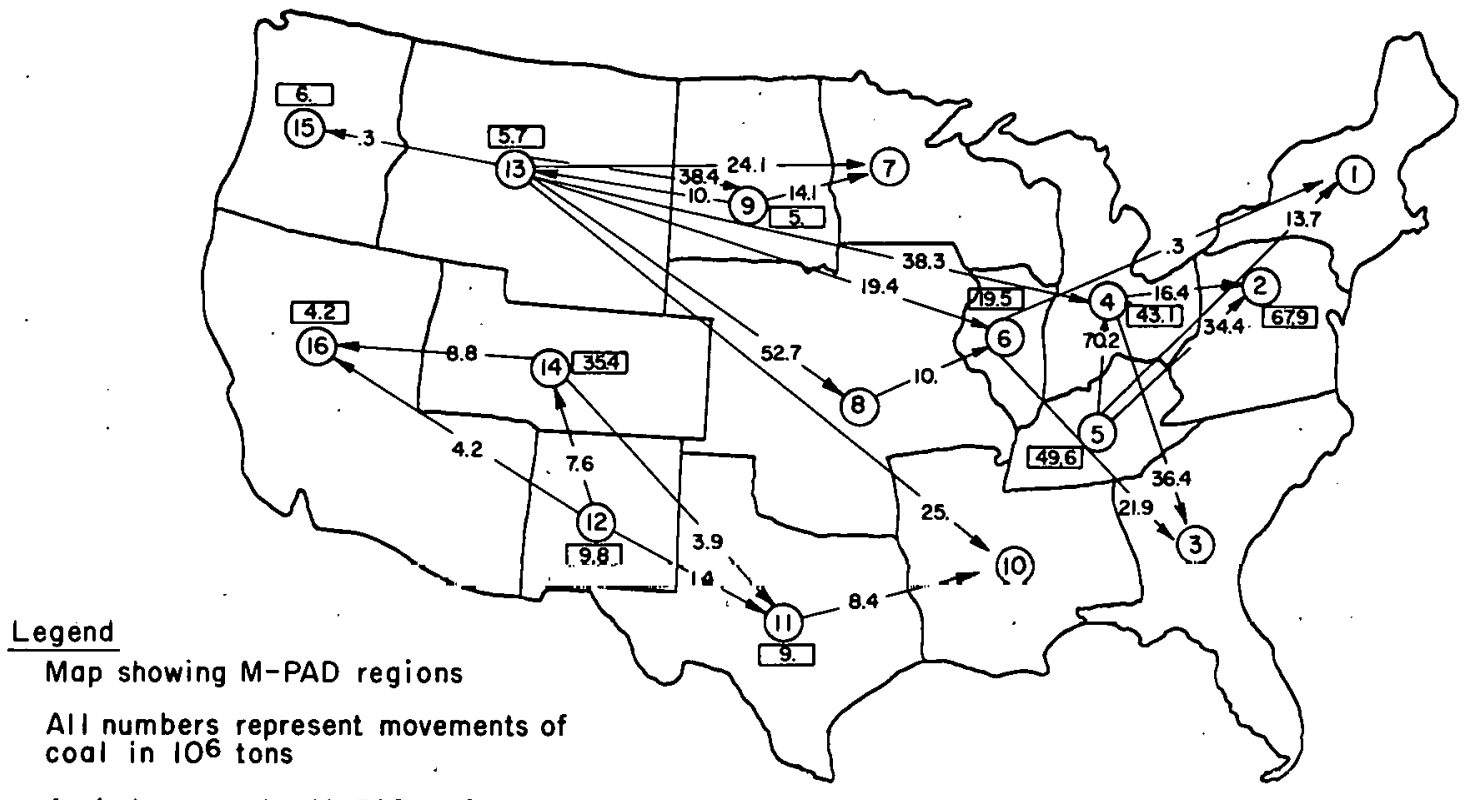

A circle around a $M-P A D$ region represents the intraregional shipments

Figure 7. Reduced unit train costs case coal flows.

and shipped coal mined internally elsewhere. A check of the data showed that waterborne carrier transportation between regions 8 and 6 was relatively very cheap; production in region 13 was at $100 \%$ of capacity so no more could be obtained from there; and greater use of region 6's only two coal types, $C$ and $E$, both having relatively high sulfur to Btu content, would have violated environmental standards. So the results were reasonable.

Slurry pipeline usage was affected less than in the previous run. Usage of Links 1,4 , and 5 was the same as the base case; usage of Link 3 dropped to $3 \%$ of capacity as before; usage of Link 2 fell from $55 \%$ to $43 \%$. 


\section{Chapter V \\ CONCLUSIONS AND RECOMMENDATIONS}

\section{Conclusions}

The RESPONS model utilizes the linear programming methodology and shares the capabilities and limitations of this modeling approach. As with any model, the adoption of simplifying assumptions and the quality of available data further limit the applications for which the model is appropriate. The RESPONS report contains a discussion of these matters at its very beginning and provides (page 5) a list of examples of broad application areas in which parametric changes in the national energy systems can be usefully explored with this model. To quote, "For example, the model can help the energy planner in determining:

- The response of the national energy system to changes in: Sulfur emission regulations Transportation system capacities Coal production capabilities Costs of coal energy conversion facilities Availabilities of alternative sources of energy Energy demand projections Alternative energy supply scenarios

- Preferred locations of new coal conversion facilities

- The value of additional:

Regional coal production capacity Transportation capacity Energy conversion measures 
- Those elements in the national energy system to which the system is most sensitive, i.e., those elements in which small changes are likely to effect major policy decisions."

This validation and assessment study of the RESPONS model has yielded a number of general conclusions regarding the strengths and weaknesses of the model and of its applicability to policy analyses in its present form. The model could be used directly in a comparative assessment of the conversion technologies used to transform coal into useful intermediate energy forms (liquids, gases, or electricity) and the transport of these energy forms to a demand center. With due regard for certain types of regional differences, the model can indicate preferred technologies among those under development and their relative values in a benefit/cost sense, given projections of the technical and economic characteristics and the price and availability of competing conventional resources. Alternatively, the analytical procedure can be reversed to indicate RED objectives for specific technologies in terms of their cost and technical characteristics relative to competing systems. For a given technology, the economically viable ranges of cost and technical characteristics can be explored. For instance, the mode.1. might be used to investigate the question of at what natural gas price, and in what regions, various coal gasification processes would become attractive.

RESPONS is also an appropriate tool for the exploration of the impacts of sulfur emission standards on the coal sector. The sulfur dioxide constraints play a major role in determining the range of feasible solutions. Therefore, the model can be used to investigate effects of differing regional environmental conditions and standards on the types of coal preferred for given applications and markets. Changes in mining patterns under different regional sulfur emission standards can bc determined. Technologies can be evaluated in the light of their contributions toward alleviating adverse impacts. Extension of the data base to include other 
environmental emissions could extend this strength of the model considerably.

Although the modeling of the electric sector permits competition among base-loaded plants, RESPONS cannot otherwise be used to study interfuel competition or substitution possibilities since demands for liquids, gases, or solids are specified exogenously. However, use of RESPONS in conjunction with an interfuel substitution model could overcome this limitation, permitting analyses of the effects on the energy system of different energy demand projections, alternative energy supply scenarios, or variable availabilities of alternative sources of energy. The preferred technologies in each market (liquids, gases, electricity) can be identified within limitations on coal production and transport modes.

There are several areas in which RESPONS is not an appropriate tool. It should not be used to "forecast" the responses of national or regional energy systems to changes in various parameters, and it should not be relied on for definitive answers on the siting of facilities or on the choice of transportation modes. While the model output may indicate patterns of facility location and coal energy flows, these should be regarded only as first approximations because of simplifying assumptions made about transportation and its costs. Specific decisions about facility siting and transportation modes require in-depth engineering analyses.

Since transpurtation capacities are not as yet adequately quantified, particularly in the coal sector, RESPONS should not be used to study issues involving them until more data have been collected. The model output should be examined carefully to see that the solution does not imply unrealistically high transportation capacity for any mode (especially for waterborne carriers). Another note wilh regard to transportation is that lignites cannot be shipped in the open more than a few hundred miles, since they tend to dry up and blow away, so model output should be checked to make sure lengthy shipments are not implied. 
Finally, it should be made clear that the RESPONS model does not simulate producer/consumer behavior. The objective of the model is to minimize total system cost while meeting demand. Assuming that the costs in the model are reasonably accurate in real-world terms, the output indicates how the least-cost configuration could be achieved. There is, however, no implied guarantee that either producers or consumers will behave in this fashion. The model thus should be used as a normative tool only.

The original area of concern in development of the RESPONS model is embodied in the name of the project: the Clean coal Energy: Source-to-Use Economics Project. The coal sector received a great deal more attention and in-depth analysis than other competing energy resources. The extraction, processing, and environmental impacts of other fuels are ignored. RESPONS should be applied to coal-related policy questions only.

The preceding chapters and the Appendix contain a number of suggestions for improving the RESPONS data base and enhancing the modeling capability. The more important of these are reiterated below.

Recommendations

In this section, the major recommendations are highlighted without repetition of the detailed rationales for them. Most of the recommendations are addressed to data-related problems since the objectives of this study relate primarily to questions of what should be done to the model and data base, in their current state, before using them for analysis. It is felt that few, if any, changes need to be made to the slructure of the model for this purpose. The few model changes suggested ds lelt to be espccially appropriate for ERDA/AFE applications and are among the many model modifications and extensions suggested within the RESPONS report itself. It is strongly suggested that thoee recommendations impacting areas of direct concern to a user be implemented prior to model use. 
1. Regionalization. It is recommended that supply and demand regions be decoupled and centroids chosen for each that reflect coal transportation mode realities. Data pertinent to coal supply regions should be generated on the basis of the 23 Bureau of Mines coal districts. Data pertinent to energy demand regions should be generated on the basis of the five PAD districts, the nine Census regions, the 16 MPAD districts, on the 48 states, depending on the level of precision required. Choice of the most disaggregated (the states) has much to recommend it for data collection, since aggregation to all other regions becomes straightforward.

2. Slurry Pipeline Costs. The data base cost values for allowed slurry pipeline links are calculated from hypothetical pipelines of varying capacity using (undocumented) Bechtel Corporation costing data and procedures. The cost of real-world pipelines is dependent upon many additional factors, such as terrain traversed, water availability, project usage fractions, etc. It is recommended that an independent validation of the hypothetical pipeline costing procedure be obtained and that assumed slurry pipeline lengths be chosen to be comparable to assumed unit train distances.

3. Facility Costs. The capital costs for construction of new power plants or synthetic conversion plants were calculated for the scenario data base using "typical utility financing methods" "Substantial disagreements were found between RESPONS data and both standard NCAES numbers and values calculated using independently derived financing factors. A number of apparent internal inconsistencies were noted in the computation of the annual fixed costs for electricity generating plants. It is recommended that these discrepancies be resolved and effects of regional variations in capital cnsts be incorporatcd.

4. Coal Mining Capacity Constrainte. The scenario results indicated dramatic and unrealistic shifts in regional mining patterns from 1975 to 1985. It is recommended that constraints be developed on the mining capacity for each coal type in each region in order to provide a more realistic picture of future mining possibilities. A redefinition of coal types might be useful. 
5. Environmental Factors. RESPONS is well suited to exploration of the impacts of sulfur emission standards on the coal sector. It is recommended that regional data defining standands for other pollutants, e.g., particulates, be developed for model use in order to extend this capability. This would allow examination of the impacts of a variety of environmental standards on the allocation of coal resources to demand regions.

6. Energy Demands. Since energy demands drive the RESPONS model, it is important to have a reliable set as a ctarting point for many different analyses. It is recommended that effort be directed at developing a good set of "base case" regional projections of energy demand for future years. Sophisticated methods, using economic and demographic projections, are currently under development at Brookhaven and elsewhere and should be exploited.

7. Interfuel Substitution. The RESPONS model is designed to explore problems of coal allocation. In order to broaden the policy analysis capability, it is recommended that the coupling of RESPONS to a model which explores interfuel substitution questions be considered. Such a coupling might be either direct or indirect, but the impact of the coupling on choices of energy supply values in the RE'SPUNS model 1tself shuuld be carefully detenmined.

8. Water Availability and Use. Though meaningful values for the future availability of water for energy-related purposes may be hard to determine, there are clearly policy issues, e.g., slurry pipeline transport feasibility, where such constraints play an important role. It is recommended that water availabllity constraint values be developed, particularly if the supply regionalization scheme suggested under Recummendation 1 is adopted. Alsn, there are large differences between the undocumented values given by Bechtel for unit water requirements of advanced technologies and values inferred from other sources. It is recommended that these differences be explored and resolved. Unit water requirements for slurry pipelines should also be provided. 
9. Power Plant Capacity Projection. Current utility forecasts have been used to provide negional projections of the capacities of coal and noncoal fired power plants in 1985 for the scenario runs. Such utility forecasts seem quite reasonable to use for short-term "base case" projections. It is recommended, however, that effort be directed at determining how best to make estimates of longer term projections and, in particular, determining if regional departures from straight utility forecasts due to different (and changing) regional environmental or resource constraints are likely to evolve.

10. Operation and Maintenance Costs. In considering the OEM costs for future plants, the RESPONS report notes that the available data indicate significant cost increases for all types of power plants over the levels expected based on O\&M costs for existing facilities. It is recommended that adjustments be made to the data to reflect this. Also, the costing data are apparently derived for high plant factors, even though OEM costs are highly plant-factor dependent. It is recommended that the relation between total and o\&M costs be determined under varying load assumptions.

11. Electric Transmission Center. The examination of the costs of electricity transmission provided in the RESPONS data base indicated some significant discrepancies between the costs in the table and those computed using the procedure described in the RESPONS report. It is recommended that these discrepancies be examined and resolved.

12. Mine-Mouth Coal Prices. The model data base provides a mine-mouth coal price in 1985 for each coal type in each MPAD region. Coal pricing is potentially an extremely volatile factor in regional energy policy analyses, and the many market forces which are involved in the setting of mine-mouth coal prices are difficult to capture. It is recommended that the actual trends in such pricing be continuously monitored to uetermine if significant departures from current forecasts are indicated at any time. Similarly, the model data base provides a value for the mineable reserves of each coal type in each MPAD region. These values should be considerably 
less volatile than prices. It is recommended, however, that they be periodically monitored in order to keep the data base up-to-date in this regard.

13. Reprogramming. The transportation formulation in the model couples each coal type in each region to every plant type which can use this coal type in all regions to which shipment is allowed. This requires the definition of about 6000 variables. It is recommended that the model be neformulated so that all coal of one type is transported to a pool in each region and then distributed to consuming plants in that region. This will result in the reduction of the number of variables to about 1000, while adding at most 240 equations, with an expected saving of computer time. This reformulation will become especially important if intermodal competition is to be modeled. 


\section{APPENDIX \\ SCENARIO INPUT DATA TABLES}

In the following pages, each of the tables which constitute the input data base for the RESPONS demonstration run on ERDA Scenario $\mathrm{V}$ are considered. The tables for this scenario are contained in Appendix $C$ of ERDA-76-109. Since many of the input values were not changed from those used in the demonstration run on ERDA Scenario 0, the tables for this run, contained in Appendix $B$ of ERDA-76-109, were considered also.

Each table is identified by its table, its code name (or the code names of subtables), its line span in the Appendix listing, and the Appendix page or pages on which it will be found. Line spans and pages in both Appendices are included for the tables which appear in both.

The following characteristics, where appropriate, are considered for each table: method of generation, sources of information, assumptions used, algorithms developed, quality limitations, and ease of modification. Since none of thse characteristics were explored in depth, many of the comments are judgmental and point to the need for detailed consideration if the table involves a system component crucial to a particular analysis or policy issue. The more important of the recommendations for future consideration are included in the chapter on Conelusions and Recommendations. 
Table Name:

Code Name:

Line Span:

Page No.:
Coal Classification

T: COALTYPE

$952-995$

B-22

This table defines the values of the sulphur content and average heat content (in Btus/pound) of each of the 15

types of coal which are mined, transported, and consumed in the model runs. The 15 coal type categories were chosen as representative of all the kinds of coal available from mines in the United States. The data same from the Rurean of Mines (BOM) Minerals Availability System tapes. The BOM heat content data are given on a dry basis and have been converted to their equivalents for as-received coal on the basis of the moisture content indicated in. BOM analyses.

An attempt was made to validate the coal classification system by conducting a survey of "coał types" for all coal consumed by electric utilities in plants of $25 \mathrm{MWe}$ or greater. This information is contained in the Federal Power Commission's (FPC) 1976 summary of its own Form 423 ("The Annual Summary of Cost and Quality of Steam-Electric Plant Fuels, 1975," Staff Report of FPC, May 1976). Since utilities account for the largest share of coal consumed, this would seem to he a useful tool for checking the classification scheme. The results of this survey indicated that no unusual coal types were in use. The classification system, therefore, appears adequate.

A study was made of the consequences of the regional breakdown of coal types demanded by the results of the 1985 Scenario $\mathrm{V}$ run: The intent was to determine the reasonableness of the 1985 demands for coal of various types, given the present distribution of coal type amounts mined in each region. This was done by surveying each coal mining district in order to determine the percentage of each coal type presently mined. The district data were then aggregated to the MPAD level in a manner identical to that used by Bechtel. The results are 
shown in Table 21. The value of the percentage of that type of coal mined in the MPAD is given first (as determined from the FPC summary of Form 423), followed by the percentage of that type of coal which will be mined in the MPAD according to the 1985 model run. Total tonnages per year are also indicated for each MPAD for 1975 and 1985. (The 1985 total tonnage values are taken from the Scenario $V$ Base Case Output Report, page G-4). As can be seen, the results indicate a large number of dramatic shifts, including the shutting down of all. functioning mines in some MPADs and the opening of large numbers of new seams. The reason for this shift is clear. In 1975 very few states were in compliance with federal emission regulations, and utilities were burning low-cost high-sulphur coal whenever possible. The imposition of $\mathrm{SO}_{2}$ emission constraints for 1985 causes an enormous shift to low-sulphur coals. Since the model uses high costs for coal scrubbing and no costs for blending, the "optimal" choice of blending results in the complete closing of all mines which cannot produce the "right" types of coal. This does not seem a realistic conclusion, and results from the fact that the model presently puts a constraint only on total mining capacity in each MPAD. Constraints on each coal type in a given MPAD would provide a better picture of reality. For example, the demand for low-sulphur high-Btu Montana coal will very likely be enormous in 1985 (particularly if slurry pipelines are in place), although the demand today is very small. A realistic measure of just how much of Montana's expected $12 \%$ capacity surge could possibly be of type $J$ is needed. 
Percentaç Distribution 1975/1985 Coal Production

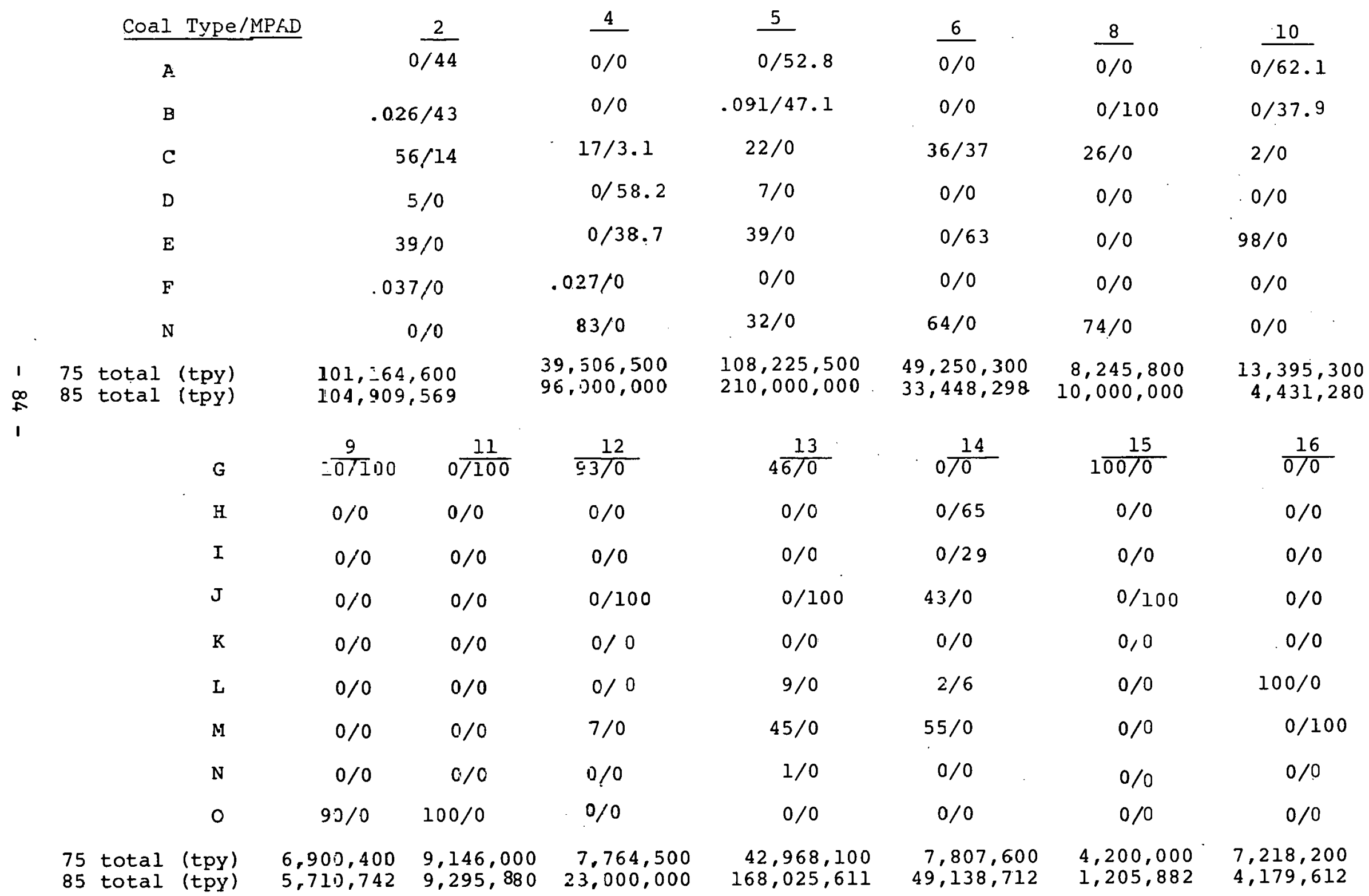


Table Name:

Code Name:

Line Span:

Page No.:
Coal Mining Capacity

T:CPRD

997-1036

B-23

This table lists the 1985 mining (production)

capacity in each MPAD region in units of thousands of tons per year. The sources of data include the 1973 BOM

Mineral Yearbook and other sources for actual state-bystate production in 1973-74 and Coal Week of 21 July 1975 for projected new capacity additions above 1974 levels to 1985 , again on a state-by-state basis. These figures were then aggregated to give the tabled capacities for 1985 in the 16 MPAD regions. It was noted that the total national capacity of $1,169,000$ ( $x 10^{3}$ tpy $)$ was greater then the value in the ERDA scenarios in order to insure that model solutions remained feasible when sensitivity runs were performed.

An article in the February, 1976 issue of Coal Age (p. 106), written by George F. Nielson, editor-in-chief of the Keystone Coal Industry Manual, contains more recent projections on capacity in the 1975-85 time frame. These data indicate a decrease in projected new capacity additions of some 43 million tons per year (tpy) in the 1975-85 period, compared to that shown in Table 5-3 (page 60) of the RESPONS report. In addition, it seems clear from the article that the model data base includes mined metallurgical coal. Since coal use in the steel industry is not modeled as such in RESPONS, it would seem reasonable to exclude the projected increases in the capacity for metallurgical coal from the MPAD totals. The Coal Age article cited above states that approximately 90 million tpy of the 535 million tpy of new capacity will be in mctallurgical coal and details the sources of this coal. With these numbers, a new set of values for this table have been computed and are listed in Table 22 (the "Difference" values). The subtraction of metallurgical coal from total coal capacity in the MPADs involved is shown explicitly so that later adjustments can be made based on new information on either total or metallurgical coal capacities. These 
results should alter the 1985 model results, especially in MPADs $5(Q E)$ and $8(Q H)$, where coal is already mined at $100 \%$ of capacity and where projected capacity is now indicated as Iower than in the scenario runs.

Table 22

1985 Coal Mining Capacities, BY MPAD

\begin{tabular}{|c|c|c|c|}
\hline MPAD & Total & Metallurgical & Difference \\
\hline QA & 0 & 0 & 0 \\
\hline QB & 326,350 & 61,700 & 264,650 \\
\hline QC & 0 & 0 & 0 \\
\hline QD & 92,850 & 0 & 92,850 \\
\hline$Q E$ & 187,950 & 7,750 & 180,200 \\
\hline$Q F$ & 94,900 & 2,500 & 92,400 \\
\hline QG & 0 & 0 & 0 \\
\hline $\mathrm{QH}$ & $7,5.50$ & 0 & 7,550 \\
\hline $\mathrm{QI}$ & 37,000 & 0 & 37,000 \\
\hline QJ & 35,310 & 11,750 & 23,560 \\
\hline QK & 26,600 & 0 & 26,600 \\
\hline QL & 26,700 & 0 & 26,700 \\
\hline QM & 205,200 & 0 & 205,200 \\
\hline QN & 64,980 & 4,530 & 60,450 \\
\hline QO & 6,300 & 0 & 6,300 \\
\hline $\mathrm{QP}$ & $11, \cap \cap n$ & 0 & 11,000 \\
\hline TOTAL & $1,122,690$ & 88,230 & $1,034,460$ \\
\hline
\end{tabular}




\begin{tabular}{|c|c|}
\hline $\begin{array}{l}\text { Table Name: } \\
\text { Code Name: }\end{array}$ & $\begin{array}{l}\text { Coal Imports } \\
\mathrm{Z}: \text { COIMPORT } \\
\mathrm{T}: \text { CPRDXX }\end{array}$ \\
\hline $\begin{array}{l}\text { Line Span: } \\
\text { Page No.: }\end{array}$ & $\begin{array}{l}1038-1067 \\
B-24\end{array}$ \\
\hline
\end{tabular}

This table accounts for the import of coal into the United states. It consists of two subtables. Z:COIMPORT defines the coal type(s) available for import into each MPAD; $T: C P R D X X$ specifies the cost and quantity available for each allowed coal type in each MPAD. The tables are structured so that the proper cost/quantity values are associated with the proper coal type/MPAD identifiers.

There are no entries in these tables for the 1985 scenarios since no coal imports were permitted. This seems reasonable for two reasons. First, the purpose of the demonstration run was to explore the nation's ability to provide its own energy needs, allowing only the minimum required oil imports to satisfy the optimization conditions. Second, the actual level of imports into the country has, in fact, been steadily declining. According to the FPC 1976 Annual Survey, only about a half million tons were imported in 1975. The receiving states were Alabama, Florida, and Massachusetts. In 1974, total imports amounted to 0.966 million tons. Thus, the actual importance of imported coal is so small that inclusion in the model would have no impact on the results. Low priority should be assigned to development of the base data for this table. 


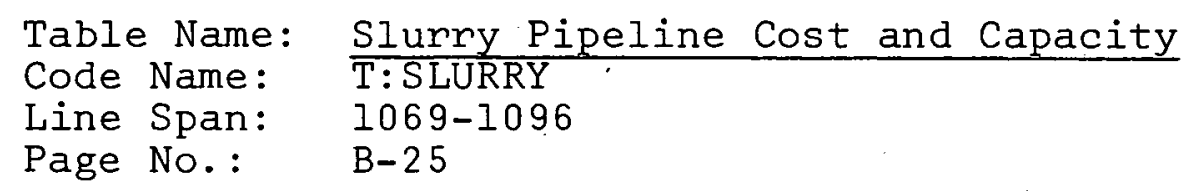

In one of the System Definition tables, code name $\mathrm{Z}$ : SLURLINK, the five coal slurry pipeline links allowed in the model demonstration runs for 1985 use are defined. The table $\mathrm{T}$ : SLURRY given the costs and capacities to be associated with the five allowed links defined in Z: SLURLINK, with costs in dollars/ton and capacities in millions of tons per year.

The details for this table are contained in the section entitled Slurry Pipeline Costs and Capacities in Chapter III and are not repeated here. 
Table Name: Emission and Emission Sensitivity

Code Name: T:EPA

$\mathrm{T}:$ SIP

T: SULPHUR

$\mathrm{T}: \mathrm{SCEFF}$

Line Span: $1098-1176$

Page No.: $\quad B-26-B-27$

This table contains the treatment of $\mathrm{SO}_{2}$ emission regulations and scrubber efficiency factors in the model. Two subtables, T:EPA and $\mathrm{T}$ :SIP, provide listings by MPAD of $\mathrm{SO}_{2}$ emission limits, in pounds/million Btu fuel input, for three types of coal-fired facilities: residential, commercial, industrial (RCI) (Type 3); nonscrubber power plants (Type 4); and scrubber-equipped power plants (Type 5). T:EPA provides federally imposed emission limits, and T:SIP provides limits from State Implementation Plans. The condition that must be met is

$$
\left(1-\text { scrubber efficiency) } * 2 * \mathrm{~S}_{\mathrm{c}} * 10^{-2} /\left(\mathrm{b}_{\mathrm{c}} * 10^{-6}\right) \leq \mathrm{T}\right. \text {, }
$$

where $S_{C}$ is the percentage sulfur content, $b_{C}$ is the Btu content, and $\mathrm{T}$ is the emission limitt given in $\mathrm{T}: \mathrm{EPA}$.

Subtable T: SULPHUR provides a capability for varying the sulphur emission constraints independently for the three plant types. This ability to insert a multiplier for T:EPA and T:SIP allows national-average sensitivity analyses without the need to change individual MPAD table values.

The final subtable, $\mathrm{T}$ :SCEFF, specifies the $\mathrm{SO}_{2}$ emission control efficiency for Type 5 plants (and for Type 3 , if used). An undocumented value of $85 \%$ is indicated in the table for Type 5 plants.

It should be simply noted at this point that the only emission and emission control considered by RESPONS is sulfur. Other emissions, e.g., particulates, are of considerable interest if true environmental concerns are to be addressed by the model. If they are to be included, it will be necessary to collect regional 
data defining emission standards for other pollutants, and also efficiency and capacity factors and costs for the emission's control technologies, the effects of controls on conversion facility efficiencies, and other quantities. New tables will have to be created and some model reprogramming will be required. Since the model seems well suited to consider the impact of emission standards, inclusion of other pollutants would broaden its capabilities substantially. 


$\begin{array}{ll}\text { Table Name: } & \text { Exogenous Electricity Tables } \\ \text { Code Name: } & \text { T:EXOGMULT } \\ & \text { T:EXOGELCT } \\ \text { Line Span: } & \text { li78-1214. } \\ \text { Page No.: } & \text { B-28 }\end{array}$

These two subtables were not used for scenario modeling but exist for sensitivity analysis on the cost and quantity of additional supplies of electricity. The additional electricity is not provided by generating capacity within other MPADs on the mnitel, hence the use of the term "exopenous."

The first subtable, T:EXOGMULT, is a single entry which. varies the cost of exogenous electricity to all MPADs by the specified multiplicative factor. The second subtable, T:EXOGELCT, specifies the delivered costs (in mills/kWh) and maximum quantities (in millions of megawatt-hours per year) of exogenous electricity to individual MPADs. For an unspecified reason, entries are provided for only six MPADs (1, 4, 7, 9, 13, and 15). The capability was obviously not used in the scenario runs, since the multiplier is set at 1.0 and all maximum quantity values are set to 0 . An unexplained value of $10 \mathrm{mills} / \mathrm{kWh}$ is provided as the cost to all six MPÁDs. User-provided values would presumably be required for both costs and quantitles if this feature were used. 


$\begin{array}{ll}\text { Table Name: } & \text { Energy Demand } \\ \text { Code Name: } & \text { T:DEMAND } \\ \text { Line Span: } & 1216-1257 \text { (Scenario 0) } \\ & 26-66 \text { (Scenario V) } \\ \text { Page No.: } & \text { B-29 (Scenario 0) } \\ & \text { C-2 (Scenario V) }\end{array}$

This table provides the set of demands for fuels and electricity in each MPAD. The fuel requirements are given in terms of coal, natural gas, crude oil, and refined petroleum products. The total coal demand is expressed in two components: coal required to fire electricity generating plants and coal required for residential, commercial, and industrail (RCI) use, The coal demand for electricity generation is not directly expressed but is created endogenously by the model for the explicitly listed demands for electricity. The electricity demand is given in terms of megawatt-hours for each MPAD. The fuel demands for RCI, gas, crude, and refined products are given in terms of trillions of Btu, and a total nonelectric fuels use is included as a simple sum of these values.

Since the energy demand values drive the model, demand inputs will depend upon the subject under study. For the RESPONS demonstration runs, national total demands were determined by proper aggregation of the functional end-use demands developed for two of the 1985 Scenarios ( $O$ and $V$ ) described in ERDA-48. These natinnal total dcmands for electricity, KCl coal, natural gas, and crude oil were then disaggregated to the MPAD level by various techniques.

Regional demands for electric power in 1985, at the air quality control region level, prepared at the Oak Ridge National Labonatory, * were aggregated to the MPAD level, and the fraction of the lotal for each MPAD was calculated, This fraction was then applied to the national total demands indicated in the

ॠTyrell, T.J., Projections of Electrical Demand, ORNL-NSF-EP-50, November, 1973. 
scenarios to determine the actual MPAD electricity demand for the model.

The regional demands for RCI coal were obtained from projections done at the PAD level at the University of Illinois ("U.S, Energy and Fuel Demand to 1985: A Composite Projection by User Within PAD Districts", October, 1974) and at the state level at the Stanford Research. Institute ("Energy Supply and Demand Situation in North America to 1990", March, 1974). Fractional demands of the totals were computed at the PAD level and then disaggregated with the state level data to MPAD fractions. These were then applied to the total national RCI demands for the two scenarios to obtain the required MPAD demands for the model runs.

By similar procedures, the MPAD demands for crude oil and natural gas were determined. 1973 regional demands for crude oil were obtained from BOM values ("1973 Petroleum Statement Annual", Minerals Industry Survey, 1973) and used directly as 1985 regional demands. The PAD district projections for natural gas from the University of. IIlinois work cited above were used, and these were disaggregated to the MPAD level using historic consumption data from the BOM ("Natural Gas Production and Consumption: 1973", Minerals Industry Survey, August, 1974). For the two scenario runs, the demand for refined petroleum products was set to zero in all MPADs.

For the purpose of model demonstration, these techniques for determining regional demands are quite adequate and probably do not distort the results significantly as compared to more detailed methods of estimation. The whole problem of projecting future demands at the regional level (MPAD and others) in actual policy use of the model should be explored carefully since the use of varying projections, including distorted ones, can he veny revcaling with regard to system behavior. At the least, effort should be directed at developing a useable set of base case regional projections for future years as a starting point for analysis. Sophisticated methods, using economic and demographic projections, are currently under development and should be exploited. 


$\begin{array}{lll}\text { Table Name: } & \text { Energy Supply } \\ \text { Code Name: } & \text { T:NATFUEL } \\ \text { Line Span: } & \begin{array}{l}1259-1304 \text { (Scenario 0) } \\ \text { Page No.: }\end{array} \\ & \text { B-30 (Scenario 0) } \\ & \text { C-3 (Scenario V) }\end{array}$

This table provides the model with the quantities, prices and heat contents of the natural gas and crude oil available for use in each MPAD region. The natural gas and oil quantities are expressed in billions of standard cubic feet (scf) and millions of barrels (bbl), the prices in dollars/millions of scf and dollars/bbl, and the heat contents in Btus/scf and Btus/bbl. In 1985, 90\% of Alaskan crude is assumed to be shipped to MPAD 16 (California, Nevada, Arizona) and 10\% to MPAD 15 (Washington, Oregon).

As with the energy demand values, national totals for natural gas and crude oil supply quantities were derived from the two ERDA 1985 scenarios. The portion of the national total for crude oil due to domestic production was disaggregated to the MPAD level using 1975 regional reserve estimates (from the Oil and Gas Journal, 7 April 19.75, p. 44) and the portion due to imports was disaggregated using 1973 regional import statistics (from "Petroleum Statement, Annual, "Table 14, page 15 in "Refinery Receipts of Foreign Crude," BOM, 1973). A similar technique, using the same Oil and Gas Journal article, was used to disaggregate domestic natural gas production for both scenarios. The smal. amount of imported natural gas in Scenario $D$ was disaggregated using 1973 regional import statistics (from "National Gas Production and Consumption, Annual", Table 4, page 5, BOM, 1973).

For the model demonstration runt, the 1985 average purchase price (cost, insurance, freight) of all imported crude oil was taken to be $\$ 15$ per barrel at.its port of entry. The same price of $\$ 15$ per barrel at its point of extraction was then assumed for all oil produced domestically in 1985. Similarly, 
the assumption was made that all natural gas would be sold in 1985 on an equivalent cost per Btu with crude oil. This led to a value of $\$ 2.76$ per thousand scf for the cost of domestic natural gas at the point of extraction and for the small amount of imported oil, in Scenario 0, at the point of entry in 1985. No rationale was given for these choices and assumptions.

The average heat content value used for all crude oil consumed was $5,555,555 \mathrm{Btu} / \mathrm{bbl}$ and for all natural gas was 980 Btu/scf. These were the values used by ERDA in the original scenario. As was the case with energy demand, choice of future energy supply factors will be made by a model user on the basis of the details of the policy options under study. Quantities and costs of available fuels in a given future year will certainly be highly dependent on choices made, say, in the fuel transportation sector, the main area this model was designed to explore. As long as interfuel substitutions are not part of the optimization procedures, as in the model demonstration runs, choices of values for this table are not critical. Where these values provide supply constraints, such that, for example, where coal-derived gas would be substituted for unavailable natural gas to meet an indicated demand, the values chosen would impact the policy making process. Care should then be exercised in deriving such a table, and the interrelations of quantity and cost themselves would need to be considered. 


$$
\begin{array}{ll}
\text { Table Name: } & \text { Coal Export } \\
\text { Code Name: } & \text { T:COEXPORT } \\
\text { Line Span: } & 1306-1332 \text { (Scenario 0) } \\
\text { Page No.: } & \text { B } 15-141 \text { (Scenario V) } \\
& \text { C-4 (Scenario O) } \\
&
\end{array}
$$

Since the two ERDA scenarios which were used for demonstration of the model called for the export of some coal, this table was introduced to account for it. The coal type exported was taken to be a high-quality coal, type A. The historical values for 1973 exports (source unspecified) were used to assign the amnunts in the table (in units of thousands of tons per year) to MPADs 2 and 6 . Addition of exports of other coal types from other MPAD regions is an available option. There is no cost explicitly assigned to the coal included in the export shipment.

Unless coal export considerations are important to a particular study, more detail in this table is not required, 


$\begin{array}{ll}\text { Table Name: } & \text { Water Availability } \\ \text { Code Name; } & \text { T:WATER } \\ \text { Line Span: } & 1334-1365 \\ \text { Page No.: } & \text { B-3I }\end{array}$

This table provides values for the maximum amount of water (in units of millions of gallons/year) available in each MPAD for all coal-related energy system activities - mining, electric power generation, and synthetic fuels production. The maximum limit is for all such activities collectively, not individually. For the ERDA scenario runs used for model demonstration, such water availability constraints were not used at all and no infor-. mation was provided by which such constraints could be quantified if so desired.

Water is clearly an important resource requircment within the coal energy supply system - for dust control and washing, for slurry pipelines, for cooling in coal-fired power plants, and for synthetics processing. Water is also required for other fuels in the energy system. Examples would include oil shale processing, nuclear and oil and gas power plants, oil and gas production, and refinery use. The model, however, does not quantify water usage for these processes.

It should be noted that there are some substantial problems associated with assigning energy water availability limits. For example, synthetics processing requires large quantities of fresh water whereas power plants can use fresh or saline water. There is no mechanism for differentiating among water qualities, and use of fresh water availability alone would unduly constrain the model. There is also a real problem in estimating the future size of competing nonenergy uses - irrigation, industrial, drinking water, recreation, etc. - since these have many social . determinants.

In order to try to achieve perspective on this problem, use was made of a study of water needs made for the FEA's Project Independence Blueprint ("Water Requirements, Availabilities, 
Constraints, and Recommended Federal Actions, "prepared by the Water Resources Council, November, 1974). Table 10 (Page 42) of this report provides projections for 1985 of regional consumption nonenergy use of fresh and saline water (together) as well as values for total current water supply. Where the regional breakdown did not correspond with the MPAD level, data from state sources were used to estimate approximate values. A number of sources suggest that a reasonable assumption to make is that roughly half of the water available for energy use could be used for coal system activities. Thus, values for this table of water availability constraints were calculated by taking half the difference between MPAD total current supply and the 1985 projected nonenergy demands. The values are listed in Table 23, and are intended only as indicative of rough upper bounds.

The MPAD level of regionalization does have drawbacks in the water area. For example, MPAD 13 contains "water-rich" Idaho and "water-poor" Montana and Wyoming and only interbasin transfers could make sense of using Idaho water for, say, Wyoming coal gasification plants, though the model wuld simply allow this through its regional definition. The Water Resources Council report points up other relatively "dry" areas in apparencly water=rich regions. Whether there is any straightforward way to create a capability for the model to endogenously apply meaningful water availability constraints will require further detailed study. Redefinition of supply regions (as discussed in chapter III) should help to overcome this problem. 
Table 23

Proposed Water Availability Table Values for 1985 Coal Energy Use

\begin{tabular}{cr} 
MPAD & $\begin{array}{r}\text { Available } \\
\text { (Billiors }\end{array}$ \\
\cline { 2 - 2 } 1 & 5051.5 \\
2 & 6107.0 \\
3 & 6588.6 \\
4 & 1958.9 \\
5 & 4232.6 \\
6 & 179.6 \\
7 & 2382.0 \\
8 & 4668.4 \\
9 & 600.7 \\
10 & 1093.8 \\
11 & 2742.3 \\
12 & 250.5 \\
13 & 1557.6 \\
14 & 277.5 \\
15 & 402.2 \\
16 & 3411.5
\end{tabular}




$\begin{array}{ll}\text { Table Name: } & \text { Model-Wide Advanced Capacity (Total U.S.) } \\ \text { Code Name: } & \text { T:ADVCAPAC (Scenario O) } \\ \text { Line Span: } & 1367-1387 \text { (Scenario V) } \\ \text { Page No.: } & \begin{array}{l}143-164 \text { (Scenario } \\ \text { B-32 (Scenario O) } \\ \end{array} \quad \mathrm{C}-4 \text { (Scenario V) }\end{array}$

This table provides upper limits on the national aggregate of installable capacity for each of three classes of advanced technology facilities - combined-cycle power generation, coal gasification, and coal liquefaction. The regional upper limits on capacities are set elsewhere in the model; they serve to define possible capacity growth in each MPAD without any other constraints, such as capital, being operative. These nationwide upper limits would provide constraints to total capacity growth of the advanced technologies to amounts appropriate to the actual level of planned capital funding.

In Scenario 0, no new technology regional capacities were called for so the table was not used. In scenario $V$, total national gasification and liquefaction were read off as $0.92 Q$ and 0.480 , respectively. In the table, upper capacity limits are set at 750 and 100, respectively, with no statement of units. [By private communication, Bechtel personnel stated that an error was made in the computation of the table values (which should be in billions of scf of natural gas and millions of barrels of crude).] The regional capacities were completely unconstrained so the model simply put the facilities in the best region for the optimal solution, namely Bi-Gas in MPADs 2 and 14 and SRC. in MPAD 13.

There is nothing in the documentation to indicate whether table entries are actually used to indicate binding or nonbinding accounting rows in the model, or whether values greater than zero actually form the right-hand sides of appropriate constraint equations. From the model structure, they apparently do serve as right-hand sides. 
Table Name: Model-Wide $\mathrm{SO}_{2}$ Scrubber Capacity (Total U,S.) Code Name: T:SCRUBCAP

Line Span: 1389-140.6.

Page No.: $\quad B-32$

This table can be used to set an upper limit on the aggregate capacity of existing plus new coal-fired electricity generating plants which have $\mathrm{SO}_{2}$ emission controls. Two later tables ( $\mathrm{T}$ : COCPGAP and $T$ :NEWCPGCP) specify the regional capacities for the sum of controlled and noncontrolled plants, one for existing plants and one for new plants. Since it is a national constraint, it is a one-value table.

In the ERDA scenario runs, the value was set to -1 , indicating no bound on capacity. The note with the table indicates that this means that "the row type is set as N", that is, the constraint is nonbinding. It should be noted that the effect of using " -1 " as a data entry is not unique throughout the data base; it means different things in different places. 


$\begin{array}{ll}\text { Table Name: } & \text { Facility Input/Output Characteristics } \\ \text { Code Name: } & \text { T:RCITHERM } \\ & \text { T:CPGTHERM } \\ & \text { T:APGTHERM } \\ & \text { T:GASTHERM } \\ & \text { T:CRDTHERM } \\ \text { Line Span: } & 1408-1440 \\ \text { Page No.: } & \text { B-33 }\end{array}$

These subtables contain conyersion factors. which are used in the coal energy conservation equations, $\mathrm{COECH}(r)(p)$. Also included are water use for electricity generation and for synthetic manufacture, and the Btu content of synthetic products. Each subtable will be considered in turn.

\section{RCITHERM}

RCI energy demand is given in $1 a^{12}$ Btu, while coal flow variables are in units of $10^{3}$ tons. The calculation for the conversion from $10^{3}$ tons coal to 1012 Btu demand is:

\section{$\left[10^{3}\right.$ tons $] *[2 \times 1061 \mathrm{bs} / 103$ tons $] *[\mathrm{Btu} / \mathrm{lb}] *[1012] *\left[10^{-12}\right]$.}

The THERM entry in the table is the product of the numerator of the second term and the fifth term.

\section{CPGTHERM}

Electricity generation is in $10^{6} \mathrm{MWh}$, coal flow is in $10^{3}$ tons. The -calculation for the conversion factor is

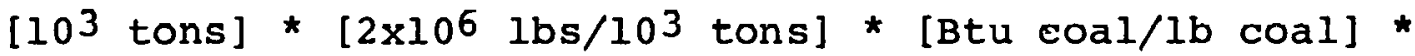

[Btu coal $/ \mathrm{kWh}^{-1} *\left[\mathrm{MWh} / 10^{3} \mathrm{kWh}\right] *[106] *\left[10^{-6}\right]$ :

The THERM entry in the table is the product of the numerator of the second term and the seventh term. Water usage is given in terms of $10^{9}$ gallons per $10^{6} \mathrm{MWh}$.

\section{APGTHERM}

Electricity generation is in units of $10^{6}$ MWh while coal flow is in $10^{3}$ tons. The calculation is 
[103 tons] * $\left[2 \times 10^{6} 1 \mathrm{bs} / 10^{3}\right.$ tons] * [Btu coal/1b coal] *

$\left[\right.$ Btu coal $/ \mathrm{kWh}^{-1} *\left[\mathrm{MWh} / 10^{3} \mathrm{kWh}\right] *\left[10^{6}\right] *\left[10^{-6}\right]$.

The THERM entry in the table is the product of the numerator of the second term, the fourth term, the fifth term, and the seventh term. The implied heat rates for low-Btu and FBC combined cycle plants are $8000 \mathrm{Btu} / \mathrm{kWh}(0.4266$ efficiency) and $8968.6 \mathrm{Btu} / \mathrm{kWh}$ ( 0.38 efficiency), respectively. Water usage is given in $10^{9}$ gallons per $106 \mathrm{MWh}$.

GASTHERM

The table lists Btu content per scf of synthetic gas produced by the facilities, and water usage in $10^{9}$ gallons/scf. Synthetic gas output is in units of $10^{9}$ standard cubic feet (scf), coal flow is in $10^{3}$ tons. The calculation for the conversion factor is

$\left[10^{3}\right.$ tons $]$ * $\left[2 \times 10^{6} \mathrm{lbs} / 10^{3}\right.$ tons $]$ * [Btu/1b] * [Btu coal/scf $]^{-1}$ * $\left[10^{9}\right] *\left[10^{-9}\right]$.

The THERM entry in the table is the product of the numerator of the second term, the fourth term, and the sixth term. The implied conversion efficiencies are $600 \mathrm{scf} / 10^{6} \mathrm{Btu}(0,5568$ efficiency since heat content of resulting gas is $928 \mathrm{Btu} / \mathrm{scf}$ ) for high-Btu Lurgi plants, and $650 \mathrm{scf} / 10^{6} \mathrm{Btu}(0.6182$ efficiency since heat content of resulting gas is $951 \mathrm{Btu} / \mathrm{scf}$ ) for high-Btu BCR Bigas plants.

CRDTHERM

The table gives Btu content per barrel of synthetic liquid product and water usage in $10^{9}$ gallons per barrel. Product output is in $10^{6}$ barrels, coal flow is in $10^{3}$ tons. The calculation for the conversion factor is

$\left[10^{3}\right.$ tons $] *\left[2 \times 10^{6} \mathrm{Btu} / 10^{3}\right.$ tons $] *[\mathrm{Btu} / 1 \mathrm{~b}] *[\mathrm{Btu} \mathrm{coal} / \mathrm{bbl}]^{-1}$ * $\left[10^{6}\right] *\left[10^{-6}\right]$. 
The THERM entry in the table is the product of the numerator of the second term, the fourth term, and the sixth term. The implied conversion efficiencies are 8,233,841 Btu coal per barrel ( 0.63 efficiency: resulting barrel contains 5,195,000 Btu) for SCR liquefaction plants and 9,629,273 Btu coal per barrel (0.60 efficiency: resulting barrel contains 5,805,000 Btu) for COED liquefaction plants.

Other sources of information were consulted to compare water requirements with the tabled values.

FACILITY

Coal-Fined Power Plants

Low-BTU Combined Cycle

FBC Combined Cyale

High-BTU Lurgi Gasification

High-BTU Bigas Gasification

SRC Liquefaction

COED Liquefaction
TABLE VALUE

0.00041

0.050000

0.000977

0.1555

0.0979

0.432

0.432
OTHER VALUE

$0.94^{1}$

$0.895^{2}$

$0.029^{1}$

$0.413^{1}$

$0.413^{1}$

Before the model is used in policy studies in which water use and availability are of importance, unit water requirements for these facilities should be determined to the accuracy required for the policy application. Unit water requirements for slurry pipelines should also be determined.

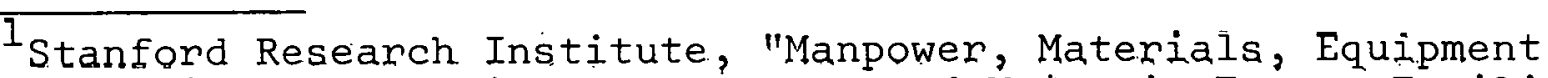
and Utilities Required to operate and Malitain Lnergy Faciliticu", March, 1975.

2 Bureau of Mines, "Economic Analysis of Westinghouse Low-Btu Gasifination - Combined-Cycle Power Generating System Producing 134..1 Megawatts", March, 1976:
} 


$\begin{array}{ll}\text { Table Name: } & \text { Existing Facilities Capacity } \\ \text { Code Name: } & \text { T:CORCICAP } \\ & \text { T:COAPGCAP } \\ & \text { T:COGASCAP } \\ & \text { T:COCRDCAP } \\ \text { Line Span: } & 1442-1554 \\ \text { Page No.: } & \text { B-34-B-35 }\end{array}$

This set of subtables define the existing regional capacities for combined-cycle power plants, coal gasification plants, and coal liquefaction plants, and indicate whether there is a demand for RCI coal in the region. Entries in the three plant subtables have several meanings. A "-I" entry means that no such facilities exist, and the model will not generate corresponding rows and columns in the matrix, i.e., will not create transportation links for such plants. A "0" entry results in the creation of matrix rows and columns (transportation links) but does not use them due to the indicated zero regional capacity. This provides a capability for easy subsequent sensitivity runs of the model in which capacities are introduced. A positive number defines the actual existing capacity for which transportation links are created to supply.

Values for the capacity of the two levels of combined-cycle plants considered in the model ( $T$ :COAPGCAP) are given in units of millions of megawatt-hours. Values for the capacity of the two kinds of coal gasification plants considered ( $T$ :COGASCAP) are given in units of millions of scf. Values for the two kinds of coal liquefaction plants consirerer ( $T$ :COCRDCAP) are given in units of millions of barrels.

The subtable for RCI capacity (T:CORCICAP) indicates whether or not there is demand for RCI coal in the region. Any tabular value greater than zero causes the required transportation links to be created. The actual level of regional demand is specified elsewhere, in T:DEMAND (line span 1216-1257).

For the model runs, all entries for all MPADs for combinedcycle gasification and liquefaction plants were set equal to 
"I", indicating the existence in 1985 (the model's "present" for the scenarios) of no such facilities. Transportation links were created for all MPADs for RCI coal demand by using the nominal positive value of "10.0" throughout.

These four subtables seem to be straightforward. They serve to define just what transportation links the model is required to generate and the regional capacities for the three types of facilities considered. 


$\begin{array}{ll}\text { Table Name: } & \text { New Facility Capacity } \\ \text { Code Name: } & \text { T:NEWRCTCP } \\ & \text { T:NEWCPGCP } \\ & \text { T:NEWOTHCP } \\ & \text { T:NEWAPGCP } \\ & \text { T:NEWCRDCP } \\ & \text { T:NEWGASCP } \\ & 1556-1700 \text { (Scenario 0) } \\ \text { Line Span: } & 167-311 \text { (Scenario V) } \\ & \text { B-36-B-38 (Scenario 0) } \\ \text { Page No: } & \text { C-5-C-7 (Scenario V) }\end{array}$

This set of subtables is very similar to those described under "Existing Facilities Capacity," establishes regional capacities for various new facilities. An additional subtable relates to regional RCI coal demand. For conventional coalfired power plants ( $T$ :NEWCPGCP), noncoal power plants (T:NEWOTHCP), combined-cycle power plants ( $T$ :NEWAPGCP), coal liquefaction plants ( $T: N E W C R D C P$ ), and coal gasification plants ( $T$ "NEWGASCP), the values have the following meanings, A "ll" indicates no facilities will exist and no transportation links will be created. A positive number causes the creation of transportation links required to serve that level of new plant capacity. An entry of "INF" (meaning infinite or unbounded) means that new facility capacity is available without limit.

The regional capacity values for all types of power plants are given in units of millions of megawatt-hours, for liquefaction plants in units of millionc of banrels, alld for gasification plants in units of billions of scf. (These units are not defined in the table documentation but are inferred from the documentation on Facility Input/Output Characteristics, page B-33.) Individual regional capacities are specified for nonscrubbing and scrubberequipped coal-fired power plants; for oil, gas, nuclear, and hydroelectric noncoal powen plants; and for two types of combinedcycle power plants, liquefaction plants and gasification plants.

For the RCI capacity ( $T$ : NEWRCICP), a documentation note states that it is an artificial table and that "it should always have ( -1 ) entries for all regions." 
For both model demonstration scenario runs, the RCI capacities in all regions were given " -1 " values, as specified in the note, and all regional power plant capacities were set to "0." to create unused but available transportation links for electricity generating facilities. For liquefaction and gasification, capacity values of "INF" were introduced in the Scenario V run so that the model would create as much capacity as: was required by the optimal solution.

As with the exisling facility capacity subtables, these subtables seem straightforward, serving to generate the required new facility capacity values. 
Table Name: New Facility Cost. Data

$\begin{array}{ll}\text { Code Name: } & \mathrm{T}: \text { APGCOST } \\ & \mathrm{T}: \text { GASCOST } \\ & \mathrm{T}: \text { CRDCOST } \\ & \mathrm{T}: \text { NCPGCOST } \\ & \mathrm{T}: \mathrm{NOTHCOST} \\ & \mathrm{T}: \mathrm{NAPGCOST} \\ & \mathrm{T}: \mathrm{NGASCOST} \\ & \mathrm{T}: \mathrm{NCRDCOST} \\ \text { Line Span: } & 1702-1882 \\ \text { Page No.: } & \mathrm{B}-39-\mathrm{B}-42\end{array}$

This table provides the regional values for the cost of creating new facilities to meet the energy demands of a given scenario. The costs of power generation by new coal-fired plants (CPG); by new oil, gas, nuclear, and hydroelectric plants (OTH); and by new combined-cycle plants (APG) are given in mills/kWh. The costs for conversion of coal to natural gas (GAS) are given in dollars/million scf and of conversion of coal to crude (CRD) in dollars/bbl. Capital construction costs and O\&M costs were computed and added together. Where appropriate, fuel costs were then added also.

The details for this table are contained in the section entitled "The Costing of Energy. Facilities" in Chapter III and are nøt repeated here. 
Table Name:

Code Name:

Line Span:

Page No.:
Existing Coal-Fired Plant Capacities

T: COCPGCAP

1884-1924 (Scenario 0)

314-353 (Scenario V)

B-43 (Scenario 0)

$\mathrm{C}-3$ (Scenario $\mathrm{V}$ )

This table provides regional values for the generating capacity of existing coal-fired power plants, given in units of miliions of megawatt-hours/year. The data culumns show scparate values for total regional nonscrubber ('lype 4 ) plants and scrubber-equipped (Type 5) plants. The documentation states that the model's capacity constraint row is on the sum of plant Types 4 and 5 . The regional total has been arbitrarily divided into equal halves with one half assigned to each plant type; presumably, any division of the total would serve. Actual specification of capacity for $\mathrm{SO}_{2}$ scrubbing in such plants is provided, on a national basis only, in Table T:SCRUBCAP.

The total 1985 capacities in the two scenario tables were taken directly from the results of the original ERDA scerario runs, namely, 1283.34 million MWh/year (Scenario a) and 976.60. million. $\mathrm{MHw} /$ year (Scenario V). [A typographical errur' in line 320 of the Scenario $\mathrm{V}$ table indicates that the Scenario V total is 1283.3 million MWh/year. The table is correct, however, properly summing to the true 976.70 million MWh/year value.] Disaggregation to the MPAD level was achieved by using data obtained from the Federal Power Commission. FPC Form 383 is a ten year ahead utility forecast of additions and deletions of generating facilities. The 1980 forecast were used to determine each MPAD's fraction of the total. Two other (perhaps not independent) sources were examined to determine if the regional distribution was reasonable. From the two sources ("Steam Electric Plant Air and Water Quality Data for the Year ended Dec. 31, 1973, "FPC, January, 1976 and "Proposed Generating Capacity Changes for the Period 1975 through 
1984," as reported April 1, 1975 in response to FPC Docket R-362, Order 383-3) it was concluded that the disaggregation technique was reasonable and was done correctly.

For detailed policy studies, it would be useful to explore regional departures from such straight utility forecasts which are likely to evolve due to different (and changing) regional environmental or resource constraints. This will certainly be necessary for policy studies with a longer time frame than to 1985 . 
Table Name: Existing NonCoal-Fired Plant Capacities

Code Name: T:OTPOWCAP.

Line Span: 1926-1964 (Scenario 0)

Page No.: $\quad$ B-44 (Scenario O)

C-9 (Scenario V)

A counterpant to the preceding table, this table provides values for regional generating capacities for all noncoal-fired power plants - oil; gas, nuclear, and hydropower - in units of millions of megawatts per year. The term "existing," it should be noted, refers to plants assumed to exist in 1985; the table values do not describe currently existing plant capacities.

The total (national) 1985 capacities in the two scenario tables weretaken directly from the results indicated in the original ERDA scenario runs. Disaggregation to the regional (MPAD) level was carried out by using the data obtained from the same FPC Form 383 summaries described in the preceding table. The 1980 forecast was once again used to determine the MPAD fractions of the total.

Since the disaggregation method is quite reasonablc and the data used quite recent, the table values seem adequate for the model demonstration runs. As with coal-fired plants, some policy studies might profit from due consideration of regionspecific conditions which might cause departures from current utility forecasts, particularly for times beyond the 1985 year used here. 
Table Name: Existing Plant Costs

Code Name: T:CPGCOST

T:OTHCOST

Line Span: $1966-2064$

Page No: B-45-B-46

This table provides regional cost values for existing coal (with and without scrubbers), oil, gas, nuclear, and hydroelectric power generation facilities. No capital costs are included for the existing plant stock, except for the additional cost incurred for stack scrubbers. The values, therefore, include the operation and maintenance (OEM) costs for all facilities, with fuel costs added for noncoal facilities, Values are in units of mills/kWh.

As noted in the discussion under table: New Facility Cost Data (Line Span 1702-1882), exponential fits were made to various annual sets of FPC data detailing the variation of O\&M costs with plant capacities. Data back to 1969 were used for some plants, presumably because 1972 data were not yet available when the table was developed. For the scenario runs, a nominal plant size for each facility was used for all noncoal plants to define a single OEM cost value for use in all MPAD regions. For coal-fired plants, weighted average costs for each MPAD, based on projecting existing individual facility sizes, were used to get region-specific o\&M coal plant values. All derived OEM costs were escalated at 7 per cent per year from the appropriate year to 1985 and then deflated at 5 perccent to 1975 mills.

There seems to be two numerical errors associated with the O\&M calculations. The proper value for hydroelectric plants should be $2.41 \mathrm{mills} / \mathrm{kWh}$ instead of the listed value of $3.07 \mathrm{mills} / \mathrm{kWh}$. The second is associated with the additional cost for scrubbers. It was stated that an additional OEM charge of $2 \mathrm{mills} / \mathrm{kWh}$ in 1973 mills was assumed for plants with FGD systems. Properly escalated and deflated, this should add $2.77 \mathrm{mills} / \mathrm{kWh}$ for 1985 cost in $1975 \mathrm{mills}$ rather than $3.64 \mathrm{mills} / \mathrm{kWh}$ added in the table. [Under the assumptions stated in the documentation for the "New Facility Cost Data" table (page B-39), the difference is 4.57 . $\left.\dot{u} . y_{b}=3.62 \mathrm{mills} / \mathrm{kWh}.\right]$ 
For the scenario run data base, values of OEM costs for existing plants, as determined for this table, were used without change for the new facilities of the New Facilities Cost Data table. Data for new facility $0 \& M$ costs were gathered from "Manpower, Materials, Equipment, and Utilities Required to Operate and Maintain Energy Facilities", Stanford Research Institute, March, 1975 and are presented in Table 7-5 (page 124) of the RESPONS report. Although no use was made of these data in the scenario runs, the report does note that "the data shown in Table 7-5 indicate significant increases in operating and maintenance costs for all types of electric generating facilities over the levels that would be expected basul on operating and maintenance costs for facilities already in existence." Adjustments to these costs should be made.

It should also be noted that o\&M costs are quite dependent on the plant factor assumed. Since all costing is apparently being done with high plant factors on a base-load basis, the lack of consideration of load distribution might lead to incorrect costing. The relation between total cost and OEM cost must be carefully considered under varying load assumptions. 
Table Name: Coal-Fired Plant Heat Rates

Code Name: T:HTRATE

Line Span: 2066-2102

Page No.: $B-47$

This table provides regional values for the heat rate (i.e., the number of Btu's required to produce one kilowatt-hour of electric power) for existing nonscrubbing or scrubber-equipped coal-fired power plants. The units are thus Btu's/kWh.

The values actually provided in the table for the scenario runs show no regional variation in heat rate, i.e., the value is the same in all sixteen MPADs. Detailed documentation is provided (pp. 118-119) which indicates variations in the heat rate with variations in base-load plant unit size. Although. there are substantial regional unit size differences across the country, the average annual heat rate of 9749 Btu input per kWh. output assumed in the original ERDA scenarios was used in all regions for nonscrubber plants (Plant Type 4). This corresponds to an average annual thermal efficiency of 35 per cent. For those plants equipped with scrubber control systems, the themal efficiency was reduced a nominal 10 percent (to 31.5 per cent), yielding a national average heat rate of 10,832 . Btu, used in all regions. 
Table Name: Coal Transportation Costs

Code Name: T:TCCOAL(MPAD)

Line Span: 2117-2250

Page No.: $\quad B-48-B-50$

This table provides the inter-MPAD costs of transportation levied against all allowed transportation modes for coal shipments, in units of dollars per ton of coal. Allowed modes of coal transport for the scenario runs are conventional rail (designated $R$ in the table), unit trains (designated $U$ ), and waterborne carriers;i.e., barges (designated $W$ ). Slurry pipeline costs are considered elsewhere (Line Span 1069-1096). A table value of "-l" is used for those links for which the transportation mode is not allowed. The estimated 1985 transportation costs (in 1975 dollars) were determined for each allowed inter-MPAD link for each of the allowed transport modes by determining an inter-MPAD distance. and using a unit carrier cost.

For conventional rail and unit trains, railway system atlases and maps were used to define the existing rail network and the shortest rail-haul distances between the adopted set of MPAD centroid cities. The straight-line distances between all centroids were calculated and a linear regression fit was made to the set to provide a functional relation between short-haul and straight-line distances. There were sufficient differences between Eastern and Western correlations that two linear equations were used:

$$
\begin{array}{ll}
D=1.21 S+23.0 & \text { [Eastern, MPAD 1-11], } \\
D=1.62 S-.75 .5 & \text { [Wectenn, MPAD 12-16], }
\end{array}
$$

where $D$ is the desired inter-MPAD rail-haul, distance for the cost computation and $S$ is the computed whaight-line (great. circle) inter-MPAD centroid distance. These formulae have been checked and found to be generally within about \pm 10 per cent for distances less lhan 500 miles and within about \pm 5 per cent for longer distances, using standard rail distance tables. [Minor correction. The longitude of Peoria, the centroid of MPAD 6 in Table 4-3 (page 54), is 08935, not 07835.] 
Barge-haul distances were determined directly from measured river routes between the major loading and unloading docks, one to each involved MPAD $[2,4,5,6,7,8,10]$, and not by MPAD centreid-to-centroid distances, as with unit trains and rail.

The transportation rates are, of course, a function of the haul distance. For conventional rail tariffs, the FEA's 1972 Carload Waybill Statistics were used to create a hyperbolic regression rate equation of the form:

$$
C=179.5 \mathrm{D}^{-0.446} \text {, }
$$

where $C$ is the conventional rail rate in mills/ton-mile, and $D$ is the short-haul rail distance, in miles. For unit train costs, internal Bechtel data were used to create a rate-distance schedule for a nominal Western unit train at 1974 cost levels. Similarly, for barge rates, internal Bechtel data were used to develop another hyperbolic regression rate equation of the form;

$$
C=20.93 \mathrm{D}^{-0.285} \text {, }
$$

where $C$ is the barge transportation rate in 1970 dollars (in mills per ton-mile) and $D$ is the one-way barge distance (in miles). The 1970 values were escalated by 34 per cent to estimate 1975 rates: Curves of the unit 1985 transportation costs (in 1975 cents/tonmiles) versus distance (in miles) are shown in Figure 6-4 (page 102) of the RESPONS repurl. Escalation was taken as 7.5 per cent per year and the deflation rate used was 5 per cent.

A check of some of the computations indicated that the calculation of the coal transportation costs in this table were carried out correctly. The tabled values for the three modes seem to be in line with current rates, except that down river barge rates were lower (by approximately 33 percent) and up river rates were higher (by approximately 25 percent) than the table values. [See FEA's "Input to the Project Independence Evaluation 
It should be noted that for the scenario runs only a single one of the three modes in this table were permitted to carry coal between any MPAD origin-destination pair. That is, two of three modes for each pair has a "-l" entry and the third has a value. As noted earlier, only the cheapest mode. was allowed in order to avoid creating variables unnecessarily. The LP will always choose the least expensive mode first and, in the absence of capacity constraints, will never be forced to choose a second.

System Integration Model for Transport of Eliergy Materials, Vol.. II," page IV-6, November 1974.] Since barge hauling is a highly competitive mode in many areas, it would be wonthwhile to redevelop new rates reflecting proper weighting of stream direction loads. 
Table Name: Coal Distribution Costs

Code Name: T:DCCOAL

Line Span: 2252-2282.

Page No.: B-5I

This table provides the weighted average value for the intra-MPAD costs for the distribution of coal by all transport modes except slurry pipelines. Units are dollars per ton of coal, although this is not indicated in the documentation. These costs are added to the inter-MPAD transpontation costs contained in the preceding table. Distribution costs within each MPAD were computed using the cost formula given for the preceding table, applying 1973 estimated region-specific modal splits to obtain a total weighted average from each mode involved.

While it was impossible to determine from independent data whether the absolute magnitude of the values used for the scenario runs were accurate or not, the relative magnitudes seemed appropriate. The real question here lies in the appropriateness of simply attaching a distribution charge to the inter-MPAD transportation charge for coal mined in one MPAD and consumed in another. The question arises from the rationale provided in the documentation (page 51) for the choice of regional centroids: only "one point within each geographic region was chosen for both the supply and the demand centroid" and that "the city chosen as the centroid was generally close to major coal deposits or major energy demands." Simply adding rail distribution rates based on actual paid tariffs for overall coal movements does not seem appropriate for developing interregional coal-hauling costs. This point is discussed in some detail in the section entitled "Geography and Coal Transportation" in Chapter. III. 
Table Name: Crude Oil Transportation Costs

Code Name: T:TCCRD (MPAD).

Line Span: 2284-2401

Page No.: $\quad B-52-B-53$

This table provides the costs for interregional crude oil transport by pipeline (designated by $P$ in the table), by rail (designated by R), and by waterborne carrier (barge, designated by $W$ ), in units of dollars per barrel. A table value of " $I "$ is used to indicate that the mode is not allowed. No rail links for crude oil are allowed in the scenario runs since less than 1 . per cent of crude oil moved by this mode in 1974. Only about 5 per cent of crude oil moved by barge in 1974, and the documentation states (page 100) that nn hange traneport wao ineluded ill llue runs. This is somewhat misleading since, for example, variable QP.QO.YW, which represents crude oil transported from Region 16 to Region 15 by water, assumes a positive activity level in ERDA Scenario V. Transport here, however, is by tanker, not by barge.

A general utility financing method was used to determine capital costs for pipelines, and a similar method was used to develop operation and maintenance (OEM) costs. A nominal Bechtel-design pipeline of diameter 36 inches, length of 1000 miles, capacity of 800,000 barrels per day, and coct of $\$ 400$ million was used to derive the constants for a summary cost equation, the first term of which represents the capital costs and the second the $0 \& M$ costs. For crude oil pipelines: where

$1974 \$$ per bbl $=\left[0.21(\mathrm{D} / 36)^{\mathrm{F}-2}+0.08(\mathrm{D} / 36)^{1.4}\right] \mathrm{S} \times 10^{-3}$,

$\mathrm{D}=$ pipeline diameter (in inches),

$S=$ straight-line distance between MPAD cenţroide (in miles),

$F=1.3$ for $D>36$ inches (also for $D=1.36$, see page 106.2,

$F=1.1$ for $D<36$ inches.

The 1974 dollar costs were escalated by 7.5 per cent to estimate 1975 costs, and 1985 costs were obtained in 1975 dollars with a net escalation rate of 2.5 per cent per year. 
An attempt was made to check the internal consistency of the data by making use of the inter-MPAD capacity values tabulated in the table Crude $0 i 1$ Pipeline Capacities (Line Span 2618-2714). According to the RESPONS report (page 108), capacity, in millions of barrels per year, is related to diameter, in inches, by

$$
\text { Capacity }=288(\mathrm{D} / 36)^{2} \text {. }
$$

All inten-MPAD capacity values were translated into pipeline diameters with this formula and an $F$ value was assigned to each depending upon the value of $D$. With these values for $D$ and $F$ and the known distances between MPAD centroids, the costs could be computed from the summary cost equation, above. The results conformed, so that the cost and capacity data are internally consistent.

Costs are tabled for intra-MPAD pipelines but are nowhere explained or documented.

An attempt at independent validation of crude oil pipeline costs and capacities was made by examining the costs and capacities of some actual pipelines. Data were gathered on twenty pipelines from company financial reports and from the $0 i l$ and Gas Journal during 1975-76. Examples are (with costs in 1975 dollars per barrel and capacities in thousands of barrels per day):

\begin{tabular}{|c|c|c|c|c|c|c|}
\hline Pipeline & $D($ in. $)$ & $\underline{L}$ (miles) & Calc. Cost & $\begin{array}{c}\text { Reported } \\
\text { Cost } \\
\end{array}$ & $\begin{array}{l}\text { Calc. } \\
\text { Capacity }\end{array}$ & $\begin{array}{l}\text { Reported } \\
\text { Capacity }\end{array}$ \\
\hline 1 & 30 & 18 & 0.06 & 0.19 & 269.7 & 280.0 \\
\hline 2 & 30 & 510 & 0.46 & 0.56 & 269.7 & 245.0 \\
\hline 3 & 30 & 476 & 0.42 & 0.62 & 269.7 & 260.0 \\
\hline
\end{tabular}

1. Lakehead Pipeline, Indiana to Ontario

2. Seaway Pipeline, Texas to Oklahuma

3. Texoma Pipeline, Texas to Oklahoma

On the whole, the capacity agreements were quite good. The cost estimates tended to be less precise, but accounting and costing 
proccedures for the reported costs are not known. Costs also reflect economies of scale, FPC guidelines, and specific pipeline peculiarities, e.g., terrain. One can conclude, however, that the costs used are reasonable surrogates when used as weighted average costs for a complex set of pipelines between MPADs. The cost structure seems to depend upon the accuracy of the Bechtel characterization of their nominal pipeline. 
Table Name: Gas Pipeline Transportation Costs

Code Name: T:TCGAS (MPAD)

Line Span: 2403-2503

Page No.: $\quad$ B-54-B-55

This table provides the cost for allowed interregional gas transport via pipeline in units of dollars per million scf.

As with the calculation of crude oil pipeline costs for the preceding table, a general utility financing method was used to determine capital costs for gas pipelines, and a similar method was used to develop operation and maintenance (O\&M) costs. A nominal Bechtel-design pipeline of diameter 36 inches, length of 1000 miles, capacity of 870 million scf per day, and cost of $\$ 430$ million was used to derive the constants for a summary cost euation, the first term of which represents the capital costs and the second the OEM costs. For gas pipelines:

1974 \& per million scf $\left.=[0.02](D / 36)^{F-2}+.0 .059(D / 36)^{1.4}\right] \mathrm{S}$, where

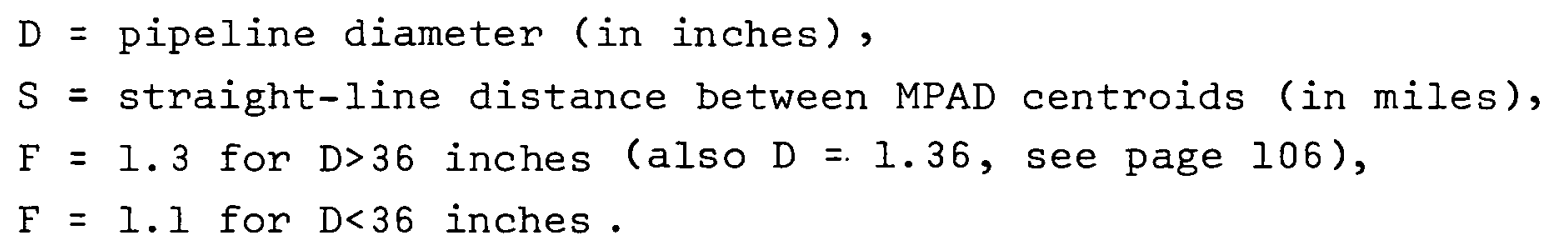

The 1974 dollar costs were escalated by 7.5 per cent to estimate 1975 rnsts, and 1985 costs weine ubtalned in 1975 dollars with a net escalation rate of 2.5 per cent per year.

As with crude oil pipelines, an attempt was made to check the internal consistency of the data by making use of the interMPAD capacity values tabulated in the table Gas Pipeline Caparities (Line Span 2511-2617). According to the RESPONS report (page 108) capacity, in billions of suf per year, is related to diameter, in inches, by

$$
\text { Capacity }=313(D / 36)^{2} \text {. }
$$


All inter-MPAD capacity values were translated into pipeline diameters with this formula and an $F$ value was assigned to each depending upon the value of $D$. With these values for $D$ and $F$ and the known distances between MPAD centroids, the costs could be computed from the summary cost equation, above. The results conformed, so that the cost and capacity data are internally consistent.

Costs are tabulated for intra-MPAD pipelines but are nowhere explained or documented.

An attempt at independent validation of gas pipeline costs and capacities was made by examining the costs and capacities of some actual and projected pipelines. Data were gathered from company reports and from the $\underline{0 i l}$ and Gas Journal during 1975 and 1976. Examples are (with costs in 1975 \$ per million scf and capacities in millions of barrels per day):

\begin{tabular}{|c|c|c|c|c|c|c|}
\hline Pipeline & $D($ in. $)$ & L(Miles) & $\begin{array}{l}\text { Calc. } \\
\text { Cost }\end{array}$ & $\begin{array}{l}\text { Reported } \\
\text { Cost }\end{array}$ & $\begin{array}{l}\text { Calc. } \\
\text { Capacity }\end{array}$ & $\begin{array}{l}\text { Reported } \\
\text { Capacity }\end{array}$ \\
\hline$\perp$ & 16 & 91 & 811.11 & ח & 61.8 & 70 \\
\hline 2 & 30 & 15 & 53.2 & 50.0 & 217.4 & $200-220$ \\
\hline 3 & 38 & 1725 & 237.5 & 250.0 & 348.7 & 400 \\
\hline 4 & 24 & 72 & 111.0 & 129.4 & 139.1 & $125-150$ \\
\hline 5 & 36 & 87 & 65.1 & 282.5 & 313.0 & $275-350$ \\
\hline
\end{tabular}

1. Colorado Interstate, Colorado to North Dakota

2. Natural Gas Pipeline of America, Louisiana to Texas

3. Northern Border, Saskatchewan to Pennsylvaria

4. ONG

5. Cove Point, Maryland 
On the whole, the capacity agreements were very good. The cost estimates tended to be less precise, but accounting and costing procedures for the reported costs are not known. Costs also reflect economics of scale, FPC guidelines, and specific pipeline peculiarities, e.g., terrain. One can conclude, however, that the costs used are reasonable surrogates when used as weighted average costs for a complex set of pipelines between MPADs. The cost structure seems to depend upon the accuracy of the Bechtel characterization of their nominal pipeline. 
Table Name: Gas Pipeline Capacities

Code Name: T:PBGAS(MPAD)

Line Span: 2511-2617

Page No.: $\quad$ B-56-B-57

This table lists the weighted average capacities of the nominal inter-MPAD gas pipeline links in units of billions of scf per year. An entry of "-I" is used to indicate an infinite, or unconstrained, capacity. The weighted average diameters were obtained by using maps of actual pipelines in the lower 48 states to sbtain an aggregate of all pipeline sizes flowing between MPADs. After eliminating small-diameter and short-distance 1.inss, the weighted average diameters for an inter-MPAD network of pipelines were determined. Diameters (in inches) were translated into capacities by use of the equation

$$
\text { Capacity (billions/scf/year) }=313(D / 36)^{2} \text {. }
$$

The value of 313 billion scf/year represents the average flow per year of the nominal pipeline used to create gas pipeline costs.

For the scenario runs, capacities for all intra-MPAD pipelines (the distribution network) were set to infinite capacity. No explanation is provided for this, but it presumably was done simply to insure feasibility of the problem. Local distributional constraints might be important in some situations, but in general it is logical to assume that whatever gas is imported into a region to meet local demand will find an adequately sized distribution system available to service it. Two cases are expliciled noted within the table where pipeline capacity constraints caused problems. Lines 2581-2582 state "All pipelines emanating from Texas are assumed to have infinite capacity. Thin is nesessary for feasibility." Lines 2588-2590 state "The pipeline from New Mexico to Texas is to have an infinite capacity. This is necessary to assure feasibility." Whether this was an a priori judgement or a conclusion based on model applications is not clear. 
As noted in the discussion of the table Gas Pipeline Transportation Costs (Line Span 2403-2503), the computational methodology used to determine pipeline costs and capacities was checked for internal consistency and was found to be consistant. Also noted there was an independent validation attempt made by examining existing pipeline data. The capacity agreement was found to be very good. Details may be examined by referring to the discussion of that table. 
Table Name: Crude Oil'Pipeline Capacities

Code Name: T:PBCRD(MPAD)

Line Span: 2618-2714

Page No.: $\quad$ B-58-B-59

This table lists the weighted average capacities of the inter-MPAD crude oil pipeline links in units of millions of barrels per year. An entry of " $-I$ " is used to indicate an infinite, or unconstrained, capacity. As in the case of gas pipelines discussed in the preceding table, the weighted average diameters were obtained by using maps of actual pipelines in the lower 48 states to obtain an aggregate of all pipeline sizes flowing between MPADs. After eliminating small-diameter and short-distance lines, the weighted average diameter for an inter-MPAD network of pipelines were determined. Diameters (in inches) were translated into capacities by use of the equation:

$$
\text { Capacity (millions bbl/year) }=288(\mathrm{D} / 36)^{2} \text {. }
$$

The value of 288 million bbl/year represents the average flow per year of the nominal pipeline used to create crude oil pipeline costs. It should be noted that a similar exercise was apparently performed for pipelines carrying refined petroleum products, but no further use was made of the information.

For the scenario runs, capacities for all intra-MPAD pipelines (the distribution network) were set to infinite capacity. No explanation is provided for this, but it presumably was done simply to insure feasibility of the problem. Local distributional contraints might be important in some situations, but in general it is logical to assume that whatever crude oil is imported into a region to meet local delland will find an adequately sirn. distribution system available to service it. Appanently. it was necessary or desirable to add thrèe pipeline: links not in existence. in 1975 , edcil with no capacity constraint.

As noted in the discussion of the table Crude Oil Transportation Costs (Line Span 22.84-2.401), the computational methodology used to determine pipeline costs and capacities was checked for internal 
consistency and was found to be consistent. Also noted there was an independent validation attempt made by examining existing pipeline data. The capacity agreement was found to be quite good. Details may be examined by referring to the discussion of that table. 
Table Name: Electric Transmission

Code Name: T:ETRAN(MPAD)

Line Span: 2716-2783

Page No.: $\quad B-60-B-6 I$

This table gives the costs and efficiencies for inter-MPAD transmission of electricity. The units of cost are mills per kilowatt-hour. The efficiency is defined as the ratio of power delivered to power generated (the value being less than unity due to line losses). An algorithm was developed to determine reasonable inter-MPAD transmission line distances and the costs and line losses associated with these distances. The problem is compounded, of course, by the various line voltages used to handle various load and distance requirements.

The FPC Regional Maps of Principle Electric Facilities were used to enumerate the number of ac transmission lines operative in 1973 between continguous MPADs, associating with each line a distance, a line voltage, and a power capacity. As was done for other transportation modes, a linear regression fit was used to relate line distances to straight-line distances, resulting in the equations

$$
\begin{array}{ll}
Y=1.22 X+1.19 & \text { (for } 115 \mathrm{kV} \text { lines), } \\
Y=1.20 \mathrm{X}+63.59 & \text { (for } 230 \mathrm{kV} \text { and greater lines), }
\end{array}
$$

where $Y$ is the transmission line distance and $X$ the measured atraight-line distance, both in miles.

Although transmission costs vary considerably, average 1970 costs were obtained from the FPC's "The 1970 National Power survey, Part T" (December, 1971). For varying line voltages, a unitdistance cost equation was developed of the following form:

$$
c=5.56-0.731 \ln (\mathrm{V}) \text {, }
$$

where $C$ is the 1970 cost in mills per $\mathrm{kWh} / 200$ miles and $V$ is the line voltage in $\mathrm{kV}$. Weighted average inter-MPAD line voltages were derived from the original data collected from FPC Regional Maps and were used to define the inter-MPAD costs. As noted in the documentation, these are optimum line loading costs and thus 
lower than expected actual costs. The computed costs were escalated from 1970 to 1985 at a net rate of 2.5 per cent per year to obtain 1985 costs in 1975 mills.

Transmission line losses are determined primarily by the line loading (in MW) and the line voltage (in $\mathrm{kV}$ ). Using data from the same FPC National Power Survey used for costs, above, a typical set of line losses due to line loading was employed to develop a "best case" relation of the form.

$$
\text { In } \mathrm{L}=3.44-1.19 \text { In } \mathrm{V} \text {, }
$$

where $\mathrm{V}$ is the line voltage in $\mathrm{kV}$ and $\mathrm{L}$ is the fractional MW line loss. The same weighted average inter-MPAD line voltages used for costing were used to define the inter-MPAD efficiencies.

A spot check was made of a few of the transmission costs and efficiencies by going back to the FPC Regional Maps and trying to duplicate the full procedure by hand. This was done fior four lines, with the following results:

Source Destination Pair

1

2

3

4

\begin{tabular}{|c|c|}
\hline \multicolumn{2}{|c|}{$\operatorname{Cost}(\mathrm{mills} / \mathrm{kWh})$} \\
\hline Computed & Tabled \\
\hline 15.48 & 18.28 \\
\hline 9.36 & 9.73 \\
\hline 11.2 & 4.11 \\
\hline 17.25 & 18.44 \\
\hline
\end{tabular}

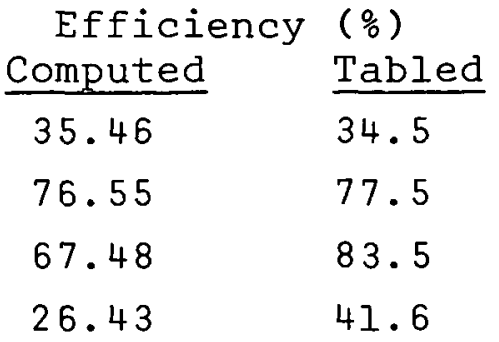

1. Austin - Aztek (MPAD 11 to MPAD 12)

2. Bakersfield - Aztek (MPAD 12 to MPAD 16)

3. Portland - Bakersfield (MPAD 15 to MPAD 16)

4. Portland - Gedette (MPAD 13 to MPAD 15)

Some noticeable discrepancies can be seen. For instance, the use of a nnst of $4.11 \mathrm{mills} / \mathrm{kWh}$ for the Portland-bakersfield line seems too low for the transmission distance of approximately 900 miles. A closen look at the detailed values in this table. seems warranted. 
Table Name: Coal Supply

Code Name: T:CPRD(MPAD)

Line Span: 2785-2901

Page No.: $\quad B-62-B-64$

This table provides values for the reserves (in thousands of tons) of each of the 15 coal quality types used in the model (defined as to heat content and sulphur content in the table Coal Classification, Line Span 966-995) in each MPAD. In addition, a mine-mouth cost (in 1975 dollars per ton) is provided for each coal type in each MPAD. Where it was not possible lu generate a region-specific cost for a given coal type, the national average cost of that coal type is listed, properly documented as such.

The data on mineable reserves were obtained from the Bureau of Mines (BOM) Minerals Availability System Tapes, aggregated by coal type for each MPAD. A sput chcck of the tahled values indicated that they are of the correct order.

The price of each coal type in each MPAD was determined as follows. Average 1973 prices by ctats and hy AQCR were obtained from BOM data, with the average specific-sulphur content noted. $\Lambda$ prioe-to=sulphur relationship was determined and lie averagc price was allocated to lle differcnt onal types mined in the region by the relation

where

$$
P_{i j}=\bar{P}_{j} \frac{P\left(Q_{i j}\right)}{P\left(\bar{Q}_{j}\right)},
$$

$$
\begin{aligned}
P_{i j} & =\text { price of coal quality } i \text { in region } j, \\
\bar{P}_{j}= & \text { forecast average price of coal in regiul } j, \\
P\left(\bar{Q}_{j}\right)= & \text { price of coal of forecast average quality in region } j \\
& \text { according to the equation below, } \\
P\left(\bar{Q}_{i j}\right)= & \text { price of coal of quality } i \text { in region } j, \text { according to } \\
& \text { the equation }
\end{aligned}
$$

$$
\begin{aligned}
P & =9.77(Q)^{-0.336} . \\
& -132-
\end{aligned}
$$


The 1973 prices were escalated to 1975 prices by a nominal 10 per cent per year and then converted to 1985 prices in 1975 dollars by a net escalation rate of 5 per cent per year.

Forecasting of future coal prices in the complex region/ quality structure used here would seem to be a nearly impossible task. Although the formulation outlined above is in no way able to reflect the many market forces involved in the setting of coal prices, it does capture a number of the more significant variables. No data were identified which cast doubt on the general trend of the tabled values, but coal pricing is a potentially volatile factor in energy policy studies at the regional level. Continuing effort should be directed to exploration of actual pricing trends to determine if later data suggest significant. departures from the forecast 1985 regional price structure indicated by the set of tabulated values. Such changes might be most likely to occur where national average prices rather. than regional prices were entered, sometimes for all of the coal mined in the region. It would be worthwhile exploring any possible causal impact of these prices on the problem of the dramatic shifts in the quantity of coal of different types mined in many regions. This problem is discussed in some detail in the discussion of the table Coal Classification (Line Span 952-995).

Mineable reserves are likely to be much less volatile than coal prices but it would be well to continuously monitor new resources data in order to keep the data base up to date in this regard. It is also clear that if future policy problems necessitate modification of the coal classification scheme adopted in the present use of the model, awareness of the current status of regional mineable reserves (as well as the price vs quality structure) will be a great aid in generating the required new values for this table. 